\title{
Interventional oncology in the management of breast and kidney cancer
}

Citation for published version (APA):

Aarts, B. M. (2020). Interventional oncology in the management of breast and kidney cancer. [Doctoral Thesis, Maastricht University]. Maastricht University. https://doi.org/10.26481/dis.20201023ba

Document status and date:

Published: 01/01/2020

DOI:

10.26481/dis.20201023ba

Document Version:

Publisher's PDF, also known as Version of record

\section{Please check the document version of this publication:}

- A submitted manuscript is the version of the article upon submission and before peer-review. There can be important differences between the submitted version and the official published version of record.

People interested in the research are advised to contact the author for the final version of the publication, or visit the DOI to the publisher's website.

- The final author version and the galley proof are versions of the publication after peer review.

- The final published version features the final layout of the paper including the volume, issue and page numbers.

Link to publication

\footnotetext{
General rights rights.

- You may freely distribute the URL identifying the publication in the public portal. please follow below link for the End User Agreement:

www.umlib.nl/taverne-license

Take down policy

If you believe that this document breaches copyright please contact us at:

repository@maastrichtuniversity.nl

providing details and we will investigate your claim.
}

Copyright and moral rights for the publications made accessible in the public portal are retained by the authors and/or other copyright owners and it is a condition of accessing publications that users recognise and abide by the legal requirements associated with these

- Users may download and print one copy of any publication from the public portal for the purpose of private study or research.

- You may not further distribute the material or use it for any profit-making activity or commercial gain

If the publication is distributed under the terms of Article $25 \mathrm{fa}$ of the Dutch Copyright Act, indicated by the "Taverne" license above, 
Interventional oncology in the management of breast and kidney cancer

B.M. Aarts 
Interventional oncology in the management of breast and kidney cancer (c) 2020 B.M. Aarts

ISBN: 978-94-6375-940-3

Cover and lay out: Birgit Vredenburg en Elisa Calamita, persoonlijkproefschrift.nl Printing: Ridderprint | www.ridderprint.nl

The publication of this thesis was financially supported by the Netherlands Cancer Institute and the Maastricht University.

All rights reserved. No part of this thesis may be reproduced, distributed or transmitted in any form or by any means, without the permission of the author. 


\title{
Interventional oncology in the management of breast and kidney cancer
}

\author{
PROEFSCHRIFT \\ ter verkrijging van de graad van doctor aan de Universiteit Maastricht, \\ op gezag van de Rector Magnificus, Prof. dr. Rianne M. Letschert \\ volgens het besluit van het College van Decanen, \\ in het openbaar te verdedigen \\ op 23 oktober 2020 om 16.00 uur \\ door \\ Brigitte Maximiliana Aarts \\ Geboren op 11-11-1990 te Rotterdam
}




\section{Promotor:}

Prof. dr. R.G.H. Beets-Tan

\section{Copromotoren:}

Dr. E.G. Klompenhouwer, Antoni van Leeuwenhoek Ziekenhuis

Dr. F.M. Gómez Muñoz, Universidad de Barcelona

\section{Beoordelingscommissie:}

Prof. dr. V.C.G. Tjan-Heijnen, voorzitster

Prof. dr. M.W. de Haan

Prof. dr. G.A. van Koeveringe

Prof. dr. M. van Goethem, Universitair Ziekenhuis Antwerpen

Prof. dr. M.G.E.H. Lam, Universitair Medisch Centrum Utrecht 


\section{CONTENTS}

Chapter 1 General introduction 7

Part I - Intra-arterial therapies for liver metastatic breast cancer

Chapter 2 Intra-arterial therapies for liver metastatic breast cancer: a systematic review

Chapter 3 Intra-arterial mitomycin C infusion in a large cohort of advanced liver metastatic breast cancer patients: safety, efficacy and factors influencing survival

Chapter 4 Sequential intra-arterial infusion of ${ }^{90} \mathrm{Y}$-resin microspheres and mitomycin $\mathrm{C}$ in chemo refractory liver metastatic breast cancer patients: a single centre pilot study

\section{Part II - Percutaneous ablation in renal cell cancer}

Chapter 5 Renal biopsies performed before versus during ablation of T1 renal tumors: Implications for prevention of overtreatment and follow-up

Chapter 6 Percutaneous microwave ablation of histologically proven T1 renal cell carcinoma

Chapter 7 Cryoablation for the treatment of residual or recurrent 105 disease after prior microwave ablation of renal cell carcinoma

Chapter 8 Cryoablation and immunotherapy: an overview of evidence on its synergy

$\begin{array}{lll}\text { Chapter } 9 \quad \text { General discussion } & 145\end{array}$

English summary $\quad 157$

$\begin{array}{ll}\text { Nederlandse samenvatting } & 160\end{array}$

$\begin{array}{ll}\text { Valorisation } & 165\end{array}$

$\begin{array}{ll}\text { Publication list } & 171\end{array}$

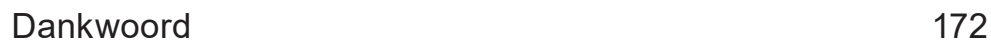

$\begin{array}{ll}\text { Curriculum vitae } & 176\end{array}$ 



\section{CHAPTER}

General introduction

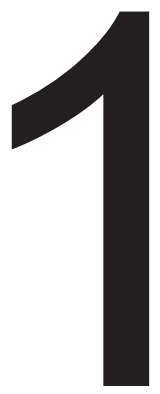


During the past decade interventional oncology (IO) has gained prominence as a minimally-invasive cancer treatment besides surgery, external beam radiation and systemic therapy. 10 procedures can be applied in the curative setting to obtain local control or in the palliative setting for symptom control. [1] This thesis investigates the value of $I O$ procedures for liver metastatic breast cancer (LMBC) and renal tumours.

\section{Part I: Intra-arterial therapies for liver metastatic breast cancer}

During intra-arterial liver-directed therapies, local drugs are administrated in the hepatic arteries to deliver high local doses at low systemic toxicities. The dual blood supply of the liver, in which the metastases are supplied mainly by the liver arteries and the liver parenchyma by the portal vein, ensures that the drugs target the liver metastases while sparing the healthy liver parenchyma [2].

Currently, intra-arterial therapies are increasingly adopted as a treatment alternative for chemo-refractory patients, suffering from primary liver tumours, neuroendocrine neoplasms and colorectal liver metastases (CRLM), not eligible for surgery [3-5]. In patients with liver metastatic breast cancer (LMBC), intraarterial therapies have so far been less commonly studied for use in clinical practice.

Compared to other neoplasms, LMBC patients present with more extensive extra-hepatic disease and are subsequently stratified for standard systemic treatment. Challenges of systemic treatment are failure to control toxicity and chemo-resistance after several lines of chemotherapeutic agents. In addition, the liver metastases often cause hepatic dysfunction affecting the efficacy and safety of systemic chemotherapy and is, therefore, often a dose-limiting factor. A break from systemic treatment (chemo holiday) may be beneficial for patients to recover from systemic therapy [6). Intra-arterial therapies can be considered to provide this chemo holiday in LMBC patients with stable extra-hepatic disease or provide a treatment option in chemo-refractory LMBC patients. [7]

Several intra-arterial therapies are available, including trans-arterial radioembolization (TARE), trans-arterial chemoembolization (TACE) and chemo infusion. During TACE and chemo infusion, high doses of chemotherapeutic agents are administered locally, and in TACE this infusion is performed along with an occlusion of the supplying arteries. TARE, on the other hand, uses 
radioactively-labelled microspheres with Yttrium-90 that emits radiation after emission of $\beta$ - particles (electrons) with only a temporary occlusive effect [8]. The differences between these therapies with regards to efficacy and safety in $L M B C$ have so far not been investigated and consequently these treatments have not yet been included in the guidelines for advanced breast cancer [9].

Mitomycin C (MMC) was a standard chemotherapy that was initially administered intravenously as a systemic treatment for breast cancer patients [10]. To date, MMC is no longer applied as a systemic agent in metastatic breast cancer, due to new upcoming chemotherapeutics and the serious, but rarely observed, adverse event hemolytic uremic syndrome (HUS) [11]. If MMC is infused intraarterially, a high first-pass effect is observed locally within the liver at minimal systemic toxicities. In 2007, Maes et al. reported the safety and efficacy of MMC arterial infusion in 30 LMBC patients, without any cases of HUS [12].

Small retrospective reports of TARE in LMBC show promising results with a disease control rate above $78 \%$ [13]. To further increase the survival of LMBC patients, a combination of TARE and MMC infusion might have the potential to be more effective than intra-arterial MMC or TARE on its own. The safety of patients treated with a sequence of different intra-arterial therapies have been reported in primary liver tumours [14]. To date, no reports are available for the sequential infusion of TARE and systemic or local chemotherapy in LMBC patients.

\section{Part II: Percutaneous ablation in renal cell cancer}

The incidence of renal cell carcinoma (RCC) has risen during the last decade, due to the expansion of imaging modalities and accidental diagnosis of (small) renal masses. Yet, the mortality rates of RCC are stable in developed countries. A minimal invasive treatment approach could be an alternative to (partial) nephrectomy obtaining optimal local control while sparing kidney function. [15]. One of the IO procedures that is increasingly adopted is percutaneous thermal ablation. Here, needles are inserted under image guidance to target tumoural lesions and achieve tumour death using extremely high $\left(100^{\circ} \mathrm{C}\right)$ or low temperatures $\left(-100^{\circ} \mathrm{C}\right)$. Ablative treatment has proven to be as effective as resection in patients with a small RCC limited to the kidney (stage I disease) who are not eligible for surgery $[16,17]$.

Most renal masses show malignant characteristics on computed tomography (CT), but up to $30 \%$ are found to be benign after (partial) nephrectomy raising 
the concern of overtreatment in small renal masses [18]. In patients scheduled for ablation, a renal mass biopsy (RMB) to obtain histological diagnosis is often performed during the same session prior to the ablative procedure. Although recent guidelines recommend to perform the biopsy in a separate session [16], in daily practice many centers prefer to do this immediately prior to the ablation. There is limited and conflicting data supporting the one or the other biopsy strategy with respect to outcome, nor are the rates of overtreatment reported in large multicenter studies.

Radiofrequency ablation (RFA) and cryoablation (CA) are the most frequently applied ablative techniques. Microwave ablation (MWA) is a recent technique and still considered experimental in the European Association of Urology guidelines for RCC. [19-22] Reports about the efficacy and safety of large cohorts of MWA are scarce, especially for T1b tumours [23, 24]. The R.E.N.A.L nephrometry score objectifies critical anatomical features of renal masses and predicts surgical complications after (partial) nephrectomy. Since lower efficacy rates after ablation are reported in tumours over $3 \mathrm{~cm}$, a modified version of the R.E.N.A.L nephrometry score is used. lerardi et al. suggested that this modified version might be predictive for oncological outcome after MWA [25].

For residual disease after percutaneous ablation or recurrence during the follow up after successful treatment, several salvage treatment options are available including repeat ablation and (partial) nephrectomy (PN). Surgery after ablation is technically challenging due to the perinephric scarring that hampers kidney mobilization. In addition, recurrences located centrally carry the risk for urine leakage with PN [26]. In many cases, a repeated thermal ablation is therefore chosen as the preferred salvage treatment modality [27]. Because the residual tumour occurs particularly near the renal sinus or renal vessels, CA is the preferred ablation technique for a better protection of the urothelial architecture compared to heat-based ablation techniques $[28,29]$. Additionally, during the CA procedure itself, optimal visualization of the ablation zone is obtained, which better provides information on the ablative margins.

In 1950, a systemic effect away from the ablated tissue was described after CA of the prostate, also known as the abscopal effect [30]. Compared to heat-producing modalities such as MWA and RFA, CA leaves the intracellular contents intact after cell destruction and provides the best environment for the immune system. However, this abscopal effect occurs rarely and is only described in case series. Hypothetically the immune initiation after ablation can be enhanced by immune checkpoint inhibitors. In recent years, the introduction 
of immune checkpoint inhibitors has gained a remarkable survival benefit in specific cancer types such as stage IV melanoma patients [31]. Unfortunately, not all patients respond to immunotherapy and preliminary animal studies suggest that percutaneous CA may help to increase the effectiveness of immunotherapy in stage IV disease because of its abscopal effect.

\section{Aim of this thesis}

The aim of this thesis is to report outcomes of intra-arterial and ablative procedures regarding safety and efficacy and to optimize the treatments by evaluating factors influencing the oncological outcome.

The main questions of this thesis are:

1. What is the role of intra-arterial therapies in $L M B C$ patients?

1a. what is the safety and efficacy of intra-arterial MMC infusion?

1b. what are the factors influencing overall survival after intra-arterial MMC infusion?

1c. is sequential intra-arterial administration of MMC after TARE feasible and safe?

2. How can we optimize oncological outcomes after percutaneous ablation in RCC patients?

2a. what is the impact of different biopsy strategies for patients with a renal mass scheduled for ablation?

2b. what is the efficacy of MWA in T1 RCC and what are the factors influencing the outcome?

2c. is CA feasible in residual or recurrent disease following MWA?

2d. what is the evidence of the effect of CA on the immune system and its synergy with immunotherapy?

\section{Outline of this thesis}

Part I: Intra-arterial therapies for liver metastatic breast cancer patients

In Chapter 2, the differences between intra-arterial therapies for LMBC patients are systematically evaluated. The safety, efficacy and factors influencing the overall survival of MMC intra-arterial infusion in LMBC patients are described in Chapter 3. Chapter 4 assesses whether it is feasible and safe to sequentially and intra-arterially administer MMC after TARE in LMBC patients. 
Part II: Percutaneous ablation in renal cell cancer

Chapter 5 evaluates different biopsy strategies for patients with a renal mass planned for an ablation. In Chapter 6 the outcome and factors influencing the outcome of MWA in T1 RCC are evaluated. The feasibility to perform CA after MWA is assessed in Chapter 7. Chapter 8 shows the available evidence of the synergy between CA and the immune system. 


\section{References}

1. Schoenberg SO, Attenberger UI, Solomon SB, Weissleder R. Developing a roadmap for interventional oncology. Oncologist. 2018;23(10):1162-70.

2. Breedis C, Young G. The blood supply of neoplasms in the liver. Am J Pathol. 1954;30(5):969-77.

3. Levy J, Zuckerman J, Garfinkle R, Acuna SA, Touchette J, Vanounou T, et al. Intraarterial therapies for unresectable and chemorefractory colorectal cancer liver metastases: a systematic review and meta-analysis. HPB (Oxford). 2018;20(10):905-15.

4. Pavel M, O'Toole D, Costa F, Capdevila J, Gross D, Kianmanesh R, et al. ENETS Consensus guidelines update for the management of distant metastatic disease of intestinal, pancreatic, bronchial neuroendocrine neoplasms (NEN) and NEN of Unknown Primary Site. Neuroendocrinology. 2016;103(2):172-85.

5. Duran R, Chapiro J, Schernthaner RE, Geschwind JF. Systematic review of catheterbased intra-arterial therapies in hepatocellular carcinoma: state of the art and future directions. Br J Radiol. 2015;88(1052):20140564.

6. Lim B, Hortobagyi GN. Current challenges of metastatic breast cancer. Cancer Metastasis Rev. 2016;35(4):495-514.

7. Gordon AC, Uddin OM, Riaz A, Salem R, Lewandowski RJ. Making the case: intraarterial therapy for less common metastases. Semin Intervent Radiol. 2017;34(2):132-9.

8. Tong AK, Kao YH, Too CW, Chin KF, Ng DC, Chow PK. Yttrium-90 hepatic radioembolization: clinical review and current techniques in interventional radiology and personalized dosimetry. Br J Radiol. 2016;89(1062):20150943.

9. Cardoso F, Senkus E, Costa A, Papadopoulos E, Aapro M, Andre F, et al. 4th ESOESMO international consensus guidelines for advanced breast cancer (ABC 4). Ann Oncol. 2018;29(8):1634-57.

10. Bradner WT. Mitomycin C: a clinical update. Cancer Treat Rev. 2001;27(1):35-50.

11. Vrdoljak E, Boban M, Omrcen T, Hrepic D, Fridl-Vidas V, Boskovic L. Combination of capecitabine and mitomycin $\mathrm{C}$ as first-line treatment in patients with metastatic breast cancer. Neoplasma. 2011;58(2):172-8.

12. Maes T, Wildiers H, Heye S, Demey W, Maleux G, Neven P, et al. Intra-hepatic Mitomycin $\mathrm{C}$ bolus infusion in the treatment of extensive liver metastases of breast cancer. Breast Cancer Res Treat. 2008;110(1):135-42.

13. Smits ML, Prince JF, Rosenbaum CE, van den Hoven AF, Nijsen JF, Zonnenberg BA, et al. Intra-arterial radioembolization of breast cancer liver metastases: a structured review. Eur J Pharmacol. 2013;709(1-3):37-42.

14. Klompenhouwer EG, Dresen RC, Verslype C, Laenen A, De Hertogh G, Deroose CM, et al. Safety and Efficacy of transarterial radioembolisation in patients with intermediate or advanced stage hepatocellular carcinoma refractory to chemoembolisation. Cardiovasc Intervent Radiol. 2017;40(12):1882-90.

15. Znaor A, Lortet-Tieulent J, Laversanne M, Jemal A, Bray F. International variations and trends in renal cell carcinoma incidence and mortality. Eur Urol. 2015;67(3):519-30.

16. Ljungberg B, Albiges L, Abu-Ghanem Y, Bensalah K, Dabestani S, Fernandez-Pello S, et al. European Association of Urology Guidelines on Renal Cell Carcinoma: The 2019 Update. Eur Urol. 2019;75(5):799-810.

17. Motzer RJ, Jonasch E, Agarwal N, Bhayani S, Bro WP, Chang SS, et al. Kidney Cancer, Version 2.2017, NCCN Clinical Practice Guidelines in Oncology. J Natl Compr Canc Netw. 2017;15(6):804-34. 
18. Kim JH, Li S, Khandwala Y, Chung KJ, Park HK, Chung BI. Association of prevalence of benign pathologic findings after partial nephrectomy with preoperative imaging patterns in the united states from 2007 to 2014. JAMA Surg. 2019;154(3):225-31.

19. McDougal WS, Gervais DA, McGovern FJ, Mueller PR. Long-term follow-up of patients with renal cell carcinoma treated with radio frequency ablation with curative intent. $J$ Urol. 2005;174(1):61-3.

20. Zagoria RJ, Pettus JA, Rogers M, Werle DM, Childs D, Leyendecker JR. Long-term outcomes after percutaneous radiofrequency ablation for renal cell carcinoma. Urology. 2011;77(6):1393-7.

21. Breen DJ, King AJ, Patel N, Lockyer R, Hayes M. Image-guided cryoablation for sporadic renal cell carcinoma: three- and 5 -year outcomes in 220 patients with biopsyproven renal cell carcinoma. Radiology. 2018;289(2):554-61.

22. Atwell TD, Carter RE, Schmit GD, Carr CM, Boorjian SA, Curry TB, et al. Complications following 573 percutaneous renal radiofrequency and cryoablation procedures. J Vasc Interv Radiol. 2012;23(1):48-54.

23. Cornelis FH, Marcelin C, Bernhard JC. Microwave ablation of renal tumors: A narrative review of technical considerations and clinical results. Diagn Interv Imaging. 2017;98(4):287-97.

24. Choi SH, Kim JW, Kim JH, Kim KW. Efficacy and safety of microwave ablation for malignant renal tumors: an updated systematic review and meta-analysis of the literature since 2012. Korean J Radiol. 2018;19(5):938-49.

25. Ierardi AM, Puliti A, Angileri SA, Petrillo M, Duka E, Floridi C, et al. Microwave ablation of malignant renal tumours: intermediate-term results and usefulness of RENAL and mRENAL scores for predicting outcomes and complications. Med Oncol. 2017;34(5):97.

26. Kowalczyk KJ, Hooper HB, Linehan WM, Pinto PA, Wood BJ, Bratslavsky G. Partial nephrectomy after previous radio frequency ablation: the National Cancer Institute experience. J Urol. 2009;182(5):2158-63.

27. Cross BW, Parker DC, Cookson MS. Salvage surgery after renal mass ablation. Urol Clin North Am. 2017;44(2):305-12.

28. Chen JX, Maass D, Guzzo TJ, Bruce Malkowicz S, Wein AJ, Soulen MC, et al. Tumor growth kinetics and oncologic outcomes of patients undergoing active surveillance for residual renal tumor following percutaneous thermal ablation. J Vasc Interv Radiol. 2016;27(9):1397-406.

29. Hinshaw JL, Lubner MG, Ziemlewicz TJ, Lee FT, Jr., Brace CL. Percutaneous tumor ablation tools: microwave, radiofrequency, or cryoablation--what should you use and why? Radiographics. 2014;34(5):1344-62.

30. Soanes WA, Ablin RJ, Gonder MJ. Remission of metastatic lesions following cryosurgery in prostatic cancer: immunologic considerations. J Urol. 1970;104(1):154-9.

31. Larkin J, Chiarion-Sileni V, Gonzalez R, Grob JJ, Rutkowski P, Lao CD, et al. Five-year survival with combined nivolumab and ipilimumab in advanced melanoma. $\mathrm{N}$ Engl J Med. 2019;381(16):1535-46. 


\section{PART}

Intra-arterial therapies for liver metastatic breast cancer 



\section{CHAPTER}

\section{Intra-arterial therapies for liver metastatic breast cancer: a systematic review}

B.M. Aarts, F.M. Gómez Muñoz, H. Wildiers, V. Dezentjé, T.R. Baetens, W. Schats, R.C. Dresen, B.J. de Wit-van der Veen, C.M. Deroose, G. Maleux, R.G.H. Beets-Tan, E.G. Klompenhouwer In submission

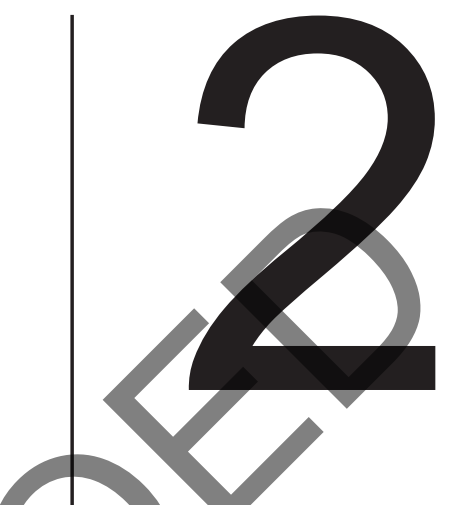




\section{CHAPTER}

Intra-arterial Mitomycin C infusion in a large cohort of advanced liver metastatic breast cancer patients: safety, efficacy and factors influencing survival

B.M. Aarts*, E.G. Klompenhouwer*, R.C. Dresen, A. Laenen, R.G.H. Beets-Tan, K. Punie, P. Neven, H. Wildiers, G. Maleux * authors contributed equally

Published in Breast Cancer Research and Treatment 2019 Aug;176(3):597-605 doi: 10.1007/s10549-019-05254-4 Epub 2019 May 7. PMID: 31065871

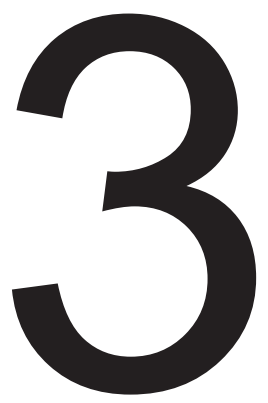




\section{ABSTRACT}

Purpose: The aim of this study was to determine the safety and efficacy of Mitomycin C (MMC) infusion in a large cohort of advanced liver metastatic breast cancer patients (LMBC) and to determine factors influencing overall survival (OS).

Methods: We retrospectively analysed LMBC patients, treated with MMC infusion between 2000 and 2017. Hepatic response was measured with baseline CT scans and first available CT scan after MMC infusion by RECIST 1.1 criteria. Adverse events were registered by the CTCAE version 5.0. OS and hepatic progression free survival (hPFS) were evaluated using Kaplan Meier estimates. After univariable analysis, a stepwise forward multivariable (MV) prediction analysis was developed to select independent pre-treatment factors associated with OS.

Results: We included 176 patients with a total of $599 \mathrm{MMC}$ infusions, mostly heavily pre-treated patients with a median time from diagnosis of MBC to MMC infusion of 36.9 months. RECIST evaluation of liver lesions $(n=132)$ showed a partial response rate of $15 \%$, stable disease of $43 \%$ and progressive disease in $17 \%$. Adverse events grade 3 and 4 were reported in $17.5 \%$. Median hPFS was 5.5 months and median OS was 7.8 months. Significant independent baseline predictors of worse OS included number of prior systemic chemotherapy lines, prior liver ablation, higher liver tumour burden, and elevated levels of bilirubin and ALT.

Conclusion: MMC infusion is safe and effective in advanced LMBC patients. An increased number of prior therapies, a higher liver tumour burden and elevated levels of bilirubin and ALT were associated with a worse OS. 


\section{INTRODUCTION}

Breast cancer is the world leading type of cancer in women [1]. Localized breast cancer has a 5 year survival rate around 99\% [2]. However, about $20-30 \%$ of women with breast cancer develop metastases at some point, which dramatically worsens the prognosis with a 5 -year survival rate of $25 \%$ (all metastatic sites included) [3]. Liver metastatic breast cancer (LMBC) eventually occurs in $50 \%$ of metastatic breast cancer patients and is associated with worse prognosis of only a few years $[4,5]$.

In most cases the initial therapy for LMBC is systemic treatment by means of chemotherapy with taxanes or anthracyclines [6]. The efficacy and safety of the systemic chemotherapy can be affected by the hepatic dysfunction caused by the metastases which is therefore often a dose limiting factor [7, 8]. Local intra-arterial therapies can offer higher local concentration of chemotherapy to the liver metastases with less systemic effect due to the arterial blood supply of the metastases $[9,10]$.

Mitomycin C (MMC) is a classical chemotherapeutic agent that was originally used as a intravenously administered chemotherapeutic agent for systemic treatment of breast cancer [11]. Due to some rare, but severe systemic toxicities like the haemolytic uremic syndrome (HUS), and new upcoming other chemotherapeutics like anthracyclines and taxanes, the use of systemic intravenously administered Mitomycin $\mathrm{C}$ has significantly declined in the last decades [12, 13]. However, when MMC is locally infused in the hepatic arteries, a high first pass is obtained to the metastases with minimal effects to the healthy parenchyma. The low systemic toxicity of MMC may provide a break from systemic chemotherapy to recover from the toxicities. Maes et al. showed the safety of intra-arterial administration of MMC without major complications in a small cohort [14].

The purpose of this study was to evaluate a large cohort of LMBC patients treated with intra-arterial infusion of MMC in order to determine safety and efficacy of the treatment and to determine pre-treatment factors associated with overall survival (OS). 


\section{METHODS}

\section{Study design}

This study was approved by the ethics committee of our institute (S60596). The requirement for an informed consent was waived, due to its retrospective nature. Patients with liver metastatic breast cancer treated with intra-arterial MMC infusion between October 2000 and December 2017 were included. All breast cancer patients were prospectively registered in a follow up database. This database plus patients records were retrospectively reviewed. Clinical results were analysed to obtain patients oncological history. All patients underwent baseline assessment of liver function, general blood count and coagulation factors at every cycle of MMC. Tumour burden was accessed by eyeballing of the total volume of tumour in the liver and was categorized as $0-25 \%, 25-50 \%,>50 \%$.

\section{Mitomycin C infusion}

Details of the MMC infusion procedure have been previously described [14]. The treatment was performed by, or supervised by, an expert interventional radiologist. Under local anaesthesia, femoral access was generally obtained in the right common femoral artery and a 4-French sheath was introduced. A micro catheter was used through a diagnostic 4-French catheter for selective catheterization of the right and left hepatic artery. A starting total of $12 \mathrm{mg}$ Mitomycin $\mathrm{C}(\mathrm{MMC})$ in a $10 \mathrm{cc}$ saline solution was administered divided over both liver lobes according to the liver volume. Subsequent dosing was done every 4 weeks or longer. Doses of Mitomycin $C$ could be adjusted by physicians according to clinical performance and laboratory results.

\section{Follow-up and Response Assessment}

Treatment was evaluated by the first available computed tomography (CT) scan after MMC infusion. We measured hepatic response by comparing the liver CT before and after MMC infusing according to the response evaluation criteria in solid tumours (RECIST) criteria 1.1 with four categories [Partial Response $(\mathrm{PR})$, Complete Response (CR), Stable Disease (SD) and Progressive Disease (PD)][15]. Two hepatic target lesions were selected for the response in the liver.

The treating physician decided to continue MMC cycles based on radiological and biochemical results and patient performance. The maximum amount of MMC cycles was, in principle, 6 cycles (because of increased subsequent risk of HUS at higher cumulative dose); however additional MMC infusions could be considered in case of disease control without side effects. Administration 
of MMC cycles was stopped in patients with progressive hepatic or extra hepatic disease or due to unstable clinical or biochemical characteristics. Adverse events were registered by the Common Terminology Criteria for Adverse Events (CTCAE) version 5.0 by retrospectively use of patient records and laboratory results.

Survival time was calculated from the date of first MMC cycle until death or loss to follow-up. Hepatic progression free survival (hPFS) was calculated from the first MMC cycle until hepatic progression on radiological images occurred.

\section{Statistics}

Pre-treatment patient and tumour characteristics are described as median and range for continuous variables and as frequencies and percentages for categorical variables. OS and hPFS were estimated using the Kaplan-Meier method starting at the date of the first cycle of MMC.

Cox proportional hazards models were used to analyse the prognostic effect of the pre-treatment characteristics on OS. Results are presented as hazard ratios $(\mathrm{HR})$ with $95 \%$ confidence intervals $(95 \% \mathrm{Cl})$. Non-linear (quadratic) trends are tested for all continuous predictors. A forward stepwise model selection procedure was applied to develop a multivariable model for independent prognostic factors associated with OS. To specify, a significance level of $5 \%$ was used for both entry and removal of variables: step by step individual variables were added to the model, selecting in each step the variable leading to the lowest $p$-value, and adding variables as long as the variable showed a significant $p$-value. Additionally, previously included variables turning nonsignificant along the procedure are removed from the model. All analyses are two-sided and a $5 \%$ significance level is assumed for all tests. Analyses were performed using SAS software (version 9.4 of the SAS System for Windows) and Statistical Package for the Social Sciences (SPSS, version 25, Chicago, IL).

\section{RESULTS}

\section{Patient Characteristics}

Table 1 shows the pre-treatment factors of the 176 patients treated with MMC between 2000 and 2017. Most patients had a ductal adenocarcinoma (84\%) with a positive oestrogen receptor $(80 \%)$, a positive progesterone receptor (66\%) and a negative Her2 status (81\%). Disease was mostly metastasized in a metachronous manner (82\%). The tumour burden of the liver was greater than $25 \%$ in 85 (50\% of the) patients. $73 \%$ of the patients had one or more extra hepatic sides of metastases (bone $n=98$, lung $n=31$, non-loco regional nodes 
$n=29$, abdominal $n=15$, pleura $n=6$, cutaneous $n=5$, mediastinal $n=5$, adrenal $n=4$, peritoneal $n=4$, brain $n=4$ ). At inclusion, patients had received a median of 4 systemic chemotherapeutic lines (range 0-11) in the metastatic setting before MMC infusion. We included only systemic chemotherapies in the metastatic setting without hormonal, HER2 therapies or chemotherapies in the adjuvant or neoadjuvant setting. Median time from diagnosis of metastatic disease until MMC infusion was 36.9 months (SD 35.6).

Table 1. Patient pre-treatment characteristics, and univariate analysis for overall survival.

\begin{tabular}{|c|c|c|c|}
\hline & \multirow[t]{2}{*}{$N=176$} & \multicolumn{2}{|c|}{ Univariate analysis } \\
\hline & & HR $(95 \%-\mathrm{Cl})$ & $p$ value \\
\hline Aetiology primary tumour & & & 0.39 \\
\hline Ductal & $142(84 \%)$ & & \\
\hline Lobular & $21(12 \%)$ & & \\
\hline Other & $7(4 \%)$ & & \\
\hline \multicolumn{4}{|l|}{ Hormone status primary tumour } \\
\hline Positive oestrogen receptor & $135(80 \%)$ & $0.9(0.6 ; 1.3)$ & 0.58 \\
\hline Positive progesterone receptor & $111(66 \%)$ & $0.96(0.7 ; 1.3)$ & 0.81 \\
\hline Positive HER2 receptor & $29(19 \%)$ & $1.1(0.7 ; 1.6)$ & 0.75 \\
\hline Triple negative receptor status & $18(11 \%)$ & $1.7(1.0 ; 2.7)$ & 0.046 \\
\hline \multicolumn{4}{|l|}{ Diagnosis of liver metastasis } \\
\hline Synchronous & $32(18 \%)$ & Ref & Ref \\
\hline Metachronous & $144(82 \%)$ & $0.8(0.6 ; 1.2)$ & 0.33 \\
\hline $\begin{array}{l}\text { Time from diagnosis of breast cancer } \\
\text { to liver metastases, months }\end{array}$ & $36.6(0-329.5)$ & $1.0(0.99 ; 1.00)$ & 0.80 \\
\hline Liver tumour burden & & & $<.0001$ \\
\hline$<25 \%$ & $85(50 \%)$ & Ref & Ref \\
\hline $25 \%-50 \%$ & $44(26 \%)$ & $2.1(1.5 ; 3.1)$ & $<.0001$ \\
\hline$>50 \%$ & $41(24 \%)$ & $2.9(2.0 ; 4.4)$ & $<.0001$ \\
\hline \multicolumn{4}{|l|}{ Extra hepatic sites of metastases } \\
\hline Yes & $129(73 \%)$ & $1.3(0.9 ; 1.8)$ & 0.18 \\
\hline No & $47(27 \%)$ & Ref & Ref \\
\hline $\begin{array}{l}\text { Median systemic chemotherapy lines } \\
\text { for MBC before MMC }\end{array}$ & $4(0-11)$ & $1.1(1.1 ; 1.2)$ & $<.0001$ \\
\hline \multicolumn{4}{|l|}{ Prior hepatic treatment } \\
\hline Surgery & $9(5 \%)$ & $0.5(0.2 ; 0.97)$ & 0.042 \\
\hline Ablation & $3(1.7 \%)$ & $5.1(1.6 ; 16)$ & 0.0058 \\
\hline Alanine aminotransferase level & & & \\
\hline
\end{tabular}


Table 1. Continued.

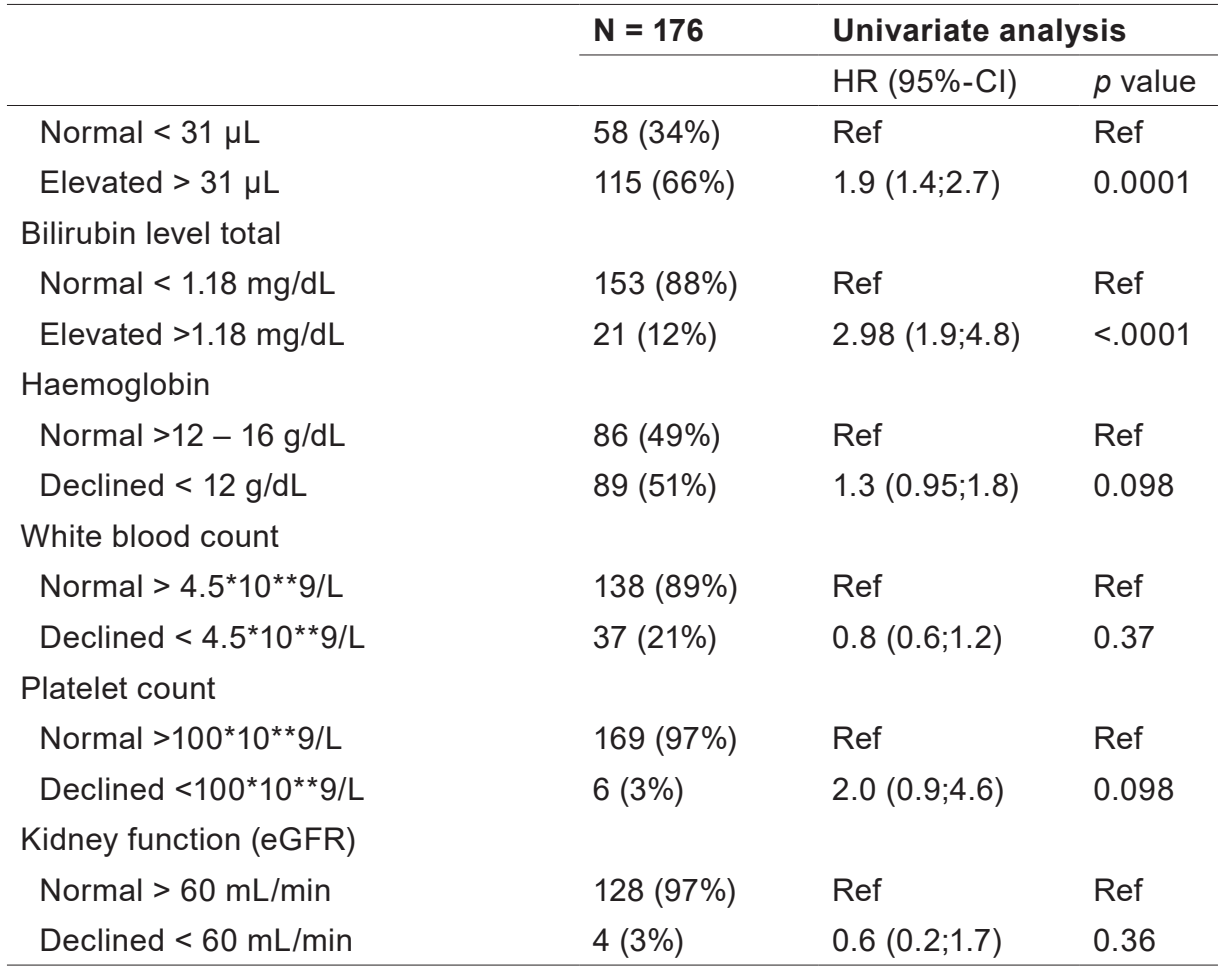

\section{Treatment Characteristics}

Table 2 shows treatment factors of the MMC infusions. A total of 599 MMC cycles were given in 176 patients. The median age at first MMC infusion was 56 years (range 26 - 86). No patients received additional chemotherapy during MMC infusion. Nine patients underwent a hepatic resection and 3 patients a percutaneous thermal ablation for their hepatic disease before MMC infusion. After MMC infusion was stopped for any reason (in most cases progression), $50 \%$ of the patients received further systemic treatment with other chemotherapies, and $9(5 \%)$ patients received local hepatic treatment consisting of intra-arterial radioembolization with yttrium $90(n=5)$, external beam radiotherapy $(n=1)$, percutaneous thermal ablation $(n=1)$ and surgery $(n=2)$. 
Table 2. Treatment characteristics and response.

\begin{tabular}{ll} 
Median age at first MMC infusion (years) & $56(26-86)$ \\
Median number of MMC cycles per patient & $3(1-11)$ \\
Median dose of MMC (mg) & $12(6-12)$ \\
Median number of cycles before response assessment & $2(1-5)$ \\
Response after MMC ( $n=132)$ & \\
Partial response & $26(14.8 \%)$ \\
Stabile disease & $76(43.2 \%)$ \\
Progressive disease & $30(17 \%)$ \\
No response assessment possible & $44(25 \%)$ \\
\hline
\end{tabular}

\section{Adverse Events}

In table 3, all clinical and biochemical adverse events in 176 patients with a total of 599 MMC infusions are listed. Thrombocytopenia was the most often occurring adverse event. No grade 5 adverse events occurred after MMC infusion. Two patients developed an adverse event concerning the kidney. The first patient developed chronic kidney failure after the sixth cycle of MMC. This patient had a mono kidney and ended with permanent peritoneal dialysis (grade 4). The second patient developed a thrombotic microangiopathy after the sixth cycle of MMC which was treated with steroids (grade 2). A second grade 4 adverse event occurred and consisted of a thrombocytopenia below $2510^{* *}$ / $/ \mathrm{L}$ which was treated by 2 packages of platelets. The fact that methyl prednisolone was also prescribe could have contributed to the thrombocytopenia.

A sepsis was seen in one patient after the second MMC infusion that was treated with systemic antibiotic treatment. One patient developed an acalculous cholecystitis that was treated with laparoscopic cholecystectomy. Eight patients experienced a haematoma at the puncture site. An allergic reaction to the contrast agent appeared in 5 patients during the procedure, of which one had to be treated with intravenous medication (grade 3 ). 
Table 3. Adverse events after MMC infusion.

\begin{tabular}{|c|c|c|c|c|}
\hline Adverse events $(n=176)$ & Grade 1 & Grade 2 & Grade 3 & Grade 4 \\
\hline \multicolumn{5}{|l|}{ Clinical n (\%) } \\
\hline Fatigue & $55(31 \%)$ & $4(2 \%)$ & 0 & 0 \\
\hline Pain & $62(35 \%)$ & $2(1 \%)$ & $3(2 \%)$ & 0 \\
\hline Nausea & $54(31 \%)$ & $2(1 \%)$ & $1(0.5 \%)$ & 0 \\
\hline Emesis & $15(8 \%)$ & 0 & 0 & 0 \\
\hline Weight loss & $8(5 \%)$ & $2(1 \%)$ & 0 & 0 \\
\hline Gastrointestinal ulcer & 0 & $1(0.5 \%)$ & 0 & 0 \\
\hline Allergic reaction & $3(2 \%)$ & $2(1 \%)$ & $1(0.5 \%)$ & 0 \\
\hline Hematoma at injection site & $7(4 \%)$ & $1(0.5 \%)$ & 0 & 0 \\
\hline Sepsis & 0 & 0 & $1(0.5 \%)$ & 0 \\
\hline Kidney disease & 0 & $2(1 \%)$ & 0 & $1(0.5 \%)$ \\
\hline Other & $35(20 \%)$ & $2(1 \%)$ & $1(0.5 \%)$ & 0 \\
\hline \multicolumn{5}{|l|}{ Biochemical n (\%) } \\
\hline Leukopenia & $53(30 \%)$ & $12(7 \%)$ & $2(1 \%)$ & 0 \\
\hline Thrombocytopenia & $96(55 \%)$ & $22(13 \%)$ & $6(3 \%)$ & $1(0.5 \%)$ \\
\hline Anaemia & $43(24 \%)$ & $10(6 \%)$ & 0 & 0 \\
\hline Increased aspartate aminotransferase & $30(17 \%)$ & $7(4 \%)$ & $3(2 \%)$ & 0 \\
\hline Increased alanine aminotransferase & $24(14 \%)$ & $4(2 \%)$ & $1(0.5 \%)$ & 0 \\
\hline Increased bilirubin & $8(5 \%)$ & $6(3 \%)$ & $8(5 \%)$ & 0 \\
\hline Increased alkaline phosphatase & $11(6 \%)$ & $4(2 \%)$ & $1(0.5 \%)$ & 0 \\
\hline Increased gamma-glut amyl transferase & $22(13 \%)$ & $3(2 \%)$ & $1(0.5 \%)$ & 0 \\
\hline $\begin{array}{l}\text { Decrease in estimated glomerular } \\
\text { filtration rate }\end{array}$ & $5(3 \%)$ & 0 & 0 & 0 \\
\hline
\end{tabular}

\section{Response by RECIST}

Post procedural CT for response assessment was available in 132 (75\%) of the patients. Median time to RECIST response assessment was after 2 cycles of MMC infusion (range 1-5). Response rate in the liver after MMC consisted of PR ( $n=26,14.8 \%)$ (figure I), SD ( $n=76,43.2 \%)$ and PD ( $n=30,17 \%)$. In 44 patients $(25 \%)$ no response assessment was obtained. 


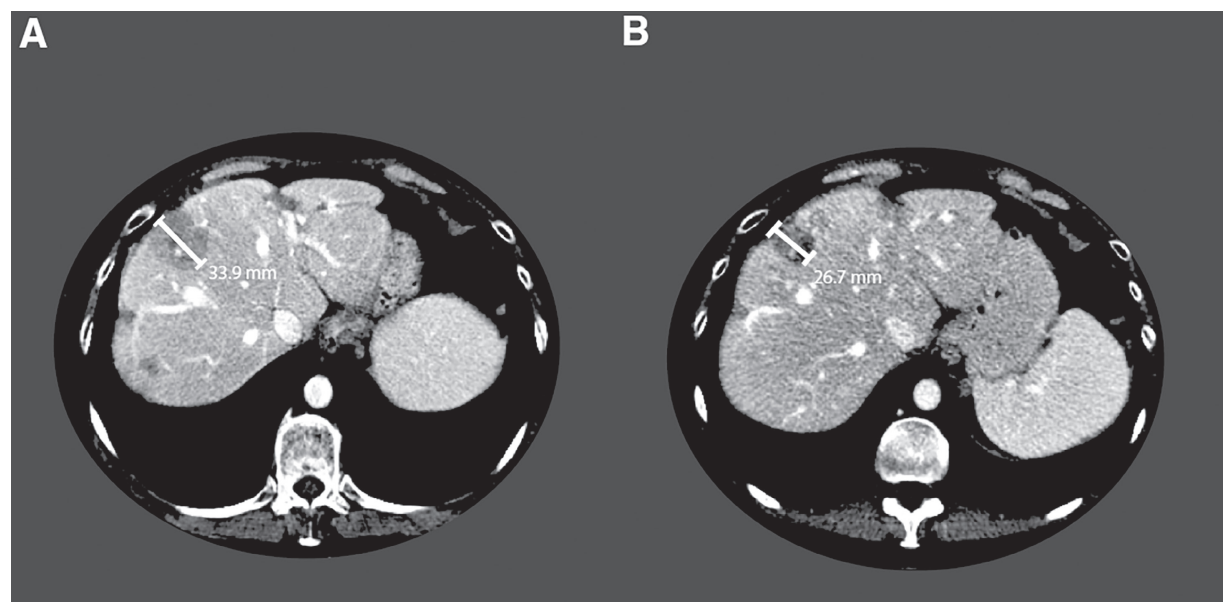

Figure 1. Hepatic response before (A) and after (B) 2 cycles of MMC

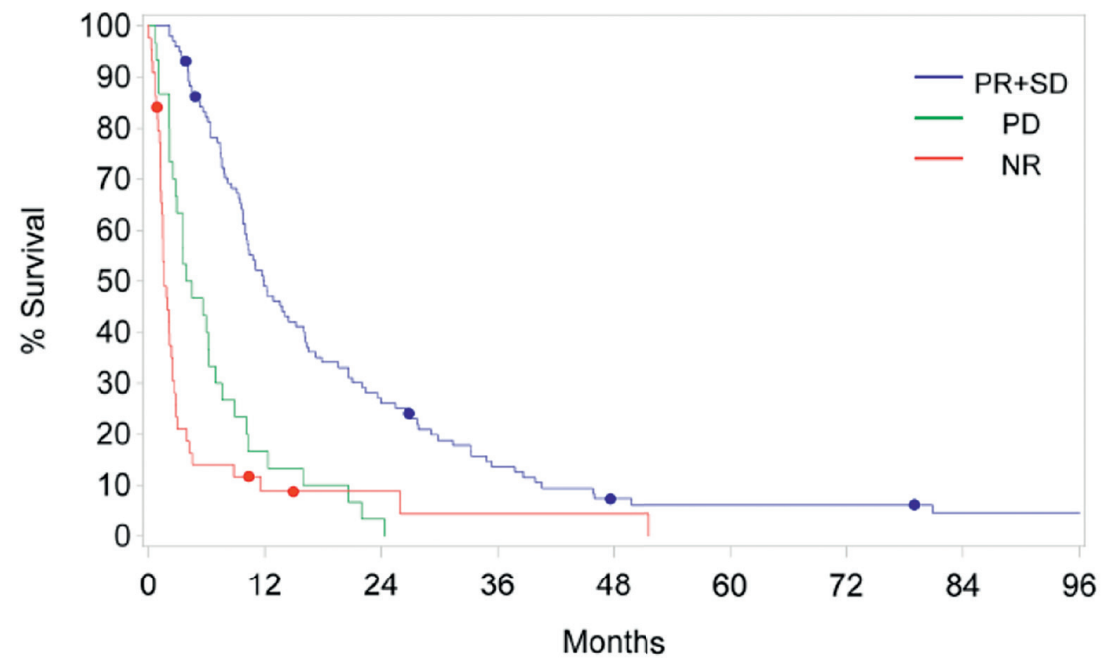

Number at risk

$\mathrm{PR}+\mathrm{SD}$

PR

$\begin{array}{rrrrrrrrr}102 & 49 & 27 & 13 & 6 & 5 & 5 & 3 & 3 \\ 30 & 5 & 1 & 0 & 0 & 0 & 0 & 0 & 0 \\ 44 & 3 & 2 & 1 & 1 & 0 & 0 & 0 & 0\end{array}$

Figure 2. Kaplan Meier curve overall survival by three groups; responders (PR + SD); non-responders (PD) and patients with no response assessment (NR). Median OS was 11.9 months for the responders, 4.2 months for the non-responders and 1.7 months for the patients with no response assessment 


\section{Survival analysis}

At time of analysis 3 patients were still alive; the other 173 patients had died. Median OS was 7.8 months (95\% Cl of 6.1-9.8). In figure II an overview is shown of the OS outlined in different groups (disease control (PR+SD), progressive disease (PD), no response assessment (NK)), a global test showed a significant difference between the three groups $(p<.0001)$. Median survival for patients that obtained disease control was 11.9 months $(\mathrm{Cl} 10-16.1)$ and 4.2 months $(\mathrm{Cl}$ 2.8-6.9) for patients that showed PD $(p<0.0001)$. In patients where no response assessment (NR) was not obtained median survival was 1.7 months (1.3-2.4 months). Median hPFS in the 107 patients in which radiological follow up was available was 5.5 months $(\mathrm{Cl}=4.5-6.8)$ as shown in figure III.

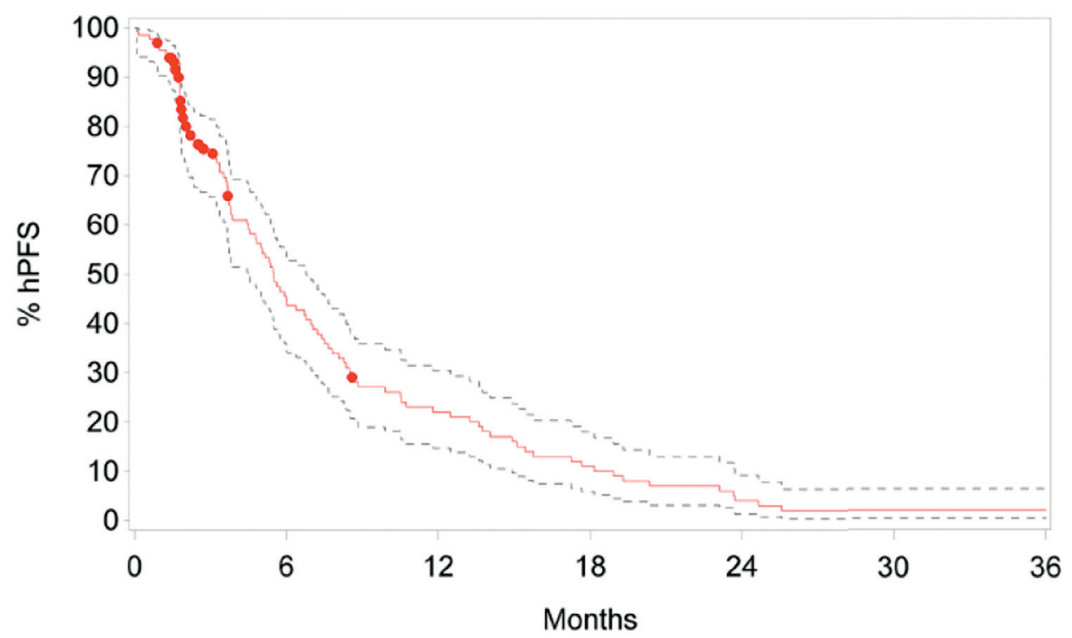

Figure 3. Kaplan Meier curve of hepatic progression free survival (hPFS) by RECIST. Median hPFS was 5.5 months

\section{Factors influencing overall survival}

Univariable analysis of the association of pre-treatment characteristics with overall survival is presented in table 1. Multivariable analysis (table 4) showed that a higher number of previous lines of systemic chemotherapy $(H R=1.2$; $\mathrm{Cl}=1.1-1.3)$, a higher tumour burden (>50\%) $(\mathrm{HR}=2.4 ; \mathrm{Cl}=1.5-3.7)$, prior ablation of the liver $(\mathrm{HR}=5.9 \mathrm{Cl}=1.8-19.4)$ and elevated levels of bilirubin $(\mathrm{HR}=2.18$; $\mathrm{Cl}=1.3-3.8)$ and alanine transaminase (ALT) $(\mathrm{HR}=1.5 ; \mathrm{Cl}=1.01-2.09)$ were independently associated with a worse OS. After the addition of response 
assessment by RECIST to the previously chosen multivariable model, PD by RECIST was significantly associated with a worse OS (PD vs PR; HR=3.98 $\mathrm{Cl}=2.3-7.02 \mathrm{p}<0.0001)$.

Table 4. Multivariable model of factors influencing overall survival.

\begin{tabular}{lllll}
\hline Variable & Test & $\mathbf{N}(\%)$ & Hazard Ratio (95\% Cl) & P-value \\
\hline $\begin{array}{l}\text { Systemic } \\
\text { chemotherapy lines } \\
\text { before MMC }\end{array}$ & $\begin{array}{l}\text { Linear trend: } \\
\text { +1 unit }\end{array}$ & $167(95 \%)$ & $1.166(1.080 ; 1.259)$ & $<.0001$ \\
Prior liver ablation & None & $173(98 \%)$ & Ref & \\
& Performed & $3(2 \%)$ & $5.938(1.818 ; 19.395)$ & 0.0032 \\
Tumour burden liver & Global test & & & $<.0001$ \\
& $<25 \%$ & $85(50 \%)$ & Ref & Ref \\
& $25-50 \%$ & $44(26 \%)$ & $2.050(1.391 ; 3.022)$ & 0.0003 \\
& $>50 \%$ & $41(24 \%)$ & $2.384(1.534 ; 3.706)$ & 0.0001 \\
Baseline bilirubin level & Not elevated & $153(88 \%)$ & Ref & Ref \\
& Elevated & $21(12 \%)$ & $2.183(1.265 ; 3.767)$ & 0.0050 \\
Baseline ALT level & Not elevated & $58(34 \%)$ & Ref & Ref \\
& Elevated & $115(66 \%)$ & $1.457(1.016 ; 2.089)$ & 0.0406 \\
\hline
\end{tabular}

ALT: alanine aminotransferase, HR: hazard ratio, $\mathrm{Cl}$ : confidence interval Continuous variables/linear trend: $\mathrm{HR}>(<) 1$ : higher (lower) risk for higher predictor level Categorical variables: global $p$-value for any difference between groups Binary variables pairwise tests: $\mathrm{HR}>(<) 1$ : higher (lower) risk for given category compared to reference

\section{DISCUSSION}

In this study we demonstrated that MMC infusion was safe and effective in a cohort of 176 heavily pre-treated LMBC patients with a total of 599 MMC infusions. Multivariable analysis showed that an increased number of prior systemic chemotherapeutic lines, a higher tumour burden of the liver, prior ablation of the liver and elevated baseline levels of bilirubin and ALT, were independently associated with a worse OS.

Progression or resistance to systemic chemotherapy often occurs in the LMBC patients, which is associated with a worse survival [16]. To overcome this resistance, local intra-arterial therapies may offer high local concentrations of chemotherapy in the liver with low toxicity providing a break from systemic chemotherapy [10,17]. Literature about MMC infusion in LMBC patients is very 
limited. Prior research demonstrated the safety of MMC in a smaller cohort of 30 patients [14]. In the present study of a large cohort, we confirmed that intra-arterial MMC infusion was safe with only $17.5 \%$ patients with a grade 3 or higher adverse events despite a heavily pre-treated metastatic breast cancer (MBC) population. These toxicity levels are low compared to other therapies for resistant metastatic breast cancer patients, such as Eribulin that has a $30 \%$ grade 4 adverse event and overall $99 \%$ adverse events [18, 19]. Ideally, intraarterial MMC should be tested in a randomized phase III study compared to systemic therapy of physician's choice, but it is unlikely that such a study will ever happen.

A known severe systemic side effect of MMC administration is HUS [12, 13]. In the present study two patients had a side effect concerning the kidney, however no HUS occurred in a total of 599 intra-arterial MMC infusions. Therefore, we conclude that MMC can be safely used by intra-arterial infusion.

In this study we observed a median OS of 7.8 months. In the literature, other groups have reported a median OS of 7 months [20], 14 months [21], 13.2 months [22], 11.4 months [23] after MMC infusion [20], MMC with Folic acid plus 5-Fluorouracil [21], and MMC plus Gemcitabine [22, 23], respectively. These differences can be explained by the differences in disease extension and amount of prior therapy received before intra-arterial infusion. The rather low OS rate in our cohort certainly reflects the advanced stage of MBC where patients had a median of 4 prior systemic treatments for metastatic disease before starting MMC and a 36.6 months interval between diagnosis of metastases and MMC infusion.

It may be important to select patients for MMC infusion that can have the most benefit of the treatment. For that reason, we performed a multivariable analysis of independent pre-treatment factors associated with OS. The independent factors associated with a poor survival were all related to extensive prior treatment and high tumour load in the liver accompanied with deteriorated laboratory liver tests. In the literature, previously reported factors for worse overall survival in LMBC patients were administration of previous therapy, higher number of metastatic locations and baseline liver dysfunction which is in line with our findings [24-27]. Patients that responded, by RECIST, to the therapy had a significantly longer OS, compared to patients that had PD or when no response assessment was possible. The very short OS of the patients without response assessment ( 1.4 months) shows that these patients probably did not responded to the therapy. Therefore, this early endpoint is useful to evaluate if continuation of the therapy is justified. This is rather opposite to 
response assessment in patients treated with systemic chemotherapy where a literature based analysis of 24 trials reported only a moderate association between objective response rate and OS in patients treated with 2nd and 3th line chemotherapies [28].

Besides chemo infusion, other intra-arterial therapies are available for LMBC patients consisting of transarterial chemo embolization (TACE) and radioembolization (TARE) [10]. Inclusion criteria for TARE and TACE are more strict, compared to chemo infusion, resulting in less advanced diseased LMBC patients with longer median overall survival (6.6-13.6 and 4.6-47 months, respectively) [29-31]. For TACE, all grade adverse events are reported up to $71 \%$ of the patients with grade $3 \geq$ adverse events in $34.7 \%$ of the patients [32, 33]. TARE is generally better tolerated than TACE, with adverse events grades around $44 \%$ [32]. Response rates whereby disease control is obtained after TARE and TACE differ widely from $52-99 \%$ and $40-83 \%$, respectively [29-31].

Limitation of our study is the retrospective nature of this study, namely the retrospective assessment of the patient records for toxicity and response assessment. Next to that, response assessment was only possible in 132 of the 176 patients and assessment of hPFS was only possible in 107 of the 176 patients. Further, patients were included over a period of 17 years in a rapidly changing therapeutic landscape.

In conclusion, intra-arterial MMC infusion was able to obtain disease control in $58 \%$ of the LMBC patients (PR and SD) with a low toxicity profile. MV analysis showed a worse OS in patients with an increased amount of prior therapies, a higher liver tumour burden and elevated levels of bilirubin and ALT. Further prospective studies are needed to determine the exact place of intra-arterial MMC infusion and other intra-arterial therapies in LMBC patients. 


\section{References:}

1. Siegel RL, Miller KD, Jemal A. Cancer statistics, 2018. CA Cancer J Clin. 2018;68(1):7-30.

2. Miller KD, Siegel RL, Lin CC, Mariotto AB, Kramer JL, Rowland JH, et al. Cancer treatment and survivorship statistics. 2016. CA Cancer J Clin. 2016;66(4):271-89.

3. Bishop AJ, Ensor J, Moulder SL, Shaitelman SF, Edson MA, Whitman GJ, et al. Prognosis for patients with metastatic breast cancer who achieve a no-evidence-ofdisease status after systemic or local therapy. Cancer. 2015;121(24):4324-32.

4. Eichbaum MH, Kaltwasser M, Bruckner T, de Rossi TM, Schneeweiss A, Sohn C. Prognostic factors for patients with liver metastases from breast cancer. Breast Cancer Res Treat. 2006;96(1):53-62.

5. Wu SG, Li H, Tang LY, Sun JY, Zhang WW, Li FY, et al. The effect of distant metastases sites on survival in de novo stage-IV breast cancer: A SEER database analysis. Tumour Biol. 2017;39(6):1010428317705082.

6. Cardoso F, Senkus E, Costa A, Papadopoulos E, Aapro M, Andre F, et al. 4th ESOESMO International Consensus Guidelines for Advanced Breast Cancer (ABC 4) dagger. Ann Oncol. 2018;29(8):1634-57.

7. Eckmann K, Michaud LB, Rivera E, Madden TL, Esparza-Guerra L, Kawedia J, et al. Pilot study to assess toxicity and pharmacokinetics of docetaxel in patients with metastatic breast cancer and impaired liver function secondary to hepatic metastases. J Oncol Pharm Pract. 2014;20(2):120-9.

8. Diamond JR, Finlayson CA, Borges VF. Hepatic complications of breast cancer. Lancet Oncol. 2009;10(6):615-21.

9. Breedis C YG. The blood supply of neoplasms in the liver. 1954.

10. Gordon AC, Uddin OM, Riaz A, Salem R, Lewandowski RJ. Making the case: intraarterial therapy for less common metastases. Semin Intervent Radiol. 2017;34(2):132-9.

11. Bradner WT. Mitomycin C: a clinical update. Cancer Treat Rev. 2001;27(1):35-50.

12. Almstedt K, Fasching PA, Scharl A, Rauh C, Rack B, Hein A, et al. Mitomycin C and Capecitabine (MiX Trial) for therapy of patients with metastasized, breast cancer pretreated with anthracycline. Anticancer Res. 2016;36(1):419-25.

13. Maisano R, Caristi N, Mare M, Raffaele M, lorfida M, Mafodda A, et al. Mitomycin C plus capecitabine (mixe) in anthracycline- and taxane-pretreated metastatic breast cancer. A multicenter phase II study. Anticancer research. 2007;27(4C):2871-5.

14. Maes T, Wildiers H, Heye S, Demey W, Maleux G, Neven P, et al. Intra-hepatic Mitomycin $\mathrm{C}$ bolus infusion in the treatment of extensive liver metastases of breast cancer. Breast Cancer Res Treat. 2008;110(1):135-42.

15. Eisenhauer EA, Therasse P, Bogaerts J, Schwartz LH, Sargent D, Ford R, et al. New response evaluation criteria in solid tumours: revised RECIST guideline (version 1.1). Eur J Cancer. 2009;45(2):228-47.

16. Atalay G, Biganzoli L, Renard F, Paridaens R, Cufer T, Coleman R, et al. Clinical outcome of breast cancer patients with liver metastases alone in the anthracyclinetaxane era: a retrospective analysis of two prospective, randomised metastatic breast cancer trials. European Journal of Cancer. 2003;39(17):2439-49.

17. Di Lascio $S$, Pagani O. Oligometastatic breast cancer: a shift from palliative to potentially curative treatment? Breast Care (Basel). 2014;9(1):7-14.

18. Cortes J, O'Shaughnessy J, Loesch D, Blum JL, Vahdat LT, Petrakova K, et al. Eribulin monotherapy versus treatment of physician's choice in patients with metastatic breast cancer (EMBRACE): a phase 3 open-label randomised study. The Lancet. 2011;377(9769):914-23. 
19. Kaufman PA, Awada A, Twelves C, Yelle L, Perez EA, Velikova G, et al. Phase III open-label randomized study of eribulin mesylate versus capecitabine in patients with locally advanced or metastatic breast cancer previously treated with an anthracycline and a taxane. J Clin Oncol. 2015;33(6):594-601.

20. Tewes M, Peis MW, Bogner S, Theysohn JM, Reinboldt MP, Schuler M, et al. Hepatic arterial infusion chemotherapy for extensive liver metastases of breast cancer: efficacy, safety and prognostic parameters. J Cancer Res Clin Oncol. 2017;143(10):2131-41.

21. Eichbaum MH, Gast AS, Bruckner T, Schneeweiss A, Sohn C. Combined Chemotherapy with Mitomycin C, Folinic Acid, and 5-Fluorouracil (MiFoFU) as salvage treatment for patients with liver metastases from breast cancer - a retrospective analysis. Breast Care (Basel). 2008;3(4):262-7.

22. Gruber-Rouh T, Langenbach M, Naguib NNN, Nour-Eldin NM, Vogl TJ, Zangos S, et al. Trans-arterial chemoperfusion for the treatment of liver metastases of breast cancer and colorectal cancer: Clinical results in palliative care patients. World J Clin Oncol. 2017;8(4):343-50.

23. Vogl TJ, Zangos S, Eichler K, Selby JB, Bauer RW. Palliative hepatic intraarterial chemotherapy (HIC) using a novel combination of gemcitabine and mitomycin C: results in hepatic metastases. European Radiology. 2007;18(3):468-76.

24. Duan XF, Dong NN, Zhang T, Li Q. The prognostic analysis of clinical breast cancer subtypes among patients with liver metastases from breast cancer. International Journal of Clinical Oncology. 2013;18(1):26-32.

25. Beslija SB, Burstein, HJ, Cocquyt V, Gnant M, Heinemann V, Jassem J et al. Third consensus on medical treatment of metastatic breast cancer. Annals of Oncology. 2009;20(11):1771-85.

26. Tsimberidou AM, Vaklavas C, Fu S, Wen S, Lim JA, Hong D, et al. Hepatic arterial infusion therapy in advanced cancer and liver-predominant disease: the MD Anderson Experience. Hepato-gastroenterology. 2013;60(127):1611-23.

27. Pieper CC, Meyer C, Wilhelm KE, Block W, Nadal J, Ahmadzadehfar H, et al. Yttrium-90 radioembolization of advanced, unresectable breast cancer liver metastases-a singlecenter experience. J Vasc Interv Radiol. 2016;27(9):1305-15.

28. Liu L, Chen F, Zhao J, Yu H. Correlation between overall survival and other endpoints in metastatic breast cancer with second- or third-line chemotherapy: Literature-based analysis of 24 randomized trials. Bull Cancer. 2016;103(4):336-44.

29. Smits ML, Prince JF, Rosenbaum CE, van den Hoven AF, Nijsen JF, Zonnenberg BA, et al. Intra-arterial radioembolization of breast cancer liver metastases: a structured review. Eur J Pharmacol. 2013;709(1-3):37-42.

30. Mouli SK, Gupta R, Sheth N, Gordon AC, Lewandowski RJ. Locoregional therapies for the treatment of hepatic metastases from breast and gynecologic cancers. Semin Intervent Radiol. 2018;35(1):29-34.

31. Wang M, Zhang J, Ji S, Shao G, Zhao K, Wang Z, et al. Transarterial chemoembolisation for breast cancer with liver metastasis: A systematic review. Breast. 2017;36:25-30.

32. Chang J, Charalel R, Noda C, Ramaswamy R, Kim SK, Darcy M, et al. Liver-dominant breast cancer metastasis: a comparative outcomes study of chemoembolization versus radioembolization. Anticancer research. 2018;38(5):3063-8.

33. Lin Y-T, Médioni J, Amouyal G, Déan C, Sapoval M, Pellerin O. Doxorubicin-loaded 70-150 $\mu \mathrm{m}$ microspheres for liver-dominant metastatic breast cancer: results and outcomes of a pilot study. Cardiovasc Intervent Radiol. 2017;40(1):81-9. 
Mitomycin C infusion in liver metastatic breast cancer patients 



\section{CHAPTER}

Sequential intra-arterial infusion of ${ }^{90} \mathrm{Y}$-resin microspheres and Mitomycin C in chemo refractory liver metastatic breast cancer patients: a single centre pilot study

B.M. Aarts*, E.G. Klompenhouwer*, R.C. Dresen, C.M. Deroose, R.G.H. Beets-Tan, K. Punie, P. Neven,

H. Wildiers, G. Maleux * authors contributed equally

Published in Radiology \& Oncology Jan 21:54(1):33-39

doi: 10.2478/raon-2020-0002

PMID: 31967966 


\section{ABSTRACT}

Purpose: The aim of the study was to evaluate the safety and feasibility of intra-arterial Mitomycin C (MMC) infusion after selective internal radiation therapy (SIRT) using yttrium-90 $\left({ }^{90} \mathrm{Y}\right)$ resin microspheres in liver metastatic breast cancer (LMBC) patients.

Patients and Methods: This prospective pilot study included LMBC patients from 2012-2018. Patients first received infusion of ${ }^{90} Y$ resin microspheres, after 6-8 weeks response to treatment was assessed by MRI, ${ }^{18} \mathrm{~F}-\mathrm{FDG}$ PET/CT and laboratory tests. After exclusion of progressive disease, MMC infusion was administrated 8 weeks later in different dose cohorts; A: $6 \mathrm{mg}$ in 1 cycle, B: 12 $\mathrm{mg}$ in 2 cycles, C: $24 \mathrm{mg}$ in 2 cycles and D: maximum of $72 \mathrm{mg}$ in 6 cycles. In cohort $D$ the response was evaluated after every 2 cycles and continued after exclusion of progressive disease. Adverse events (AE) were reported according to CTCAE version 5.0.

Results: Sixteen patients received ${ }^{90} Y$ treatment. Four patients were excluded for MMC infusion, because of extra hepatic disease progression $(n=3)$ and clinical and biochemical instability $(n=1)$. That resulted in the following number of patient per cohort; A:2 B:1 C:3 and D:6. In 4 of the 12 patients (all cohort D) the maximum dose of MMC was adjusted due biochemical toxicities $(n=2)$ and progressive disease $(n=2)$. One grade $3 A E$ occurred after ${ }^{90} Y$ treatment consisting of a gastrointestinal ulcer whereby prolonged hospitalization was needed.

Conclusion: Sequential treatment of intra-arterial infusion of MMC after ${ }^{90} Y$ SIRT was feasible in $75 \%$ of the patients when MMC is administrated in different escalating dose cohorts. However, caution is needed to prevent reflux after ${ }^{90} \mathrm{Y}$ SIRT in LMBC patients. 


\section{INTRODUCTION}

Up to 50 percent of the metastatic breast cancer $(\mathrm{mBC})$ patients eventually develop liver metastases which is associated with a poor overall survival ranging from 1-3 years [1, 2]. Liver metastatic breast cancer (LMBC) patients with limited (extra) hepatic disease can obtain a survival benefit from local treatment options, such as surgery and ablation [3, 4]. Unfortunately, most LMBC patients have extended disease whereby systemic treatment by chemotherapy or anti-hormonal therapy, in hormone sensitive breast cancer, is indicated. Systemic treatment with chemotherapy has lengthened overall survival, but haematological, gastrointestinal and neurotoxicity are dose-limiting factors with systemic administration of these agents [5]. Therapies with less systemic toxicity are therefore an attractive treatment option in LMBC patients refractory to systemic chemotherapy [6].

Several intra-arterial therapies have been applied for LMBC patients, such as radioembolization (yttrium-90 $\left({ }^{90} \mathrm{Y}\right)$ resin microspheres), chemo embolization and chemo infusion, reported as effective and safe treatment options [7-9]. Of these treatments, the best results are reported for intra-arterial radioembolization, with a disease control rate of $72-91 \%$ and an overall survival of $6.6-13.6$ months [7, 10-12]. For over 15 years, LMBC patients are treated by intra-arterial chemo infusion with Mitomycin $\mathrm{C}(\mathrm{MMC})$ in our institute whereby disease control is obtained in $58 \%$ with low adverse events in a very heavily pre-treated cohort [9].

Since primary breast cancer is sensitive for both systemic chemotherapy and external beam radiation therapy, LMBC patients might also benefit from the combined treatment of chemo infusion and selective internal radiation therapy (SIRT). However, the sequential administration of these intra-arterial therapies e.g. SIRT and intra-arterial chemo infusion, has not yet been reported. In this pilot study we prospectively analysed the safety and feasibility of the sequential intra-arterial infusion of ${ }^{90} \mathrm{Y}$ resin microspheres and $\mathrm{MMC}$ in patients refractory to conventional systemic chemotherapy.

\section{MATERIAL AND METHODS}

This prospective phase I pilot study of 16 patients was approved by the ethics committee of our hospital (S 53657). Patients were included from April 2012 until March 2018. All patients signed a written informed consent. Patient selection was performed by a multidisciplinary tumour board consisting of 
medical, surgical and radiation oncologists together with pathologists, nuclear medicine physicians and (interventional) radiologists.

In table 1, the inclusion and exclusion criteria for this pilot study are shown. Figure 1 shows the treatment schedule of ${ }^{90} \mathrm{Y}$ SIRT followed by MMC infusion in the different cohorts. The first 3 patients were allocated to cohort $A$, the second 3 patients to cohort $B$, the 3 patients thereafter to cohort $C$ and the remaining of the patients in cohort $D$. Patients first underwent the ${ }^{90} Y$ treatment and in the absence of progression, the sequential intra-arterial hepatic MMC infusions were administrated 8 weeks later.

Table 1. Inclusion and exclusion criteria

\begin{tabular}{|c|c|}
\hline Inclusion criteria & Exclusion criteria \\
\hline $\begin{array}{l}\text { Histologically confirmed diagnosis of } \\
\text { breast cancer }\end{array}$ & Bilirubin level $>1.5 x$ upper limit normal \\
\hline $\begin{array}{l}\text { Radiological evidence of liver } \\
\text { metastases }\end{array}$ & $\begin{array}{l}\text { Transaminase (AST/ALT) }>2.5 x \text { upper } \\
\text { limit normal }\end{array}$ \\
\hline $\begin{array}{l}\text { Liver only or liver predominant with } \\
\text { stable extra-hepatic disease }\end{array}$ & Creatinine $>1.2 x$ upper limit normal \\
\hline $\begin{array}{l}\text { Progressive under (multi-line) systemic } \\
\text { chemo or hormonal therapy }\end{array}$ & $\begin{array}{l}\text { Glomerular filtration rate }<60 \mathrm{~mL} / \\
\mathrm{min} / 1.73 \mathrm{~m}^{2}\end{array}$ \\
\hline Eligible for intra-arterial therapy & Neutrophils $<1000 / \mu \mathrm{L}$ \\
\hline Age $>18$ years & Thrombocytes <100 x10\%/L \\
\hline \multirow[t]{3}{*}{ Karnofsky performance $>70$} & Lung shunt fraction $>20 \%$ \\
\hline & Allergy to contrast media \\
\hline & Active use of oral anticoagulation \\
\hline
\end{tabular}

AST $=$ Aspartate Aminotransferase; ALT = Alanine aminotransferase

Radioembolization with yttrium-90 $\left({ }^{90} \mathrm{Y}\right)$ resin microspheres All ${ }^{90} \mathrm{Y}$ procedures were performed under local anaesthesia by or under direct supervision of an expert interventional radiologist (GM) and nuclear medicine physician (CD). Previously published work describes the details of the ${ }^{90} Y$ treatment [13]. Briefly, patients first underwent a detailed baseline angiogram and embolization of enterohepatic arteries with micro-coils according to the expertise of the interventional radiologist. Technetium-99m -macroaggregated albumin (99mTC-MAA) was injected in the target vessels and a planar scintigraphy was performed to determine the lung shunt fraction. Two weeks later patients underwent bilobar or unilobar injection of ${ }^{90} \mathrm{Y}$ resin microspheres (SIR spheres ${ }^{\circledR}$, Sirtex Inc, Cosgrove, Australia) under local 
anaesthesia. The activity of ${ }^{90} \mathrm{Y}$ injected in the patient was calculated based on the body surface area method. In patients where it was possible to use the partition model, the partition model was used instead of the body surface area method. Dependent on the site of lesions, the ${ }^{90} \mathrm{Y}$ resin microspheres were injected intra-arterially via a micro catheter to the right and left liver lobe (superselective). A Progreat ${ }^{\circledR}$ micro catheter (Terumo, Europe) or an anti-reflux catheter (Surefire Inc., Westminster, CO, USA) was used for injection of the microspheres. Patients received antiemetics and morphine derivates before ${ }^{90} \mathrm{Y}$ injection when required.

Figure 1. Treatment overview of the 16 patients treated with selective internal radiation therapy with Yttrium-90 containing microspheres $\left({ }^{90} \mathrm{Y} \mathrm{SIRT}\right.$ ) and mitomycin C (MMC) infusion in 4 escalating cohorts.

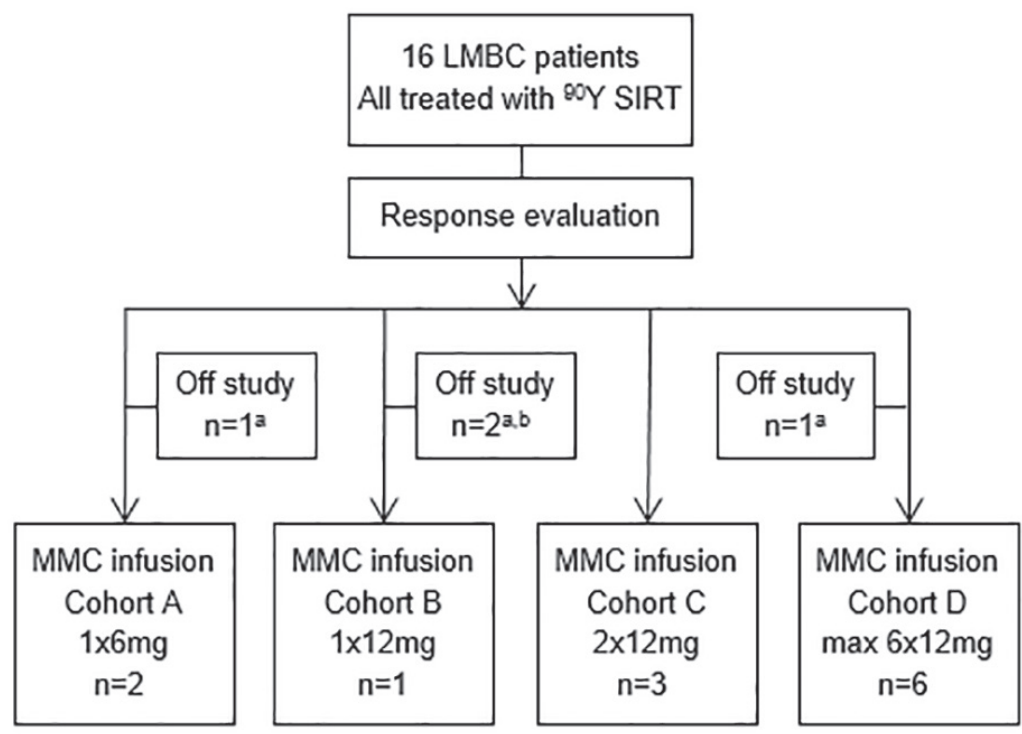

${ }^{a}$ Due to extra hepatic disease progression

${ }^{b}$ Due to the biochemical and clinical toxicities

Hepatic intra-arterial chemo infusion with MMC

Six to eight weeks after the ${ }^{90} Y$ treatment, patients underwent response assessment by magnetic resonance imaging (MRI) of the liver and a whole body $\left[{ }^{18} \mathrm{~F}\right]-\mathrm{FDG}$ positron emission tomography/computed tomography scan $\left({ }^{18} \mathrm{~F}-\mathrm{FDG} \mathrm{PET} / \mathrm{CT}\right)$ together with laboratory tests. If patients showed no untreatable progression of disease on MRI and ${ }^{18} \mathrm{~F}-\mathrm{FDG}$ PET-CT scan (bases on RECIST criteria 1.1) together with acceptable laboratory results (> $100^{*} 10^{9}$ thrombocytes/L), the intra-arterial chemo-infusion of MMC could be 
administrated. Six to ten weeks after the ${ }^{90} Y$ procedure, patients received the first infusion of MMC, as previously described by our group [14]. After local anaesthesia, vascular access was obtained by the right common femoral artery and, using a diagnostic 4-French catheter, a micro catheter was placed in the right and left hepatic arteries for injection of MMC in both liver lobes.

Ascending maximal doses of MMC were administrated in different cohorts. Patients were allocated to the MMC cohort before the ${ }^{90} \mathrm{Y}$ procedure. The first cohort (A) received one cycle of $6 \mathrm{mg} \mathrm{MMC}$, the second cohort (B) received one cycle of $12 \mathrm{mg} \mathrm{MMC}$, the third cohort (C) received 2 cycles of $12 \mathrm{mg}$ of $M M C$ and the fourth cohort (D) received the standard regime of MMC infusion consisting of a maximum of 6 cycles of each $12 \mathrm{mg}$ of MMC. Before and after the MMC infusion laboratory results were taken to determine whether the dose could be tolerated. The dose of MMC was adjusted when thrombocyte count was $<100^{*} 10^{9}$ thrombocytes/L. In the last cohort, the effect of MMC was radiologically evaluated, by CT or MRI, after every two cycles. If these evaluations showed no further intra- or extra-hepatic disease progression, the patient was rescheduled for the next 2 cycles for a maximum of 6 cycles.

\section{Outcomes}

The primary outcomes of this study included the feasibility and safety of MMC infusion after ${ }^{90} \mathrm{Y}$ SIRT. The feasibility was defined as the number of patients receiving the MMC infusion after ${ }^{90} \mathrm{Y}$ treatment. The safety was determined by the number of grade 3 and higher adverse events after $\mathrm{MMC}$ and ${ }^{90} \mathrm{Y}$ treatment and documented by the Common Terminology Criteria for Adverse Events version 5.0. For the response assessment the modified response evaluation criteria in solid tumours (mRECIST) was used to measure hepatic response by a maximum of two target lesions and categorized into four categories [Complete Response (CR), Partial Response (PR), Stable Disease (SD) and Progressive Disease (PD)] [15].

\section{Statistical analysis}

Patient and pre-treatment characteristics were presented as numbers, percentages and median time with range. Overall survival (OS) was calculated from work-up for ${ }^{90} \mathrm{Y}$ treatment until death or loss to follow up by the Kaplan Meier estimates. All analyses were performed in SPSS (IBM Corp, version 25, Armonk, NY). 


\section{RESULTS}

\section{Patient characteristics}

Table 2 shows the patient characteristics of the 16 treated women. The median time from diagnosis of metastatic breast cancer to start of the study was 28 months (range 7.7 - 91 months). Patients were 26 - 77 (median 59) years old at the start of the study. A liver biopsy was taken before start of the study in 15 patients and showed a positive oestrogen receptor in 8 patients, positive progesterone receptor in 8 patients and a negative HER2-neu status in all patients $(n=15)$. Six patients had a triple negative receptor status. Tumour burden of the liver was $<25 \%$ in 9 patients and $>25 \%$ in 7 patients. Nine patients had extra-hepatic disease with a median of 1 site (range $0-4)$ and bone $(n=5)$ as most common site. Before inclusion, the median number of chemotherapy lines in the metastatic phase was 3 regimes consisting of anthracyclines in $75 \%$ and taxanes in $81 \%$.

\section{Treatment}

Figure 1 shows a treatment overview of the 16 patients. All 16 patients underwent the ${ }^{90} \mathrm{Y}$ procedure whereby pre-embolization of extra hepatic arteries was performed in 14/16 patients. A median doses of $1.68 \mathrm{GBq}$ (range $1.043-2.140)$ was inserted in both liver lobes $(n=14)$ or one liver lobe $(n=2)$. At response evaluation five patients showed extra-hepatic disease progression, of whom, three patients were excluded for additional MMC infusion and two patient received the sequential MMC infusion, but with additional therapy of Exemestane (Aromasin $®$ ) for stabilization of their extra-hepatic disease. One patient was hospitalized after ${ }^{90} \mathrm{Y}$ SIRT for 2.5 weeks because of the side effects of the ${ }^{90} \mathrm{Y}$ treatment and excluded from further treatment.

Median time between ${ }^{90} \mathrm{Y}$ SIRT and first MMC infusion was 2.1 months (range 1.7 - 12.8 months). In one patient an interval of 12.8 months occurred, because of PD in the liver after ${ }^{90} \mathrm{Y}$ treatment. This patient first received systemic chemotherapy and after progression during this systemic chemotherapy the MMC infusion was administrated. A total of 12 patients were treated in four different cohorts of MMC doses after the ${ }^{90} \mathrm{Y}$ treatment (Figure 1). In cohort D, the maximum of 6 cycles of $12 \mathrm{mg} \mathrm{MMC}$ was administrated in 2 patients. In the other four patients the dose was adjusted $(n=2)$ and discontinued $(n=2)$ due to hematologic toxicity (thrombocytopenia) and disease progression. 
Table 2. Patient Characteristics

\begin{tabular}{|c|c|}
\hline Patient Characteristics & $N=16$ \\
\hline Median months from diagnosis metastatic disease until start of study & $28(8-91)$ \\
\hline Median age at start study in years (range) & $59(26-77)$ \\
\hline \multicolumn{2}{|l|}{ Diagnosis of liver metastasis } \\
\hline Synchronous & $2(12.5 \%)$ \\
\hline Metachronous & $14(87.5 \%)$ \\
\hline \multicolumn{2}{|l|}{ Hormone status of liver metastasis $(n=15)$} \\
\hline Estrogen receptor (positive) & $8(53 \%)$ \\
\hline Progesterone receptor (positive) & $8(53 \%)$ \\
\hline HER2Neu receptor (negative) & $15(100 \%)$ \\
\hline Triple negative receptor status & $6(40 \%)$ \\
\hline \multicolumn{2}{|l|}{ Tumor burden liver } \\
\hline$<25 \%$ & $9(56 \%)$ \\
\hline $25 \%-50 \%$ & $6(38 \%)$ \\
\hline $50 \%-75 \%$ & $1(6 \%)$ \\
\hline \multicolumn{2}{|l|}{ Prior hepatic treatment } \\
\hline Surgery/Ablation & $1(6.3 \%)$ \\
\hline Median number of chemotherapy regimens for stage 4 disease & $3(0-8)$ \\
\hline \multicolumn{2}{|l|}{ Extra-hepatic sites of metastases } \\
\hline Yes & $9(56 \%)$ \\
\hline No & $7(44 \%)$ \\
\hline \multicolumn{2}{|l|}{ Number of additional metastatic sites } \\
\hline 1 & $5(31 \%)$ \\
\hline 2 & $2(13 \%)$ \\
\hline$\geq 3$ & $2(13 \%)$ \\
\hline \multicolumn{2}{|l|}{ Location of extrahepatic metastases } \\
\hline Bone & $5(31 \%)$ \\
\hline Lung & $3(19 \%)$ \\
\hline Non-locoregional nodes & $4(25 \%)$ \\
\hline Brain & $2(13 \%)$ \\
\hline
\end{tabular}


Table 3. Number of grade 1 (G1), grade 2 (G2) and grade 3 (G3) adverse events after treatment of selective internal radiation therapy by ${ }^{90} \mathrm{Y}$ labelled microspheres infusion $\left({ }^{90} \mathrm{Y} \mathrm{SIRT}\right)$ and Mitomycin C (MMC) infusion within 30 days. No grade 3 adverse events occurred after MMC infusion.

\begin{tabular}{|c|c|c|c|c|c|c|c|c|c|c|c|}
\hline \multirow{2}{*}{$\begin{array}{l}\text { Treatment } \\
\text { Adverse events }\end{array}$} & \multicolumn{3}{|c|}{ 90Y SIRT } & \multicolumn{2}{|c|}{$\begin{array}{l}\text { MMC } \\
\text { Cohort A } \\
1 \times 6 m g\end{array}$} & \multicolumn{2}{|c|}{$\begin{array}{l}\text { MMC } \\
\text { Cohort B } \\
1 \times 12 \mathrm{mg}\end{array}$} & \multicolumn{2}{|c|}{$\begin{array}{l}\text { MMC } \\
\text { Cohort C } \\
2 \times 12 \text { mg }\end{array}$} & \multicolumn{2}{|c|}{$\begin{array}{l}\text { MMC } \\
\text { Cohort D } \\
\max \\
6 \times 12 \mathrm{mg}\end{array}$} \\
\hline & G1 & G2 & G3 & G1 & G2 & G1 & G2 & G1 & G2 & G1 & G2 \\
\hline \multicolumn{12}{|l|}{ Clinical } \\
\hline Fatigue & $2 / 16$ & - & - & - & - & - & - & $3 / 3$ & - & $2 / 6$ & - \\
\hline Pain & $5 / 16$ & $2 / 16$ & - & - & - & - & - & - & - & $1 / 6$ & - \\
\hline Nausea & $3 / 16$ & $2 / 16$ & - & - & - & - & - & - & - & $1 / 6$ & - \\
\hline Emesis & $2 / 16$ & $2 / 16$ & - & - & - & - & - & - & - & $1 / 6$ & - \\
\hline Gastrointestinal ulcer & - & $4 / 16$ & $1 / 16$ & - & - & - & - & - & - & - & - \\
\hline \multicolumn{12}{|l|}{ Biochemical } \\
\hline Leukopenia & $2 / 16$ & - & - & - & - & - & - & $2 / 3$ & - & $4 / 6$ & $2 / 6$ \\
\hline Thrombocytopenia & $3 / 16$ & $1 / 16$ & - & $1 / 2$ & - & $1 / 1$ & - & $3 / 3$ & - & $4 / 6$ & $2 / 6$ \\
\hline Anaemia & - & - & - & - & - & - & - & - & - & $4 / 6$ & - \\
\hline $\begin{array}{l}\text { Increased aspartate } \\
\text { aminotransferase }\end{array}$ & $5 / 16$ & $1 / 16$ & - & - & - & - & - & - & - & $2 / 6$ & - \\
\hline $\begin{array}{l}\text { Increased alanine } \\
\text { aminotransferase }\end{array}$ & $3 / 16$ & $1 / 16$ & - & - & - & - & - & - & - & $1 / 6$ & - \\
\hline Increased bilirubin & - & - & - & - & - & - & - & $1 / 3$ & $1 / 3$ & - & - \\
\hline $\begin{array}{l}\text { Increased alkaline } \\
\text { phosphatase }\end{array}$ & $2 / 16$ & $1 / 16$ & - & - & - & - & - & $1 / 3$ & - & $2 / 6$ & - \\
\hline Decreased eGFR & - & $1 / 16$ & - & - & - & - & - & - & - & - & - \\
\hline $\begin{array}{l}\text { Increased gamma- } \\
\text { glutamyl transferase }\end{array}$ & $4 / 16$ & $1 / 16$ & - & - & - & - & - & $1 / 3$ & - & $4 / 6$ & - \\
\hline
\end{tabular}

eGFR = estimated glomerular filtration rate

\section{Adverse events}

Table 3 shows the adverse events after the ${ }^{90} \mathrm{Y}$ SIRT and MMC infusion. After the ${ }^{90} \mathrm{Y}$ treatment one grade 3 adverse event occurred, consisted of a gastric ulcer treated with proton pump inhibitors and hospitalization. The most common grade $1 / 2$ adverse events after ${ }^{90} Y$ SIRT were pain $7 / 16$, nausea $5 / 16$ and ulcer 4/16. An elevation in liver function test (aspartate, alanine and gamma-glutamyl transferase) was seen in 8/16 patients. No grade 3 or higher adverse events occurred after MMC infusion. The most common grade 1/2 adverse event was thrombocytopenia in 11/12 patients and leukopenia in 8/12 patients. 


\section{Response}

Response evaluation of the liver after 6 to 8 weeks after ${ }^{90} Y$ treatment $(n=16)$ revealed $P R$ in 10 patients and SD in 6 patients (Figure 2). Extra hepatic response evaluation showed PD in 5 patients and SD in 11 patients. Additional hepatic response of MMC infusion after ${ }^{90} \mathrm{Y}$ treatment was PR in 4/12 patient, SD in 5/12 patients and PD in 3/12 patients.

\section{Follow-up and survival}

After the study, nine patients were eligible to receive systemic chemotherapy and one patient was eligible for surgery and underwent a segmentectomy. The median OS was 12.6 months (95\% Cl 10.23-15.0).
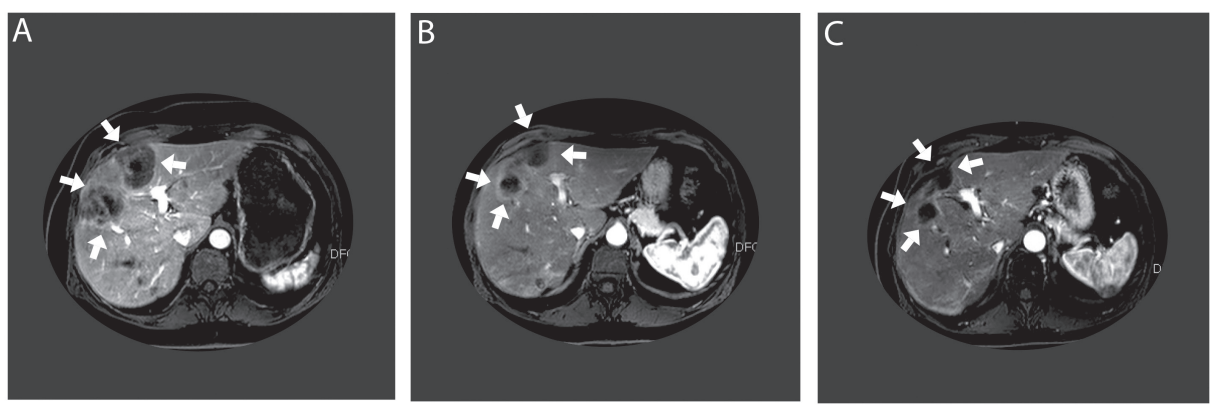

Figure 2. Hepatic response on magnetic resonance imaging (MRI) before 90Y treatment (A), after $90 \mathrm{Y}$ treatment (B) and after 2 cycles of MMC infusion (C). C is a partial response relative to $A$. Arrows indicate the liver metastases.

\section{DISCUSSION}

Intra-arterial therapy is a treatment option in patients with chemo-refractory liver dominant metastatic breast cancer [6]. In our institute MMC infusions are performed for almost 20 years for chemo refractory LMBC whereby a disease control of $58 \%$ is obtained with low grade adverse events [9]. In the present study we investigated whether MMC infusion is feasible and safe after ${ }^{90} \mathrm{Y}$ SIRT.

The sequential treatment of ${ }^{90} \mathrm{Y}$ followed by MMC was possible in $75 \%(12 / 16)$ of the enrolled patients. Only low grade adverse events (grade 1 and 2) were observed after the MMC infusions. In addition, the gradual escalation of the MMC infusions, ranging from $6 \mathrm{mg}$ in 1 cycle to a maximum of $72 \mathrm{mg}$ in 6 cycles, caused no additional adverse events. 
During the regular MMC protocol of our institute, patients can receive a maximum of $72 \mathrm{mg}$ in 6 cycles whereby close monitoring is performed to adjust, postpone or stop the MMC infusion after each cycle [9]. In current study, the same protocol was followed in the last cohort, subsequently 4 patients did not receive all $6 \mathrm{MMC}$ cycles. Thus, this pilot shows that the regular protocol of MMC can be followed after prior treatment with ${ }^{90} \mathrm{Y}$. Patients maintained their performance status after the sequential treatments, and so 9/12 patients were eligible for systemic therapy afterwards and 1/12 even for hepatic surgery. Therefore, this combination treatment can be used as a drug holiday from systemic treatment.

We did observe a high amount of gastrointestinal ulcers after ${ }^{90} \mathrm{Y}$ SIRT ( $\mathrm{n}=5$, $31 \%$ ). All these patients underwent pre-embolization and received a bilobar treatment in the left and right hepatic artery. Despite these precautions, the ulcers occurred probably due to reflux and non-target deposition of the ${ }^{90} \mathrm{Y}$ resin microspheres which is a known risk of ${ }^{90} \mathrm{Y}$ treatment for LMBC [16]. After the introduction of an anti-reflux catheter in the last 6 patients, no more ulcers occurred. According to the literature, several factors are associated with reflux of ${ }^{90} \mathrm{Y}$ resulting in gastrointestinal ulcering, namely prior administration of monoclonal antibodies (i.e. bevacuzimab, trastuzumab), the type of ${ }^{90} Y$ microspheres and the dose of ${ }^{90} \mathrm{Y}$. [10,17]. In the present study no correlations were found for prior monoclonal antibodies treatment and the dose of ${ }^{90} \mathrm{Y}$ with the development of gastrointestinal ulcers. The development of the gastrointestinal ulcers in the current study was probably caused by several pre-treatment and treatment related factors. The use of the anti-reflux catheter showed improvement with no further reported gastrointestinal ulceration. Therefore, caution is definitely needed in future studies.

The median OS of radioembolization in LMBC patients ranges from 6.6 - 13.6 months, which is in line with the median OS of 12.6 in this study [10,11, 18-20]. The median OS was higher compared to earlier studies where patients received only MMC infusion (12.6 versus 7.6 months) $[9,14]$. However, the inclusion criteria for this study were more strict than our routine indications for MMC infusion. Consequently, patients had less extensive local and extra hepatic disease with a better performance status compared to our previous reported cohort of patients treated with MMC infusion only.

The main limitation of this study consists of small patient number in the cohorts and the long inclusion period. 
In conclusion, the sequential treatment of intra-arterial infusion of MMC after ${ }^{90} \mathrm{Y}$ therapy is feasible with limited low grade adverse events after MMC. The regular MMC protocol can be followed with adjustment of MMC dose based on clinical, radiological and biochemical parameters. However, caution is needed to prevent reflux after ${ }^{90} \mathrm{Y}$ SIRT in LMBC patients. Further research is needed to show whether the combination of ${ }^{90} \mathrm{Y}$ and $\mathrm{MMC}$ has a benefit over the treatment of MMC or ${ }^{90} \mathrm{Y}$ alone in LMBC patients. 


\section{References}

1. Eichbaum MHR, Kaltwasser M, Bruckner T, De Rossi TM, Schneeweiss A, Sohn C. Prognostic factors for patients with liver metastases from breast cancer. Breast Cancer Res Treat. 2006;96(1):53-62.

2. Siegel RL, Miller KD, Jemal A. Cancer statistics, 2018. CA Cancer J Clin. 2018; 68(1):7-30.

3. Ruiz A, Sebagh M, Wicherts DA, Castro-Benitez C, Van Hillegersberg R, Paule B et al. Long-term survival and cure model following liver resection for breast cancer metastases. Breast Cancer Res and Treat. 2018;170(1):89-100.

4. Golse N, Adam R. Liver metastases from breast cancer: what role for surgery? indications and results. Clin Breast Cancer. 2017;17(4):256-265.

5. Ghersi D, Wilcken N, Simes RJ. A systematic review of taxane-containing regimens for metastatic breast cancer. Br J Cancer. 2005;93(3):293-301.

6. Gordon AC, Uddin OM, Riaz A, Salem R, Lewandowski RJ. Making the case: intra-arterial therapy for less common metastases. Semin Intervent Radiol. 2017;34(2):132-139.

7. Smits ML, Prince JF, Rosenbaum CE, van den Hoven AF, Nijsen JF, Zonnenberg BA et al: Intra-arterial radioembolization of breast cancer liver metastases: a structured review. Eur J Pharmacol. 2013;709(1-3):37-42.

8. Wang M, Zhang J, Ji S, Shao G, Zhao K, Wang Z et al. Transarterial chemoembolisation for breast cancer with liver metastasis: A systematic review. Breast. 2017;36:25-30.

9. Aarts BM, Klompenhouwer EG, Dresen RC, Laenen A, Beets-Tan RGH, Punie K, et al. Intra-arterial Mitomycin $C$ infusion in a large cohort of advanced liver metastatic breast cancer patients: safety, efficacy and factors influencing survival. Breast Cancer Res Treat. 2019; 176(3):597-605.

10. Fendler WP, Lechner H, Todica A, Paprottka KJ, Paprottka PM, Jakobs TF et al. Safety, efficacy and prognostic factors after radioembolization of hepatic metastases from breast cancer: a large single center experience in 81 patients. J Nucl Med. 2016;57(4):517-23.

11. Pieper CC, Meyer C, Wilhelm KE, Block W, Nadal J, Ahmadzadehfar H et al. Yttrium-90 radioembolization of advanced, unresectable breast cancer liver metastases-a singlecenter experience. J Vasc Interv Radiol. 2016;27(9):1305-1315.

12. Gordon AC, Salem R, Lewandowski RJ. Yttrium-90 radioembolization for breast cancer liver metastases. J Vasc Interv Radiol. 2016;27(9):1316-1319.

13. Maleux G, Deroose C, Laenen A, Verslype C, Heye S, Haustermans K et al. Yttrium-90 radioembolization for the treatment of chemorefractory colorectal liver metastases: Technical results, clinical outcome and factors potentially influencing survival. Acta Oncologica. 2016;55(4):486-495.

14. Maes T, Wildiers H, Heye S, Demey W, Maleux G, Neven P et al. Intra-hepatic Mitomycin $\mathrm{C}$ bolus infusion in the treatment of extensive liver metastases of breast cancer. Breast Cancer Res Treat. 2008;110(1):135-142.

15. Tirkes T, Hollar MA, Tann M, Kohli MD, Akisik F, Sandrasegaran K. Response criteria in oncologic imaging: review of traditional and new criteria. RadioGraphics. 2013;33:13231341.

16. Pieper CC, Willinek WA, Thomas D, Ahmadzadehfar H, Essler M, Nadal $\mathrm{J}$ et al: Incidence and risk factors of early arterial blood flow stasis during first radioembolization of primary and secondary liver malignancy using resin microspheres: an initial singlecenter analysis. Eur Radiology. 2016;26(8):2779-2789.

17. Collins J, Salem R. Hepatic radioembolization complicated by gastrointestinal ulceration. Semin Intervent Radiol. 2011;28(2):240-245. 
Chapter 4

18. Saxena A, Kapoor J, Meteling B, Morris DL, Bester L. Yttrium-90 radioembolization for unresectable, chemoresistant breast cancer liver metastases: a large single-center experience of 40 patients. Ann Surg Oncol. 2014;21(4):1296-1303.

19. Bangash AK, Atassi B, Kaklamani V, Rhee TK, Yu M, Lewandowski RJ et al. 90Y radioembolization of metastatic breast cancer to the liver: toxicity, imaging response, survival. J Vasc Interv Radiol. 2007;18(5):621-628.

20. Jakobs TF, Hoffmann RT, Fischer T, Stemmler HJ, Tatsch K, La Fougere $C$ et al. Radioembolization in patients with hepatic metastases from breast cancer. J Vasc Interv Radiol. 2008;19(5):683-690. 



\section{PART}

Percutaneous ablation in renal cell cancer 



\section{CHAPTER}

Renal biopsies performed before versus during ablation of T1 renal tumors: Implications for prevention of overtreatment and follow-up

C.V. Widdershoven*, B.M. Aarts*, P.J. Zondervan, M.M.E.L. Henderickx, E.G. Klompenhouwer, O.M. van Delden, W. Prevoo, A.D. Montauban van Swijndregt, R.J.A. van Moorselaar, A.Bex*, B.W. Lagerveld* * authors contributed equally

Published in Abdominal Radiology 2020 Jun 20 Online ahead of print doi: 10.1007/s00261-020-02613-4

PMID: 32564209

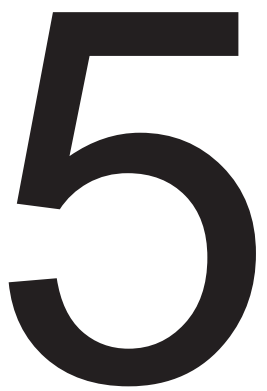




\section{ABSTRACT}

Purpose: To assess the difference between renal mass biopsy (RMB) performed either before or during the ablation procedure.

Methods: A retrospective multi-center study was performed in patients with a cT1 renal mass treated with ablation between January 2007 and July 2019, including a search in the national pathology database for patients with a RMB planned for ablation. Patient and tumor characteristics and information on malignant, benign and non-diagnostic biopsy results were collected to establish rates of overtreatment and number of ablations avoided in case of benign or non-diagnostic histology.

Results: RMB was performed in 714 patients, of which 231 patients received biopsy before planned ablation, and 483 patients at the time of ablation. Pathology results before ablation were malignant in 63\% (145/231), benign in $20 \%(46 / 231)$ and non-diagnostic in 17\% (40/231). Pathology results at the time of ablation were malignant in $67.5 \%$ (326/483), benign in $16.8 \%(81 / 483)$ and non-diagnostic in $15.7 \%$ (76/483), leading to a total of $32.5 \%$ of ablation of benign or non-diagnostic lesions. Of the patients with a benign biopsy obtained before ablation, $80.4 \%$ (37/46) chose not to undergo ablation. Patients with inconclusive biopsy before planned ablation, chose an informed individualized approach including ablation, repeated biopsy or no intervention in $56 \%, 34 \%$ and $10 \%$.

Conclusion: This study emphasizes the importance of obtaining a biopsy prior to the ablation procedure in a separate session to lower the rate of potentially unnecessary ablations. 


\section{INTRODUCTION}

Renal cell carcinoma (RCC) accounts for $2-3 \%$ of all malignancies worldwide and is the tenth most common tumor in both males and females in western countries [1,2]. The incidence of small localized RCC lesions $(<4 \mathrm{~cm})$ has dramatically increased in the last decade due to the expansion of imaging modalities. Standard treatment for small renal masses (SRMs) is a partial nephrectomy [3], but in comorbid or elderly patients, a more minimal invasive treatment can be preferred, such as focal thermal ablation or active surveillance or stereotactic radiotherapy $[4,5]$.

Although some renal masses show malignant characteristics on radiological images, up to $30 \%$ are found to be benign after (partial) nephrectomy $[6,7]$. Renal mass biopsy (RMB) can be performed to differentiate between a malignant or benign renal tumor. The renal cancer guideline of the European Association of Urology (EAU) recommends to perform a percutaneous RMB before the ablation procedure [4]. However, in clinical practice different strategies are applied with biopsies performed either before the ablation in a separate session or at the time of the ablation procedure itself.

The reason for performing a biopsy at the time of ablation is regularly to allow both procedures to be performed in one session. The disadvantage of this strategy is overtreatment or uncertainty regarding follow-up in case pathological assessment or remains non-diagnostic $[8,9]$.

This study aims to evaluate the differences between RMB performed before or at the time of ablation in terms of histological diagnosis and rate of treatment of benign tumors and uncertainty.

\section{METHODS}

\section{Patient selection}

This multi-center retrospective study was conducted in the Renal Cancer Network Amsterdam, consisting of the OLVG hospital, the Netherlands Cancer Institute (NKI), and Amsterdam University Medical Center (AUMC). The study had appropriate institutional review board approval from each institution. A data transfer agreement was obtained to execute a pooled data analyses of the three centers together. 
Patients treated by ablation for a renal tumor between January 2007 - July 2019 were included. Furthermore, the PALGA database, the nationwide network and registry of histo- and cytopathology in the Netherlands, was searched for patients who were diagnosed by means of an RMB in the three centers mentioned above and were not treated due to either a benign or non-diagnostic biopsy result. All patients were discussed in a multidisciplinary tumor board consisting of urologists, medical oncologists and (interventional) radiologists and these reports were retrospectively evaluated. If the board decided that the patient was not intended to be treated with an ablation, the patient was excluded from this study. Consequently, patients planned for (partial) nephrectomy or with a renal infection or abscess were excluded. If the board advised a patient to be treated with an ablation, the patient would be included.

Only primary tumors limited to the kidney and smaller than seven centimeter were included (cT1 tumors). Patients were excluded from the study in case of prior surgery or ablation of the kidney or intrarenal metastases from another primary malignancy.

Renal masses were diagnosed by a board of certified abdominal radiologists on multiphase computed tomography. An RCC was suspected when a hypervascular mass was found on contrast-enhanced CT. Lesions were considered suspicious for malignancy when an increase of at least 15 Hounsfields units after contrast administration was observed. When a suspected lesion was found on US, a multiphase CT with an arterial, corticomedullary and nephrogenic phase was performed. From 2017 onwards, all patients (treated and non-treated) were discussed in a multicenter multidisciplinary tumor board between the three centers during a weekly video conference meeting. Patients with a tumor $\leq 4 \mathrm{~cm}$ (cT1a) were offered the choice between surgical and ablative procedures or active surveillance, unless patient comorbidity supported a specific choice. Ablation for tumors $>4 \mathrm{~cm}$ and $\leq 7 \mathrm{~cm}$ (cT1b) was only offered for highly comorbid patients who were not eligible for surgery. All procedures were performed or supervised by an experienced, board certified, interventional radiologist.

\section{Biopsy before the ablation procedure}

Biopsies before the ablation were taken in a separate session from the ablation procedure. RMB was guided by ultrasound (US) or computed - tomography (CT) under local anesthesia. Different biopsy needles were used in each hospital (Center 1: Argon Medical 18G, Center 2: co-axial Bard® Magnum ${ }^{\circledR}$ 
18G, Center 3: Cook 16 G or 18G). After the biopsy procedure, patients were given two hours bed rest with monitoring of vital signs.

Biopsy at the time of ablation

Biopsies were taken in the same session as the ablation procedure, immediately before the start of the thermal ablation. The ablation procedure was performed by US and/or (cone beam) CT guidance under local or general anesthesia depending on the patient, tumor characteristics and preference of the physician. Different ablation techniques, such as radio frequency ablation, micro wave ablation, laparoscopic and percutaneous cryoablation were used in the three hospitals.

\section{Pathologic evaluation}

Histological assessment was performed at each hospital according to the EAU guidelines by an experienced genitourinary pathologist. The Union for International Cancer Control/American Joint Committee on Cancer classification was used when an RCC was diagnosed by the pathologist [4]. Results were regarded as diagnostic if the tissue sample was either defined as definitively benign or malignant or if a preference for a diagnosis was made by the pathologist. Biopsies were considered non-diagnostic if the biopsy tissue only contained normal parenchyma, fibrosis, necrosis or was not representative. In case of an oncocytic neoplasma in which no differentiation between a benign or malignant oncocytic lesions could be performed, the lesion was classified as "no diagnosis" (Table 2). For the pathological analysis, the specific staining protocol for the suspicion of renal neoplasms was followed. Those stains included cytokeratins, vimentin, cadherins, RCC Marker and other RCC-specific markers. The analyses were performed by a board certified urogenitary pathologist.

\section{Data analysis}

Patient and radiologic tumor characteristics and pathology results were collected to establish rates of diagnostic accuracy, overtreatment and avoided ablation in case of benign histology. Patients were divided into two groups: those receiving a biopsy before a planned ablation, and those receiving a biopsy during the ablation procedure (see Figure 1). Adverse events after the biopsy were classified according to the Clavien-Dindo classification [10].

Continuous variables are shown as median with interquartile range and categorical variables as numbers and percentages. Differences between groups were calculated by the Chi-square method for the categorical data and 
an independent t-test and Mann Whitney $U$ test for the numerical variables. All tests were two-sided and p-values below 0.05 were considered statistically significant. Statistical analysis was conducted with SPSS V.25 (IBM Corp, Armonk, NY, USA).

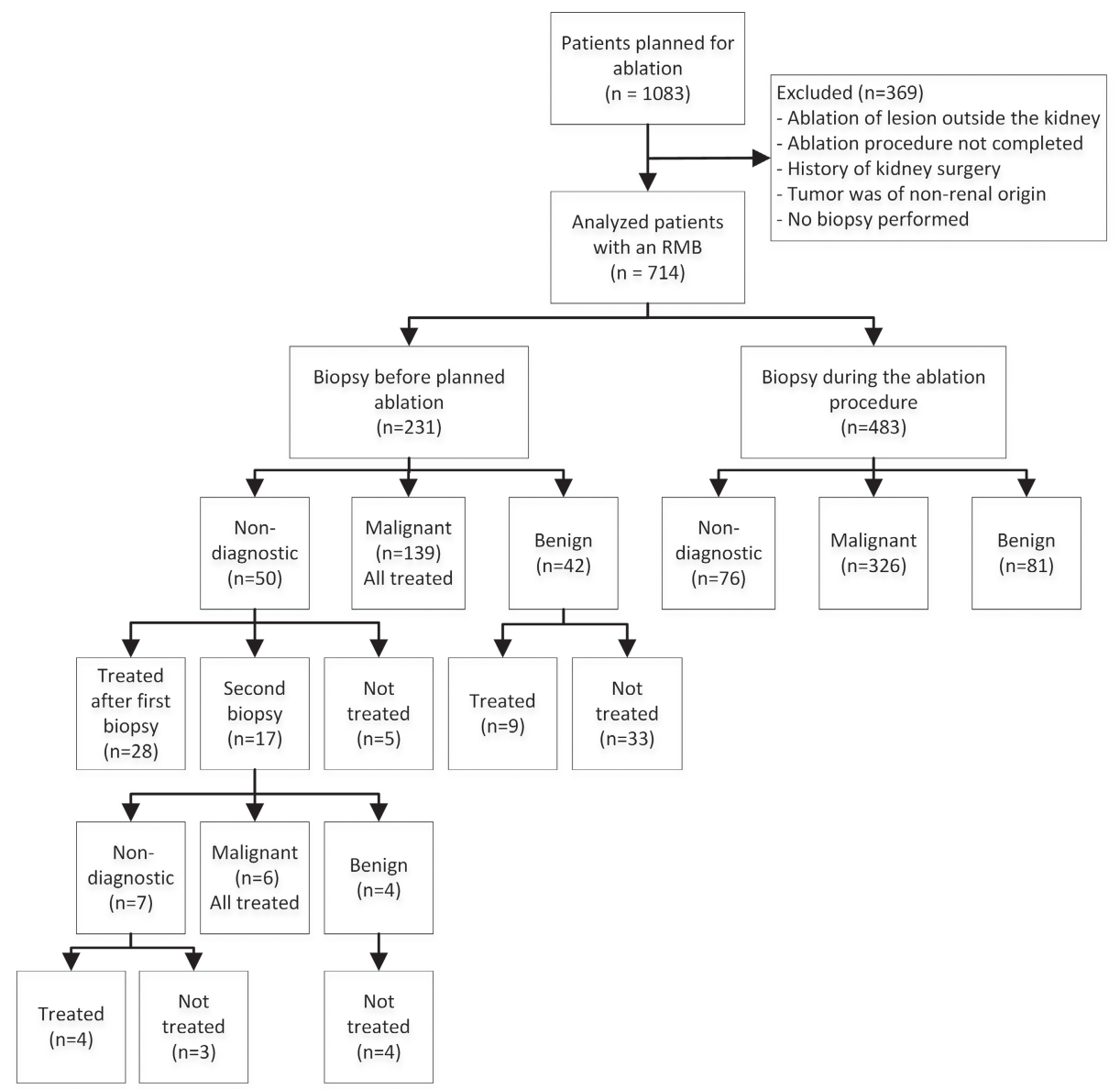

Figure 1. Flow chart of the biopsies performed before or at the ablation.

\section{RESULTS}

\section{Pretreatment characteristics}

A total of 1070 patients were scheduled for thermal ablation in the three hospitals between January 2007 and July 2019. Of these, 356 patients did not meet the inclusion criteria and were excluded, in the majority of the cases because they received treatment without a biopsy, multiple ablations in the 
same patient (whereby only the first ablation was taken into account), treatment of tissue other than the kidney or prior history of renal surgery, leaving 714 patients for analysis (Figure 1 and table 1).

Table 1. Patient characteristics

\begin{tabular}{lllll}
\hline $\begin{array}{l}\text { Patient } \\
\text { characteristics }\end{array}$ & $\begin{array}{l}\text { Total group } \\
(\mathbf{n = 7 1 4 )}\end{array}$ & $\begin{array}{l}\text { Biopsy performed } \\
\text { in a separate } \\
\text { session before } \\
\text { the ablation } \\
\text { procedure }(\mathbf{n = 2 3 1 )}\end{array}$ & $\begin{array}{l}\text { Biopsy performed } \\
\text { in same session } \\
\text { as the ablation } \\
\text { procedure }(\mathbf{n}=483)\end{array}$ & $\mathbf{p}$ \\
& & $68(59-74)$ & $70(62-76)$ & 0.070 \\
\hline $\begin{array}{l}\text { Median age (IQR) } \\
\text { Gender }\end{array}$ & $69(61-75)$ & & $296(61.3 \%)$ & 0.250 \\
Male. $n(\%)$ & $448(62.7 \%)$ & $152(65.8 \%)$ & $187(38.7 \%)$ & 0.250 \\
\hline
\end{tabular}

Significance was assumed for $p<0.05$

Biopsy before planned ablation in a separate session

231 patients underwent a biopsy in a separate session before the ablation. Pathology results after the first biopsy were malignant in $60.2 \%$ (139/231), benign in $18.2 \%$ (42/231) and non-diagnostic in $21.6 \%(50 / 231)$.

In the benign group, 33/42 patients (78.5\%) were not treated as a result of the benign pathology result. Nine patients in this group wished to be treated. Of the 50 patients in the non-diagnostic group, 28 chose ablation. In 17 patients, a second biopsy was performed, resulting in six malignant biopsies (all treated), four benign biopsies (all not treated) and seven non-diagnostic biopsies (three treated). Altogether, a total of 37 patients ( $80 \%$ of the benign tumors) chose not to undergo a planned ablation, due to a benign biopsy result.

After the second biopsy, the final pathology results before ablation were malignant in $63 \%(145 / 231)$, benign in $20 \%(46 / 231)$ and non-diagnostic in $17 \%$ (40/231). In the group of 40 patients who had a non-diagnostic result after a second biopsy, 32 opted for treatment and 8 were not treated with an ablation for personal reasons (see Figure 1). Histological results of these biopsies are shown in table 2.

Biopsy during the ablation procedure

In 483 patients, a biopsy was only performed during the ablation procedure, without having information about the histology of the tumor prior to ablation. The 
decision to perform an ablation was based upon high suspicion of malignancy on imaging. In this group, 81 (16.8\%) benign tumors were treated, $76(15.7 \%)$ tumors with a non-diagnostic pathology result and 326 (67.5\%) malignant tumors. Together, 157 patients (32.5\%) with a proven benign or non-diagnostic lesion were treated.

\section{Potential overtreatment}

In the group receiving a biopsy before a planned ablation, $80.5 \%$ of the biopsies resulted in an ablation procedure, compared to $100 \%$ in the group receiving only a biopsy during ablation. In the group only receiving a biopsy during the ablation procedure, overtreatment might have occurred in $32.5 \%$ of all ablations due to a benign or non-diagnostic biopsy result, compared to $17.7 \%$ in the group undergoing a biopsy before planned ablation and who chose for ablation despite being informed about the result $(p<0.001)$. There were no significant differences in age, gender or tumor size between the groups of patients who received a biopsy in a separate session before the ablation and the group who received a biopsy at the time of ablation.

\section{Adverse events}

Adverse events related to the renal biopsy were reported in 3 of the 714 patients $(0.4 \%)$, all of which occurred in the patients who underwent the biopsy in a separate session before the ablation. One patient $(0.14 \%)$ developed a grade $3 a$ adverse event after a biopsy before ablation (histological result: oncocytoma) consisting of a false aneurysm which was treated with embolization. The other two adverse events were grade 1 , both being patients who did not feel well after the procedure and had to be observed in the hospital, with no further medical or interventional measures taken.

\section{DISCUSSION}

Percutaneous biopsies performed in experienced centers have a high diagnostic yield, specificity and sensitivity and low morbidity [11]. In this multi-center study we evaluated the implications for treatment decisions and follow-up of biopsies performed before ablation in a separate session or during ablation. We showed that performing a biopsy during the ablation procedure led to $16.8 \%$ benign and $15.7 \%$ non-diagnostic biopsies, suggesting a potentially unnecessary ablation of renal masses in $32.5 \%$. In addition, $19.5 \%$ of the patients who were diagnosed with a benign or non-diagnostic biopsy result decided not to undergo their planned ablation. A total of 37 patients ( $80 \%$ of the benign tumors) chose not to undergo a planned ablation, due to a benign biopsy result. Performing 
a biopsy before ablation therefore reduces overtreatment and allows patients and physicians to adjust clinical management according to the biopsy results.

In this cohort, biopsies performed during the ablation procedure led to an ablation of a histologically confirmed benign tumor in $16.8 \%$ of the patients. Although, that is just marginally higher than previous reports of ablation series (ranging from $2-14 \%$ ), it is in line with the rates reported after surgery of small renal masses without previous biopsy (up to $30 \%$ )[7,12,13]. Results from our retrospective analysis demonstrate that patients who were involved in the choice of management after a benign biopsy result, chose to not undergo the ablation in the majority of the cases (80\%) and therefore avoided an unnecessary treatment.

Performing a biopsy during the ablation procedure eliminates the possibility to perform an additional biopsy and creates uncertainty for follow-up in case of an inconclusive biopsy. In our cohort, $15.7 \%$ of the patients who received a biopsy in the same session as the ablation procedure had a non-diagnostic biopsy. Physicians therefore had to consider that the renal mass was malignant and followed an intensive follow-up scheme of multiple CT or MRI scans. Contrast enhanced imaging, necessary for detection of recurrence after ablation, can be a burden in patients with chronic kidney disease including most patients planned for ablation and, in case of CT scans, expose patients to radiation. In case a non-diagnostic biopsy could be repeated and confirmed as benign, a less intensive follow-up scheme of active surveillance would have been followed. In the literature, this is reported in up to $33 \%$ of the beforehand suspected malignant renal masses after partial nephrectomy. [8,9].

Taking a renal mass biopsy (RMB) in a separate session has additional advantages. First, Tsang Mui Chung et al suggested that for percutaneous image guided ablations, an RMB can inform the interventional radiologist about the actual ablation procedure regarding patient position and percutaneous approach in case the same image guided modality is used [14]. Second, clinical impact can be achieved according to histologic subtype before treatment.

On the other hand, performance of a biopsy during the ablation avoids the need for another hospital visit. Several patients chose to undergo an ablation regardless of the benign histological result, in our cohort $19.5 \%$. Reasons for this were, for example, that patients still preferred a treatment and, in case of an angiomyolipoma, to lower the risk for bleeding $[15,16]$. Also, the risk of a biopsy can be substantial in high risk patients on anticoagulation that cannot 
be paused. In our cohort only one biopsy required an intervention. Physicians need to discuss the different histological results and their consequences with the patient in a shared decision process including the need for a biopsy.

In literature, only two other groups investigated the timing of the biopsy in patients undergoing ablation. Wells et al., recommend to perform a biopsy before the ablation in a separate session with the opportunity to take a second biopsy during the ablation. However, they only included patients who underwent ablation and consequently did not report changes of clinical management due to a benign biopsy before treatment [6]. Tsang Mui Chung et al. concluded that a biopsy during the ablation did not lead to overtreatment, because only $3 \%$ of the ablated lesions were benign. However, they included oncocytoma as not definitively benign in their analysis, which consequently lowered the rate of benign renal masses [13]. Differentiation between oncocytomas and low grade oncocytic neoplasms is difficult, since, as reported in literature, up to $35 \%$ of the oncocytomas by means of biopsy receives a different histological diagnosis after surgical resection [17]. In the present study we therefore classified oncocytic lesions that were not strictly marked as an oncocytoma as "no diagnosis", instead of an oncocytoma, and only used oncocytoma when this was strictly classified as such by the pathologist. In our study, we found 6 cases where the pathologist could not further specify the oncocytic lesion, and we have therefore included those in the "no diagnosis" group.

As with all retrospective studies, one of the main limitations of our study is that it is subject to bias, in particular selection bias. In this study no randomization was performed which resulted in a relatively small number of biopsies performed before the ablation in a separate session. Our results, however, seem to contradict this management and propagate performing the biopsy before planned ablation to avoid unnecessary treatment of benign lesions and uncertainty of follow-up of inconclusive lesions.

\section{CONCLUSION}

This study emphasizes the importance of obtaining a biopsy prior to the ablation procedure in a separate session to lower the rate of unnecessary ablations. 


\section{References:}

1. European Network of Cancer Registries. Eurocim version 4.0. Lyon, France, 2001.

2. Krokidis ME, Kitrou P, Spiliopoulos S, Karnabatidis D and Katsanos K. Image-guided minimally invasive treatment for small renal cell carcinoma. Insights into Imaging. 2018;9(3):385-390.

3. Prins FM, Kerkmeijer LGW, Pronk AA, Vonken EPA, Meijer RP, Bex A et al. Renal Cell Carcinoma: alternative nephron-sparing treatment options for small renal masses, a systematic review. J Endourol. 2017;31(10):963-975.

4. Ljungberg B, Albiges L, Abu-Ghanem Y, Bensalah K, Dabestani S, Fernández-Pello S et al. European Association of Urology Guidelines on Renal Cell Carcinoma: The 2019 Update. Eur Urol. 75(5):799-810.

5. Siva S, Bressel M, Murphy DG, Shaw H, Chander S, Violet J et al. Stereotactic abative body radiotherapy (sabr) for oligometastatic prostate cancer: a prospective clinical trial. Eur Urol. 2018;74(4):455-462.

6. Wells SA, Wong VK, Wittmann TA, Lubner MG, Best SL, Ziemlewicz TJ et al Renal mass biopsy and thermal ablation: should biopsy be performed before or during the ablation procedure? Abdom Radiol. 2017; 42(6):1773-1780.

7. Kim JH, Li S, Khandwala Y, Chung KJ, Park HK, Chung BI. Association of Prevalence of Benign Pathologic Findings After Partial Nephrectomy With Preoperative Imaging Patterns in the United States From 2007 to 2014. JAMA Surg. 2019;154(3),225-231.

8. Corcoran AT, Russo P, Lowrance WT, Asnis-Alibozek A, Libertino JA, Pryma DA. A review of contemporary data on surgically resected renal masses-benign or malignant. Urology. 2013;81(4) 707-713.

9. Shannon BA, Cohen RJ, de Bruto H, Davies RJ. The value of preoperative needle core biopsy for diagnosing benign lesions among small, incidentally detected renal masses. J Urol. 2008;180(4):1257-1261.

10. Dindo D, Demartines N, and Clavien PA. Classification of surgical complications: a new proposal with evaluation in a cohort of 6336 patients and results of a survey. Ann of Surg. 2004;240(2):205-213.

11. Marconi L, Dabestani S, Lam TB, Hofmann F, Stewart F, Norrie J et al. Systematic review and meta-analysis of diagnostic accuracy of percutaneous renal tumour biopsy. Eur Urol. 2016;69(4):660-673.

12. Atwell TD, Schmit GD, Boorjian SA, Mandrekar J, Kurup AN, Weisbrod AJ et al. Percutaneous ablation of renal masses measuring $3.0 \mathrm{~cm}$ and smaller: Comparative local control and complications after radiofrequency ablation and cryoablation. Am J Roentgenol. 2013;200(2):461-466.

13. Tsang Mui Chung MS, Maxwell AW, Wang LJ, Mayo-Smith WW and Dupuy DE. Should renal mass biopsy be performed prior to or concomitantly with thermal ablation? J Vasc Interv Radiol. 2018;29(9);1240-1244.

14. Gunn AJ and Gervais DA. Percutaneous ablation of the small renal mass-techniques and outcomes. Semin Intervent Radiol. 2014;31(1):33-41.

15. Cristescu M, Abel EJ, Wells S, Ziemlewicz TJ, Hedican SP, Lubner MG et al. Percutaneous microwave ablation of renal angiomyolipomas. Cardiovasc Intervent Radiol. 2016;39(3):433-40.

16. Prevoo W, van den Bosch MAAJ, and Horenblas S. Radiofrequency ablation for treatment of sporadic angiomyolipoma. Urology. 2008;72(1);188-191. 
Chapter 5

17. Patel HD, Druskin SC, Rowe SP, Pierorazio PM, Gorin MA and Allaf ME. Surgical histopathology for suspected oncocytoma on renal mass biopsy: a systematic review and meta-analysis. BJU International. 2017;119(5);661-666. 
Renal biopsies performed before versus during ablation of T1 renal tumors 



\section{CHAPTER}

\section{Percutaneous microwave ablation of histologically proven T1 renal cell carcinoma}

B.M. Aarts, W. Prevoo, M.A.J. Meier, A. Bex, R.G.H. Beets-Tan, E.G. Klompenhouwer, F.M. Gómez

Published in Cardiovascular Interventional Radiology 2020 Jul;43(7):1025-1033 doi: 10.1007/s00270-020-02423-7

PMID: 32052093 


\section{ABSTRACT}

Objectives: To assess the safety and efficacy of percutaneous microwave ablation (MWA) of histologically proven T1 Renal Cell Carcinoma (RCC).

Methods: We analysed patients with a histologically proven RCC $(\leq 7 \mathrm{~cm})$ treated by MWA from April 2012 - April 2018. Primary and secondary efficacy, local tumour recurrence (LTR), morbidity and mortality were reported. Efficacy was defined as no residual tumour enhancement on follow-up imaging one month after the first ablation (primary efficacy) and after re-ablation(s) for residual disease (secondary efficacy). Adverse events (AE) were registered by the Clavien Dindo classification and the common terminology criteria for $\mathrm{AE}$. Univariable and multivariable logistic regression analyses were performed to investigate a relation among pre-treatment factors incomplete ablation and complications.

Results: In 100 patients a total of 108 RCC's (85 T1a and $23 \mathrm{~T} 1 \mathrm{~b}$ ) were treated by MWA. Median size was $3.2 \mathrm{~cm}$ (IQR 2.4-4.0). Primary efficacy was $89 \%$ $(95 \% \mathrm{Cl} 0.81-0.94)$ for $\mathrm{T} 1 \mathrm{a}$ lesions and $52 \%(95 \% \mathrm{Cl} 0.31-0.73)$ for $\mathrm{T} 1 \mathrm{~b}$ lesions $(p<0.001) .15$ lesions ( $7 \mathrm{~T} 1 \mathrm{a})$ were re-ablated for residual disease by MWA in one $(n=13)$ and two $(n=2, T 1 b)$ sessions resulting in secondary efficacy rates of $99 \%$ (T1a) and 95\% (T1b, p=0.352). LTR occurred in four tumours ( $2 \mathrm{~T} 1 \mathrm{a}$, 2 T1b) after 10-60 months. Six (4\%) AE's grade >3-5 were observed (2 T1a, 4 $\mathrm{T} 1 \mathrm{~b}, \mathrm{p}=0.045$ ). Multivariable analysis showed that $m$ R.E.N.A.L. nephrometry was independently associated with incomplete ablation $(p=0.012)$.

Conclusion: Microwave ablation is safe and effective for T1a and T1b RCC lesions with a significantly lower primary efficacy for T1b lesions. 


\section{INTRODUCTION}

Renal cell carcinoma (RCC) accounts for $3 \%$ of all cancers worldwide[29]. According to the European Association of Urology (EAU) and the National Comprehensive Cancer Network (NCCN) RCC guidelines, partial nephrectomy (PN) is the gold standard for T1a RCC. Percutaneous tumour ablation is reserved for co-morbid patients and patients not eligible for surgery[20; 24]. Although reports show higher local control after PN compared to ablative therapies, similar cancer-specific survival is obtained with less renal function decline for radiofrequency ablation (RFA) and cryoablation (CA)[31].

Details of the different ablation modalities, RFA, MWA and CA, are extensively described in the literature. To summarize, MWA, compared to RFA, achieves higher temperatures in a shorter time less influenced by the heat sink effect. As a result a fast and large ablation zone with a similar applicator as RFA is achieved.[4; 19] With RFA and MWA, the evolvement of the ablation zone during the procedure is less visible compared to CA[15]. Reports about the efficacy and safety of large cohorts of MWA remain limited, especially for T1b tumours[8; 9].

In this retrospective cohort study, we report the outcomes of patients with a histologically proven RCC treated by means of MWA in a tertiary reference centre. The purpose of this study was to evaluate the safety, efficacy and factors influencing outcome of MWA in T1a and T1b RCC.

\section{PATIENTS AND METHODS}

\section{Study population}

The institutional review board of our hospital approved this retrospective study (IRBd18059). The data of all MWA's of our institute was requested through our institutes data desk and consent of all patients was checked. We included patients treated by MWA for a histologically proven T1 RCC between April 2012 and April 2018. Patients were excluded when prior therapy (chemotherapy, surgical resection or a different ablation modality) for RCC was administrated.

MWA procedure

All patients were first discussed in a multidisciplinary tumour board, consisting of urologists, radiologists and medical oncologists to decide patients eligibility for MWA. The MW procedures were performed computed tomography (CT) guided (CT Somatom Sensation Open, Siemens ${ }^{\circledR}$, Munchen, Germany). 
Patients were treated with two different MW systems (2012-2014: Evident $₫$ MW system (Covidien $®$, Dublin, Ireland), 2014-2018: Emprint ${ }^{\circledR}$ MW system (Medtronic $®$, Dublin, Ireland)). Dissection was performed with $5 \%$ glucose solution plus $10 \%$ iodinated contrast, $\mathrm{CO} 2$ and room air for tumours adjacent to vulnerable structures. Ureteric perfusion with cooled saline was used for tumours close to the collection system and the proximal ureter. Antenna placement was performed with CT fluoroscopy and optimal position verified by CT before start of the ablation. After antenna placement biopsy was performed. In principle, a power of 100 watt was used for 2-10 min according to tumour size. A margin of $5-10 \mathrm{~mm}$ was attempted to achieve complete ablation. Fluoroscopic CT check was performed to monitor the procedure. In larger tumours, the ablation was repeated with different antenna positions to achieve a complete ablation zone. With the Evident ${ }^{\circledR}$ MW system, multiple antennas were placed in the tumour according to physicians choice.

\section{Follow-up}

An institutional follow-up scheme of multiphase CT scans after 1, 3, 6, 9 and 12 months was executed. Patients with a diminished renal function were followed by (non-)contrast enhanced magnetic resonance imaging (Achieva or Ingenia,

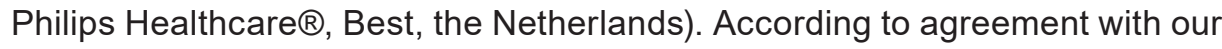
in house urologists follow-up for the first year was performed by the IR at our outpatient clinics. When no recurrence appeared patients were send back to the referring urologist. A follow-up scheme of 1 multiphase CT scan a year for 5 years was advised to the referring urologist.

\section{Data collection and statistical analysis}

Tumour characteristics were scored according to the R.E.N.A.L. nephrometry score (Radius, Exophytic/endophytic, Nearness to collecting system or sinus and Location relative to polar lines) and modified (m)R.E.N.A.L. nephrometry score, as published previously [25]. Adverse events (AE's) during ablation were registered by the common terminology criteria for adverse events (CTCAE) and post ablation AE's were registered following the Clavien Dindo classification. Primary efficacy was defined as no residual tumour enhancement visible at post contrast CT or MRI one month post ablation. Secondary efficacy was described as the percentage of tumours successfully treated for residual disease by repeated $M W A(s)[1]$. Patients treated with another secondary treatment modality (i.e. PN, radical nephrectomy (RN), RFA or CA) were excluded for the secondary efficacy. Local tumour recurrence (LTR) was defined when new enhancement within a successfully treated ablation zone occurred during the follow-up. 
Continuous variables are shown as median and interquartile ranges (IQR) and categorical data as numbers and percentages. To test differences between categories, the Chi-square or Fisher exact test was used and for non-parametric continuous variables the Mann-Witney test. To analyse the relationship between pre-treatment factors with incomplete ablations and the occurrence of complications, a logistic regression analysis was performed. Results are presented as odds ratio (OR), 95\% confidence interval (Cl) and significance levels. For the multivariable logistic regression analysis, only significant variables from the univariable analysis were included. Significance levels of $p<0.05$ were used. Analyses were performed using Statistical Package for the Social Sciences (SPSS, version 25, Chicago, IL).

\section{RESULTS}

\section{Patient and tumour characteristics}

Between April 2012 - April 2018, 226 patients underwent a MWA for their renal masses. 126 patients were excluded because of non-diagnostic biopsy $(n=55)$, benign biopsy $(n=30)$, treatment for recurrence disease after prior treatment $(n=12)$, metastatic disease $(n=23), T 3$ disease $(n=2)$, tumour debulking $(n=2)$, prior chemotherapy for tumour reduction $(n=1)$ and no follow-up imaging available after the MWA ( $n=1) .100$ patients with 108 histologically proven RCC were included in this analysis, patient and tumour characteristics are shown in table 1.

Table 1. Pretreatment characteristics

\begin{tabular}{|c|c|c|c|c|}
\hline & $\begin{array}{l}\text { All } \\
(n=108)\end{array}$ & $\begin{array}{l}\text { T1a } \\
(n=85)\end{array}$ & $\begin{array}{l}\text { T1b } \\
(n=23)\end{array}$ & $P$ value \\
\hline Number of patients & 100 & 77 & 23 & \\
\hline Median age at treatment, IQR & $71(63-77)$ & $69(63-76)$ & $74(63-77)$ & $0.285^{1}$ \\
\hline Male & 59 (59\%) & $48(62 \%)$ & $11(48 \%)$ & $0.235^{2}$ \\
\hline \multicolumn{5}{|l|}{ History } \\
\hline Cardiovascular & $30(30 \%)$ & $21(25 \%)$ & $9(39 \%)$ & $0.306^{2}$ \\
\hline Oncological & $38(38 \%)$ & $29(38 \%)$ & $9(39 \%)$ & $0.899^{2}$ \\
\hline Urological & $22(22 \%)$ & $15(19 \%)$ & $7(30 \%)$ & $0.389^{2}$ \\
\hline Median size, IQR & $3.2(2.4-4.0)$ & $2.8(2.2-3.5)$ & $4.5(4.3-5.0)$ & $0.000^{1}$ \\
\hline Laterally & & & & $0.357^{2}$ \\
\hline Right & $56(52 \%)$ & $42(49 \%)$ & $14(61 \%)$ & \\
\hline Left & $52(48 \%)$ & $43(51 \%)$ & $9(39 \%)$ & \\
\hline
\end{tabular}


Table 1. Continued.

\begin{tabular}{|c|c|c|c|c|}
\hline & $\begin{array}{l}\text { All } \\
(n=108)\end{array}$ & $\begin{array}{l}\text { T1a } \\
(n=85)\end{array}$ & $\begin{array}{l}\text { T1b } \\
(n=23)\end{array}$ & $P$ value \\
\hline Aetiology tumour & & & & $0.096^{2}$ \\
\hline Clear cell & $68(63 \%)$ & $51(60 \%)$ & $17(74 \%)$ & \\
\hline Papillary & $22(20 \%)$ & $21(25 \%)$ & $1(4 \%)$ & \\
\hline Type I & 14 & 14 & 0 & \\
\hline Type II & 4 & 3 & 1 & \\
\hline Chromophobe & $4(4 \%)$ & $4(5 \%)$ & 0 & \\
\hline Eosinophilic & $1(1 \%)$ & 0 & $1(4 \%)$ & \\
\hline Undefined renal cell carcinoma & $13(12 \%)$ & $9(11 \%)$ & $4(17 \%)$ & \\
\hline Fuhrman grade & & & & $0.501^{2}$ \\
\hline 1 & $23(21 \%)$ & $17(20 \%)$ & $6(26 \%)$ & \\
\hline 2 & $32(30 \%)$ & $23(27 \%)$ & $9(39 \%)$ & \\
\hline 3 & $6(6 \%)$ & $5(6 \%)$ & $1(4 \%)$ & \\
\hline Undefined/ Not possible & $47(44 \%)$ & $40(47 \%)$ & $7(31 \%)$ & \\
\hline Location & & & & $0.175^{2}$ \\
\hline Exophytic & $61(57 \%)$ & $44(52 \%)$ & $17(74 \%)$ & \\
\hline$<50 \%$ exophytic & $11(10 \%)$ & $10(12 \%)$ & $1(4 \%)$ & \\
\hline Endophytic & $36(33 \%)$ & $31(36 \%)$ & $5(22 \%)$ & \\
\hline Anterior & $26(24 \%)$ & $23(27 \%)$ & $3(13 \%)$ & $0.076^{2}$ \\
\hline Posterior & $62(57 \%)$ & $44(52 \%)$ & $18(78 \%)$ & \\
\hline Mid & $20(19 \%)$ & $18(21 \%)$ & $2(9 \%)$ & \\
\hline Lower pole & $31(29 \%)$ & $25(29 \%)$ & $6(26 \%)$ & $0.874^{2}$ \\
\hline Upper pole & $35(32 \%)$ & $28(33 \%)$ & $10(43 \%)$ & \\
\hline Inter pole & $42(39 \%)$ & $32(38 \%)$ & $7(30 \%)$ & \\
\hline Distance to collecting system & & & & $0.004^{2}$ \\
\hline$>7 \mathrm{~mm}$ & $66(61 \%)$ & $58(68 \%)$ & $8(35 \%)$ & \\
\hline 4-7 mm & $11(10 \%)$ & $9(11 \%)$ & $2(9 \%)$ & \\
\hline$<4 \mathrm{~mm}$ & $31(29 \%)$ & $18(21 \%)$ & $13(57 \%)$ & \\
\hline Distance to polar lines & & & & $0.155^{2}$ \\
\hline Entirely above/ below & $62(57 \%)$ & $52(61 \%)$ & $10(43 \%)$ & \\
\hline Lesion crosses 1 polar line & $27(25 \%)$ & $21(25 \%)$ & $6(22 \%)$ & \\
\hline$>50 \%$ of mass across polar line & $19(18 \%)$ & $12(14 \%)$ & $7(35 \%)$ & \\
\hline R.E.N.A.L. nephrometry score & $6(4-8)$ & $5(4-7)$ & $7(6-9)$ & $0.000^{1}$ \\
\hline Low $(4-6)$ & $68(63 \%)$ & $60(71 \%)$ & $8(35 \%)$ & $0.002^{2}$ \\
\hline Intermediate (7-9) & $28(26 \%)$ & $17(20 \%)$ & $12(52 \%)$ & $0.007^{2}$ \\
\hline High $(10-12)$ & $12(11 \%)$ & $8(9 \%)$ & $4(18 \%)$ & $0.280^{2}$ \\
\hline m.R.E.N.A.L. nephrometry score & $6(5-9)$ & $5(4-8)$ & $8(7-10)$ & $0.000^{1}$ \\
\hline Low $(4-6)$ & $59(55 \%)$ & $55(65 \%)$ & $4(17 \%)$ & $0.000^{2}$ \\
\hline Intermediate (7-9) & $29(27 \%)$ & $19(23 \%)$ & $10(44 \%)$ & $0.062^{2}$ \\
\hline High $(10-12)$ & $20(19 \%)$ & $11(13 \%)$ & $9(40 \%)$ & $0.004^{1}$ \\
\hline
\end{tabular}

$1=$ mann-witney test ${ }^{2}=$ chi square, IQR $=$ Interquartile range 
Primary and secondary efficacy

A total of $125 \mathrm{MW}$ ablations were performed in 108 tumours. The Evident ${ }^{\circledR}$ MW system was used in 14 MWA's with the use of multiple antennas (2-3) in 10 tumours. The Emprint ${ }^{\circ}$ MW system was used in the other 111 MWA's. Dissection was used in $37 \%$ of the procedures with five ureter perfusions. Patients were mostly placed in the CT scanner in a prone position (75\%), under epidural (98\%) or general (2\%) anaesthesia. Primary efficacy was achieved in 88 lesions (81\%) (table 2, figure 1a-c). T1a lesions had a significantly higher primary efficacy (89\%; Cl $0.81-0.94)$ compared to T1b lesions $(52 \%$; Cl 0.31 $0.73)(p<0.001) .15$ tumours $(53 \% \mathrm{~T} 1 \mathrm{~b})$ received a second MWA and two T1b tumours a third MWA. Secondary efficacy of MWA was reached in $97 \%$ (101/103) (all tumours), 99\% (82/83) (T1a) and 95\% (19/20) (T1b, p=0.352). Five tumours (5/20, 2 T1a and 3T1b) were not re-treated by MWA and excluded for the secondary efficacy, but were all successfully treated by means of surgery (PN; T1a) and other ablative techniques (RFA (1 T1a tumour (1x re-RFA) and $1 \mathrm{~T} 1 \mathrm{~b}$ tumour (3x re-RFA)), CA ( $n=1 ; T 1 b))$ and no treatment (patients choice). In five lesions the second MWA was incomplete (1 T1a, $4 \mathrm{~T} 1 \mathrm{~b}$ ) and were successfully treated with MWA $(n=2)$. In three lesions another ablative modality was used (CA $(n=2)$ and RFA $(n=1))$.

Table 2. Efficacy for T1a and T1b RCC lesions.

\begin{tabular}{lllll}
\hline & All & T1a & T1b & P value \\
\hline Primary efficacy & $88 / 108(81 \%)$ & $76 / 85(89 \%)$ & $12 / 23(52 \%)$ & $<\mathbf{0 . 0 0 1}$ \\
Remnant & $20 / 108(19 \%)$ & $9 / 85(11 \%)$ & $11 / 23(48 \%)$ & $<\mathbf{0 . 0 0 1}$ \\
Secondary efficacy & $101 / 103(98 \%)$ & $82 / 83(99 \%)$ & $19 / 20(95 \%)$ & 0.352 \\
Recurrence & $3 / 105(3 \%)$ & $1 / 83(1 \%)$ & $2 / 22(9 \%)$ & 0.110 \\
\hline
\end{tabular}




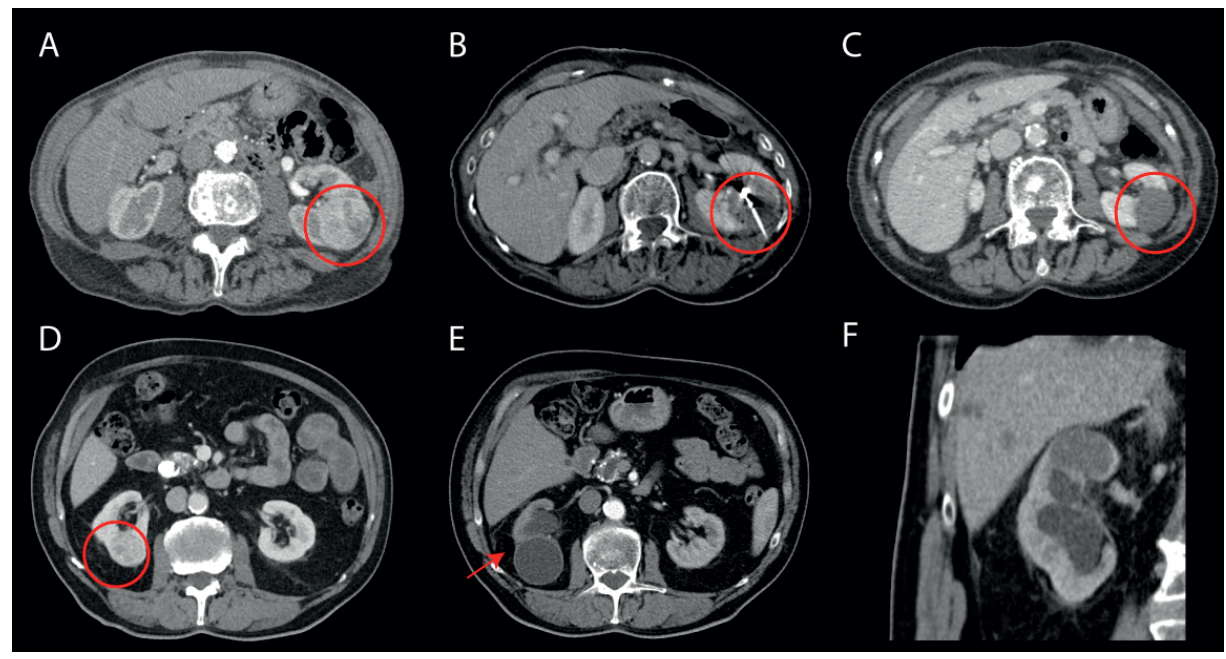

Figure 1. a-c: Microwave ablation (MWA) of a T1b tumour (A) before MWA (B) during MWA (C) one year after MWA: complete ablation. d-f: endophytic T1a lesion with a close relation to the collecting system (D). $(E+F)$ : 9 months after complete ablation, hydronephrosis of the kidney visible due to an urinary tract stenosis that occurred 3 months after the MWA (kidney function from $45 \mathrm{ml} / \mathrm{min} / 1.73 \mathrm{~m} 2$ to $19 \mathrm{ml} / \mathrm{min} / 1.73 \mathrm{~m} 2$ ) (NB this patients is familiar with liver cysts).

\section{Adverse events}

A total of 24 (19\%) AE's were observed after the 125 MWA procedures including six major AE's (4\%) with a significantly higher number of major AE's in T1b tumours (2 T1a -2\%- and 4T1b -13\%-, p=0.045)(table 3). There was no significant difference in the occurrence of all complications and $\mathrm{T}$ stage (18 T1a -20\%- and 6 T1b -18\%-, $p=1.000$ ). One major AE consisted of an active bleeding on the control scan during the MWA, which was successfully coiled embolized (CTCAE grade 3). One patient died 13 days after the ablation due to cardiac and renal failure (Clavien-Dindo grade 5). In two patients, an urinary tract stenosis arose after the MWA (Clavien-Dindo 4a) after 1 and 2 months resulting in a non-functional kidney (see figure 1d-f). In three patients, a urinary tract stenosis occurred 1, 2 and 5 months after the MWA without loss of renal function (Clavien-Dindo 1). All five lesions were endophytic T1a lesions, with a close relation to the collection system (4 lesions $<4 \mathrm{~mm}, 1$ lesions 4-7 mm). Cooling of the urinary tract system was performed in one lesion. One patient with macroscopic haematuria required transfusion with packed red blood cells and antibiotics (both grade 3 ). Nineteen (15\%) minor AE's occurred (Clavien Dindo grade 1+2). 
Table 3. Adverse events during and post ablation.

\begin{tabular}{llll}
\hline During ablation & Grade $^{\mathrm{a}}$ & $\mathbf{n}$ & T stage \\
\hline Tumour bleeding required embolization & & & \\
\hline Post ablation & 3 & 1 & T1b \\
\hline Dead within 30 days & & & \\
Urinary tract stenosis with renal function loss & 5 & 1 & T1b \\
Ureteral blood loss required endoscopic intervention & 3 & 2 & T1a \\
Infection treated with antibiotics & 2 & 2 & T1b \\
Urinary tract stenosis (without renal function loss) & 1 & 3 & T1a \\
Self-limiting (peri-renal or liver) bleeding & 1 & 4 & T1a,b \\
Pneumothorax & 1 & 3 & T1a \\
Sensibility loss of skin & 1 & 1 & T1a \\
Pain & 1 & 2 & T1a \\
Nausea & 1 & 2 & T1a,b \\
Skin burn & & 1 & T1a \\
\hline
\end{tabular}

a according to the Common terminology criteria for adverse events during ablation and according to the Clavien-Dindo Classification post ablation.

b The skin burn occurred at the antenna insertion and was successfully treated with silver sulfadiazine cream.

\section{Factors influencing outcome}

R.E.N.A.L. nephrometry score (OR 1.56, $p=0.001$ ), mR.E.N.A.L. nephrometry score (OR 1.58, $p=0.000$ ) and tumour aetiology (clear cell vs non clear cell OR $0.11, p=0.034$ ) were significantly associated with an incomplete ablation, however, only mR.E.N.A.L. nephrometry score remained significantly associated in the multivariable regression analysis $(O R=3.854 p=0.012)$ (table 4). Of the mR.E.N.A.L nephrometry score, size ( $>3$ and $>4$ ), nearness to the collecting system $(<4 \mathrm{~mm})$ and distance to the polar lines (score 3 ) were significantly associated with an incomplete ablation. 
Table 4. Pretreatment factors and their association with an incomplete ablation and the occurrence of complications after microwave ablation of T1 renal cell carcioma.

\begin{tabular}{|c|c|c|c|c|c|c|c|}
\hline \multirow[b]{2}{*}{ Variable } & \multirow[b]{2}{*}{ Test } & \multicolumn{3}{|c|}{ Univariable } & \multicolumn{3}{|c|}{ Multivariable } \\
\hline & & OR & $\begin{array}{c}95 \% \\
\mathrm{Cl}\end{array}$ & $\begin{array}{c}\mathrm{P} \\
\text { value }\end{array}$ & OR & $\begin{array}{c}95 \% \\
\mathrm{Cl}\end{array}$ & $\begin{array}{c}\mathrm{P} \\
\text { value }\end{array}$ \\
\hline \multicolumn{8}{|l|}{ Incomplete ablation } \\
\hline Tumour aetiology & $\begin{array}{l}\text { Clear cell vs non } \\
\text { clear cell }\end{array}$ & 0.107 & $0.01-0.85$ & 0.034 & 0.077 & $\begin{array}{c}0.04- \\
1.3\end{array}$ & 0.077 \\
\hline \multirow[t]{2}{*}{ Fuhrman grade $^{c}$} & Grade 1 vs grade $2+3$ & 1.286 & $0.4-4.3$ & 0.688 & - & - & - \\
\hline & Grade 1 vs unknown & 0.429 & $0.1-1.7$ & 0.221 & - & - & - \\
\hline Age & Continue & 1.005 & $0.96-1.06$ & 0.833 & - & - & - \\
\hline Gender & Male vs Female & 0.770 & $0.3-2.1$ & 0.600 & - & - & - \\
\hline History Cardiovascular & Yes vs no & 0.714 & $0.2-2.2$ & 0.551 & - & - & - \\
\hline History Oncological & Yes vs no & 0.492 & $0.2-1.3$ & 0.157 & - & - & - \\
\hline History Urological & Yes vs no & 0.882 & $0.3-2.7$ & 0.882 & - & - & - \\
\hline \multirow[t]{3}{*}{ Tumour location } & Left vs right & 1.500 & $0.6-4.0$ & 0.421 & - & - & - \\
\hline & Anterior vs Posterior & 0.391 & $0.08-1.9$ & 0.242 & - & - & - \\
\hline & Anterior vs Inter & 0.720 & $0.2-2.4$ & 0.589 & - & - & - \\
\hline System & Emprint vs Evident & 0.342 & $0.1-1.2$ & 0.086 & - & - & - \\
\hline $\begin{array}{l}\text { R.E.N.A.L. nephrometry } \\
\text { score }\end{array}$ & Continue & 1.559 & $1.2-2.0$ & 0.001 & 0.356 & $0.1-1.1$ & 0.069 \\
\hline $\begin{array}{l}\text { mR.E.N.A.L. nephrometry } \\
\text { score }\end{array}$ & Continue & 1.577 & $1.2-2.0$ & 0.000 & 3.854 & $1.3-11$ & 0.012 \\
\hline \multicolumn{8}{|l|}{ Complications } \\
\hline Age & Continue & 0.994 & $0.95-1.0$ & 0.772 & - & - & - \\
\hline Gender & Male vs Female & 1.063 & $0.4-2.6$ & 0.895 & - & - & - \\
\hline History Cardiovascular & Yes vs no & 0.729 & $0.3-2.0$ & 0.542 & - & - & - \\
\hline History Oncological & Yes vs no & 0.941 & $0.4-2.3$ & 0.895 & - & - & - \\
\hline History Urological & Yes vs no & 1.234 & $0.4-3.6$ & 0.704 & - & - & - \\
\hline \multirow[t]{3}{*}{ Tumour location } & Left vs right & 1.346 & $0.6-3.3$ & 0.517 & - & - & - \\
\hline & Anterior vs Posterior & 0.682 & $0.3-2.0$ & 0.521 & - & - & - \\
\hline & Anterior vs Inter & 0.692 & $0.2-2.7$ & 0.598 & - & - & - \\
\hline Dissection & Yes vs no & 1.091 & $0.4-2.8$ & 0.856 & - & - & - \\
\hline System & Emprint vs Evident & 1.314 & $0.3-5.2$ & 0.697 & - & - & - \\
\hline $\begin{array}{l}\text { R.E.N.A.L. nephrometry } \\
\text { score }\end{array}$ & Continue & 1.308 & $1.1-1.6$ & 0.013 & - & - & - \\
\hline $\begin{array}{l}\text { mR.E.N.A.L. nephrometry } \\
\text { score }\end{array}$ & Continue & 1.226 & 1.1-1.5 & 0.016 & - & - & - \\
\hline
\end{tabular}

${ }^{a}$ In the univariable analysis all variables were analyzed to determine the relation of

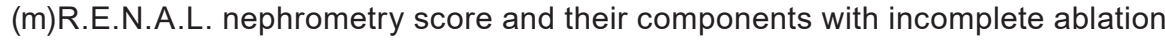
and complication.

${ }^{\mathrm{b}}$ In het multivariable analysis only the significant variables from the univariable factors were used.

c Fuhrman grade is a nuclear grading system of clear cell RCC that evaluated the nuclear size, shape and nucleolar prominence 
Univariable analysis showed that only R.E.N.A.L. nephrometry score (OR 1.308, $p=0.013$ ) and $m R$.E.N.AL nephrometry score (OR 1.577, $p=0.016)$ were associated with the occurrence of complications. Of the (m)RENAL score only the nearness to the collecting system $(<4 \mathrm{~mm})$ was significantly associated with the occurrence of complications.

\section{Follow-up}

Median follow-up time was 19 months (IQR 12-35 months; min-max 0-78 months, 90 patients (90\%) 1 year follow up available). During this period four (4\%) tumours showed LTR (2 T1a and 2 T1b tumours) after 10, 13, 26 and 60 months. One tumours was successfully treated by MWA and two recurrences by another modality (CA). One of the recurrences has not been treated yet. One patient treated by MWA for bilateral chromophobe RCC tumours, developed a new lesion in the same kidney for which he underwent active surveillance. Five patients (4 T1a tumours, $1 \mathrm{~T} 1 \mathrm{~b}$ tumours) developed metastases of which two were histologically proven RCC. During follow-up no patient died of RCC.

\section{DISCUSSION}

Percutaneous ablation is considered as treatment option in co-morbid patients with a T1 RCC tumour not eligible for PN [20; 24]. RFA and CA are widely applied and established ablation techniques that are included in guidelines contrary to MWA which has still limited supportive data $[20 ; 24 ; 26]$.

In this study, we show the result of 108 RCC's treated with MWA. There was a significantly higher primary efficacy for T1a tumours (89\%) compared to T1b tumours (52\%). In the 125 performed MWA's, 19\% AE's were observed, mostly low grade (15\%), with a significantly higher number of major AE's in T1b tumours (13\% T1b vs $2 \% \mathrm{~T} 1 \mathrm{a}, \mathrm{p}=0.045)$. The R.E.N.A.L. and mR.E.N.A.L. nephrometry score were related to incomplete first ablation and the occurrence of complications. The factors, size $(>3 \mathrm{~cm}$ and $>4 \mathrm{~cm})$, nearness to the collecting system $(<4 \mathrm{~mm})$ and distance to the polar lines (score 3$)$ of the mR.E.N.A.L nephrometry score were associated with incomplete ablation and nearness to the collecting system $(<4 \mathrm{~mm})$ for the occurrence of complications.

For all primary MWAs, a primary efficacy of $81 \%$ was observed with a primary efficacy of $89 \%$ for T1a tumours. After repeated MWA(s) a secondary efficacy of $99 \%$ was reached for T1a tumours. In the literature primary efficacy rates of MWA from $84.6-100 \%$ are reported[7; $10 ; 13 ; 21 ; 28]$. Therefore, the primary 
and secondary efficacy of T1a tumours underpins the existing evidence supporting MWA for the treatment of T1a RCC lesions .

The primary efficacy of T1b tumours (52\%) was significantly lower compared to T1a tumours ( $p<0.001$ ). In $48 \%$ of the T1b lesions a second or third ablation was performed to achieve a complete tumour ablation resulting in a secondary efficacy of $95 \%$. In the literature, lower efficacy rates of percutaneous ablation are described for tumours over $4 \mathrm{~cm}$ [28] which is in line with our findings. We shows that repeated MW ablations can achieve high efficacy rates even in large tumours. Besides the tumour size, our cohort contained difficult tumours with a close relation to the collecting system. Reports of percutaneous ablation of T1b RCCs by MWA are rare and series are small[3; 8]. Primary efficacy rates between $75 \%$ and $100 \%$ were reported in 12 and $7 \mathrm{~T} 1 \mathrm{~b}$ tumours, respectively[11; 32]. In the literature, $\mathrm{CA}$ is more commonly used as ablation technique for $\mathrm{T} 1 \mathrm{~b}$ lesions with primary efficacy rates ranging from $76 \%$ to $97.2 \%[2 ; 5 ; 12 ; 14]$. Our results show that MWA can also be used and chosen as a treatment modality in T1b tumours with consideration of a second ablation. Future costeffectiveness studies have to show the exact place of the difference ablation techniques for RCC.

The overall $A E$ rate of $19 \%$ was relatively high compared to previous percutaneous ablation and surgical studies[8; 31]. However, most AE's were low grade (15\%) with minimal consequences for the patient. In our series we found a significant difference between T1a and T1b tumour for the occurrence of major AE's. Five patients had a stenosis of the urinary tract, 1-5 months after MWA that resulted in renal function loss in two patients. Nearness to the collecting system was significantly associated with incomplete ablation and complications. Therefore, we suggest caution during MWA treatment for lesions close to the collecting system. In the literature, 13 cases of injury to the urinary tract system after MWA are reported[6;10; 18; 22; 30; 32]. Klapperich et. al observed 6 asymptomatic urinomas that resulted in renal cortex volume loss in 3 patients[18]. Preclinical work on a histologically level shows damage of MWA to the collecting system by direct puncture of the collecting system and heating of the urine during the ablation[23; 27]. Damage to the gastrointestinal tract was reported by others, but not observed in the current study[15; 17].

Multivariable analysis showed an independent association of the mR.E.N.A.L. nephrometry score for an incomplete first ablation. In addition, univariable analysis shows a relation of R.E.N.A.L. and m.R.E.N.A.L. nephrometry score with the occurrence of complications. This is in line with lerardi et al. that also 
reported an association of the $(m) R E N A L$ nephrometry score with incomplete ablation and complications after MWA [16] and Camacho et al. that first described this association after RFA and cryoablation [6]. Other groups did not find this association. To specify, Klapperich et al. only found an association between local recurrence after MWA and tumour histology characteristic, and not between the R.E.N.A.L. score and local recurrence [18]. Shakeri et al. observed a significantly higher median tumour size in lesions that required a second MWA, but no association with tumour location and R.E.N.A.L score[28]. Also, Wells and et al. did not found an association with the RENAL score and treatment outcome [32]. These reports are all opposite to our findings which may suggest that MWA is not as straight forward as previously reported.

The LTR in this study was $4 \%$ over a 108 histologically proven RCC's. In the literature LTR ranges from $0-17 \%[6 ; 11 ; 28]$, but most papers included every renal lesions without excluding non-diagnostic or benign lesions whereby efficacy and recurrence rates might be overestimated [22; 30; 32]. Surprisingly, the time to LTR was long in this current cohort which could be explained by the difficulties in detecting of recurrences in hypo vascular tumours and slow growth rates of low grade tumours.

Limitations of this study include a single centre retrospective study whereby details of the MW procedure were not complete with the lack of in house longterm follow up (>1year) in some patients. Ideally we would describe a larger cohort, but the peri-operative biopsy strategy resulted in some non-diagnostic and benign lesions.

In conclusion, primary efficacy of MWA in T1a tumours was significantly higher compared to T1b tumours. Repeated ablation was necessary in $19 \%$ achieving efficacy rates of $95 \%$ (T1a) and 99\% (T1b). Low grade AE's were seen after MWA whereby close monitoring of the urinary tract is recommended following ablation of tumours adjacent to the urinary tract. Incomplete ablation was more often seen in lesions with a larger size with a close relation to the collecting system and the polar lines accompanied expressed in a higher mR.E.N.A.L. nephrometry score. Prospective data have to determine the exact position of MWA for the treatment of RCC. 


\section{References}

1. Ahmed M, Solbiati L, Brace CL, Breen DJ, Callstrom MR, Charboneau JW. Image-guided tumor ablation: Standardization of Terminology and Reporting Criteria-A 10-Year Update. Radiology. 2014;273(1):241-60.

2. Atwell TD, Vlaminck JJ, Boorjian SA, et al. Percutaneous cryoablation of stage T1b renal cell carcinoma: technique considerations, safety, and local tumor control. J Vasc Interv Radiol. 2015;26(6):792-799.

3. Best SL, Park SK, Youssef RF, et al. Long-term outcomes of renal tumor radio frequency ablation stratified by tumor diameter: size matters. J Urol. 2012;187(4):1183-1189.

4. Brace CL. Radiofrequency and microwave ablation of the liver, lung, kidney, and bone: what are the differences? Curr Probl Diagn Radiol. 2009;38(3):135-143.

5. Buy X, Lang H, Garnon J, Sauleau E, Roy C, Gangi A. Percutaneous renal cryoablation: prospective experience treating 120 consecutive tumors. AJR Am J Roentgenol. 2013;201(6):1353-1361.

6. Castle SM, Salas N, Leveillee RJ. Initial experience using microwave ablation therapy for renal tumor treatment: 18-month follow-up. Urology. 2011;77(4):792-797.

7. Chan P, Velasco S, Vesselle $G$, et al. Percutaneous microwave ablation of renal cancers under CT guidance: safety and efficacy with a 2-year follow-up. Clin Radiol. 2017;72(9):786-792.

8. Choi SH, Kim JW, Kim JH, Kim KW. Efficacy and safety of microwave ablation for malignant renal tumors: an updated systematic review and meta-analysis of the literature since 2012. Korean J Radiol. 2018;19(5):938-949.

9. Cornelis $\mathrm{FH}$, Marcelin $\mathrm{C}$, Bernhard JC. Microwave ablation of renal tumors: $\mathrm{A}$ narrative review of technical considerations and clinical results. Diagn Interv Imaging. 2017;98(4):287-297.

10. Dong X, Li X, Yu J, Yu MA, Yu X, Liang P. Complications of ultrasound-guided percutaneous microwave ablation of renal cell carcinoma. Onco Targets Ther 2016;9:5903-5909.

11. Gao Y, Liang $P, Y u X, Y u$ J, Cheng $Z$ et al. Microwave treatment of renal cell carcinoma adjacent to renal sinus. Eur J Radiol 2016;85(11):2083-2089.

12. Gunn AJ, Joe WB, Salei A, El Khudari H, Mahmoud KH, Bready E,et al. Percutaneous cryoablation of stage $\mathrm{t} 1 \mathrm{~b}$ renal cell carcinoma: safety, technical results, and clinical outcomes. Cardiovasc Intervent Radiol. 2019;42(7):970-978

13. Hao G, Hao Y, Cheng Z, Zhang X, Cao F, Yu X, et al. Local tumor progression after ultrasound-guided percutaneous microwave ablation of stage T1a renal cell carcinoma: risk factors analysis of 171 tumors. Int J Hyperthermia. 2018;35(1):62-70.

14. Hebbadj S, Cazzato RL, Garnon J, Shaygi B, Buy X, Tsoumakidou G et al. Safety considerations and local tumor control following percutaneous image-guided cryoablation of t1b renal tumors. Cardiovasc Intervent Radiol. 2018;41(3):449-458.

15. Hinshaw JL, Lubner MG, Ziemlewicz TJ, Lee FT, Jr., Brace CL. Percutaneous tumor ablation tools: microwave, radiofrequency, or cryoablation--what should you use and why? Radiographics. 2014;34(5):1344-1362

16. Ierardi AM, Puliti A, Angileri SA, Petrillo M, Duka E and Floridi et al. Microwave ablation of malignant renal tumours: intermediate-term results and usefulness of RENAL and mRENAL scores for predicting outcomes and complications. Medical Oncology. 2017;34(5):97

17. Janzen NK, Perry KT, Han KR, Kristo B, Raman S, Said JW et al. The effects of intentional cryoablation and radio frequency ablation of renal tissue involving the collecting system in a porcine model. J Urol. 2005;173(4):1368-1374. 
18. Klapperich ME, Abel EJ, Ziemlewicz TJ, Best S, Lubner MG, Nakada SY et al. Effect of tumor complexity and technique on efficacy and complications after percutaneous microwave ablation of stage t1a renal cell carcinoma: a single-center, retrospective study. Radiology. 2017;284(1):272-280.

19. Laeseke PF, Lee FT, Jr., Sampson LA, van der Weide DW, Brace CL. Microwave ablation versus radiofrequency ablation in the kidney: high-power triaxial antennas create larger ablation zones than similarly sized internally cooled electrodes. J Vasc Interv Radiol. 2009;20(9):1224-1229.

20. Ljungberg B, Albiges L, Abu-Ghanem Y, Bensalah K, Dabestani S, Fernández-Pello S et al. European Association of Urology Guidelines on Renal Cell Carcinoma: The 2019 Update. Eur Urol. 2019;75(5):799-810.

21. Maciolek KA, Abel EJ, Posielski NM, Hinshaw JL, Lubner MG, Lee FT Jr. et al. Tumor location does not impact oncologic outcomes for percutaneous microwave ablation of clinical T1a renal cell carcinoma. Eur Radiol. 2019 Nov;29(11):6319-6329.

22. Mansilla AV, Bivins EE, Jr., Contreras F, Hernandez MA, Kohler N, Pepe JW. CTGuided microwave ablation of 45 renal tumors: analysis of procedure complexity utilizing a percutaneous renal ablation complexity scoring system. J Vasc Interv Radiol. 2017;28(2):222-229.

23. Moore C, Salas N, Zaias J, Shields J, Bird V, Leveillee R. Effects of microwave ablation of the kidney. J Endourol. 2010;24(3):439-444.

24. Motzer RJ, Jonasch E, Agarwal N, Bhayani S, Bro WP, Chang SS, et al. Kidney Cancer, Version 2.2017, NCCN Clinical Practice Guidelines in Oncology. J Natl Compr Canc Netw. 2017;15(6):804-834

25. Mouli SK, McDevitt JL, Su YK, Ragin AB, Gao Y, Namcek AA Jr, et al. Analysis of the RENAL and mRENAL scores and the relative importance of their components in the prediction of complications and local progression after percutaneous renal cryoablation. J Vasc Interv Radiol. 2017;28(6):860-867.

26. Prins FM, Kerkmeijer LGW, Pronk AA, Vonken EPA, Meijer RP, Bex A et al. Renal Cell Carcinoma: alternative nephron-sparing treatment options for small renal masses, a systematic review. J Endourol. 2017;31(10):963-975.

27. Schmitz JJ, Schmit GD, Viers BR, Atwell TD. Renal microwave ablation resulting in ureteropelvic junction stricture remote from the ablation site. J Vasc Interv Radiol. 2017;28(9):1278-1280 e1271

28. Shakeri S, Afshari Mirak S, Mohammadian Bajgiran A, Pantuck A, Sisk A, Ahuja P et al. The effect of tumor size and location on efficacy and safety of US- and CT- guided percutaneous microwave ablation in renal cell carcinomas. Abdom Radiol (NY). 2018;44(6):2308-2315

29. Siegel RL, Miller KD, Jemal A. Cancer statistics, 2018. CA Cancer J Clin. 2018;68(1):7-30

30. Thompson SM, Schmitz JJ, Thompson RH, Weisbrod AJ, Welch BT, Viers BR et al. Introduction of microwave ablation into a renal ablation practice: valuable lessons learned. AJR Am J Roentgenol. 2018;211(6):1381-1389

31. Uhlig J, Strauss A, Rucker G, Hosseini ASA, Lotz J, Trojan L, Kim HS, et al. Partial nephrectomy versus ablative techniques for small renal masses: a systematic review and network meta-analysis. Eur Radiol. 2019;29(3):1293-1307

32. Wells SA, Wheeler KM, Mithqal A, Patel MS, Brace CL, Schenkman NS. Percutaneous microwave ablation of $\mathrm{T} 1 \mathrm{a}$ and $\mathrm{T} 1 \mathrm{~b}$ renal cell carcinoma: short-term efficacy and complications with emphasis on tumor complexity and single session treatment. Abdom Radiol (NY). 2016;41(6):1203-1211. 



\section{CHAPTER}

\section{Cryoablation for the treatment of residual or recurrent disease after prior microwave ablation of renal masses}

B.M. Aarts, T.R. Baetens,

D. Corominas Munoz, S.F. Oudkerk, A.M. Solouki, A.D. Horsch,

A.Bex, R.G.H. Beets-Tan,

E.G. Klompenhouwer, F.M. Gómez

In submission 


\section{CHAPTER}

\section{Cryoablation and immunotherapy: an overview of evidence on its synergy}

B.M. Aarts, E.G. Klompenhouwer, S.L. Rice, F. Imani, T. Baetens, A. Bex, S. Horenblas, M. Kok, J.B.A.G. Haanen, R.G.H. Beets-Tan, F.M. Gómez

Published in Insights into Imaging 2019 May 20;10(1):53 doi: 10.1186/s13244-019-0727-5

PMID: 31111237 


\section{ABSTRACT}

Cancer cells can escape the immune system by different mechanisms. The evasion of cancer cells from immune surveillance is prevented by immune checkpoint inhibitors, allowing the patient's own immune system to attack their cancer. Immune checkpoint inhibitors have shown improvement in overall survival for melanoma, lung cancer and renal cell carcinoma in clinical trials. Unfortunately, not all patients respond to this therapy. In cancer management, percutaneous ablation techniques are well established for both cure and local control of many tumour types. Cryoablation of the tumour tissue results in cell destruction by freezing. Contrary to heat based ablative modalities, cryoablation induces tumour cell death by osmosis and necrosis. It is hypothesized that with necrosis, the intracellular contents of the cancer cells stay intact allowing the immune system to induce an immune-specific reaction. This immune-specific reaction can, in theory, also affect cancer cells outside the ablated tissue, known as the abscopal effect. Unfortunately, this effect is rarely observed, but when cryoablation is combined with immunotherapy, the effect of both therapies may be enhanced. Although several preclinical studies demonstrated a synergistic effect between cryoablation and immunotherapy, prospective clinical trials are needed to prove this clinical benefit for patients. In this review, we will outline the current evidence for the combination of cryoablation with immunotherapy to treat cancer. 


\section{INTRODUCTION}

Cryoablation is a percutaneous ablation technique that uses extreme low temperatures for tumour destruction [1]. During cryoablation liquefied gas, such as nitrogen or argon, is passed through cryoprobes and expands into a gaseous state at the end of the probe to create temperatures as low as $-190^{\circ} \mathrm{C}$. Cytotoxic cell destruction is achieved at temperatures below $-20^{\circ} \mathrm{C}$. To ensure complete ablation of the tumour, a circumferential margin of $1 \mathrm{~cm}$ is needed [2]. After the freezing phase, a thawing phase follows by replacing the liquefied gas with helium or internally heating the needle (available in new systems). The whole process of freezing-thawing is repeated to obtain an effective ablation. Intraprocedure computed tomography (CT) identifies the ablated zone in real time as a low-density area which corresponds to the generated ice ball (Fig. 1).

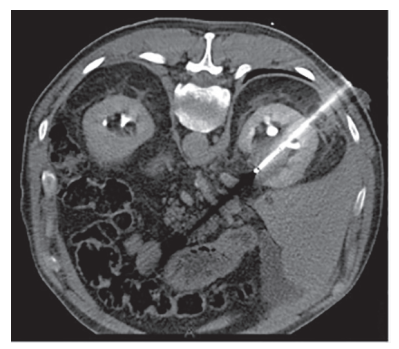

Figure 1. Cryoablation of a patient with stage IA renal cell carcinoma. The hypodense area around the needle corresponds with the generated ice ball in real time.

The procedure results in focal destruction of tumour tissue in a minimal invasive setting with reduced morbidity and mortality and represents a cost-effective alternative to surgery $[3,4]$. However, surgery remains the gold standard in most tumour types with additional pathological assessment of margins [5, 6]. A possible advantage of cryoablation is that the intracellular contents of the damaged tumour cells are preserved and can be recognised by the immune system initiating a tumour-specific immune response (Fig. 2) [7, 8].

Recently, immune checkpoint inhibitors have been studied for treatment of melanoma, renal cell carcinoma (RCC) and non-small lung cancer (NSLC). The challenge of the immune checkpoint inhibitors is that only a minority of patients respond. Therefore, a combination treatment of cryoablation and immunotherapy, might be beneficial to enhance the effect of the immune checkpoint inhibitors (Fig. 3). In the early 1970s, Shulman et al. reported the production of antibodies specifically against cryoablated tissue in rabbits $[9,10]$. This immunogenic effect potentially resulted in a "bystander effect" 
with regression of tumours outside the primary ablation zone, known as the abscopal effect, firstly defined by Mole after radiotherapy [11, 12]. Unfortunately, this effect occurs infrequently, but when cryoablation is combined with other immunomodulatory therapy, this effect might be enhanced (Fig. 3) [13]. Here, we review the current evidence on the combination of cryoablation with immunomodulatory drugs (immunotherapy).

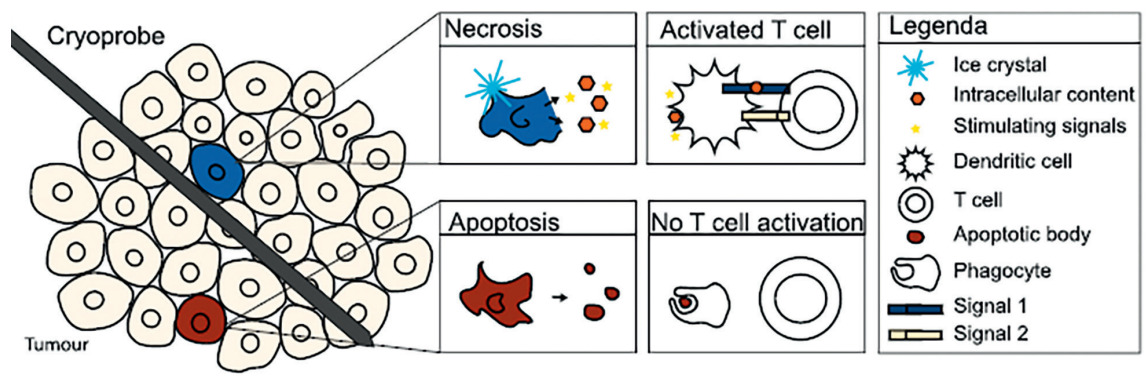

Figure 2. One of the hypotheses of how cryoablation induces an immune response is in the way cell death is induced. Cryoablation induces cell death by both necrosis and apoptosis. Necrosis releases intra-cellular contents stimulating signals (among others danger signals) that may activate $T$ cells for a specific immune response to the cryoablated tissue. Contrary, after cell death by apoptosis, only apoptotic bodies are released, without stimulating signals. Without these stimulating signals, $T$ cells are not being activated. Therefore, apoptosis may lead to an immune-suppressing signal.

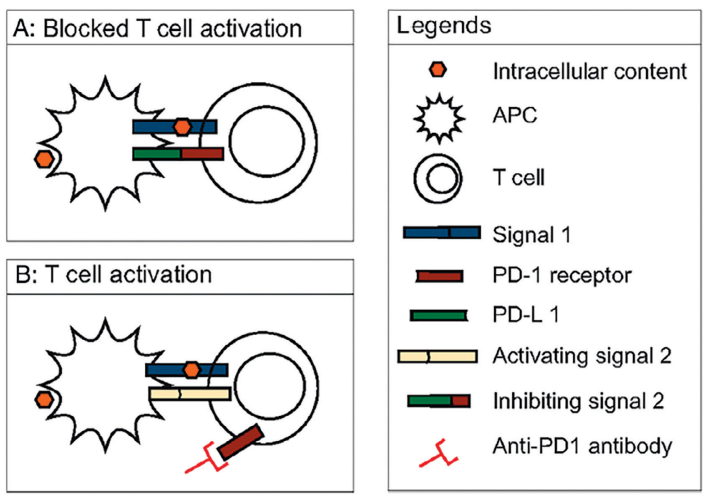

Figure 3 For T cell activation, both stimulatory signal 1 and 2 are needed. Signal 1 consists of the interaction between the major histocompatibility complex on the dendritic cell and the $T$ cell receptor. Different combinations of interactions are possible for signal 2. One inhibiting signal 2 is the interaction between programmed death receptor 1 (PD-1) on T cell and programmed death ligand 1 (PD-L1) on tumour cells or antigen presenting cells. a T cell activation is blocked by an inhibiting signal 2 between PD-L1 and PD-1 receptor binding. $b$ When an anti-PD1 antibody is used, the inhibiting signal of the $T$ cell is blocked whereby an activation signal of the $T$ cell is gathered and the $T$ cell is activated. 


\section{MATERIAL AND METHOD}

A literature search in MEDLINE was performed for available publications between 2001 and 2017 about cryoablation, its effect on the immune system and the combination of cryoablation and immunotherapy. Only full text articles available in English were included. Keywords included cryoablation, immune system, immunotherapy, melanoma and cancer. Data collection included factors related to the synergy between cryoablation and the immune system, cryoablation and immunotherapy, effect of cryoablation on tumour tissue and cryoablation technique. For immunotherapy, all therapies which could theoretically enhance the anti-cancer immune response through either stimulation of the adaptive or innate immune system were included. Studies could be performed in patients and animals. Articles about combination of different ablation modalities were excluded. A total of 45 relevant papers were identified and the most interesting and relevant studies were used for this review. To outline this paper, the studies were structured by tumour type and the current knowledge about the tumour type, cryoablation and immunotherapy was reviewed.

\section{RESULTS}

Cryoablation and the immune system

Cryoablation may be synergistic with the immune system in the way cell death is induced. After ablation, the tumour remains, releasing various factors attracting the immune system. A proposed theory regarding the potential mechanisms of cryoablation and the immune system is the danger theory of Matzinger [14, 15]. This theory proposes that after cell death by necrosis, cells secrete danger signals. These danger signals can initiate an immune response. In addition, these signals can mature dendritic cells (DCs) to fully activate T cells which may lead to a specific immune response. Cryoablation induces cell death by necrosis in which intracellular contents are still preserved while DNA, RNA and heat shock protein (HSP), which can induce danger signals, are released [16]. On the other hand, the cells in the outer margin of cryoablated tissue die from apoptosis and do not release DNA, RNA and HSP, and with no danger signal, the DCs remain immature. Immature DCs may trigger immune suppressive signals that could lead to anergy ( $T$ cell inactivation) $[17,18]$. Therefore, cryoablation can induce both an immunostimulatory and immunosuppressive response (Fig. 2). In addition, cytokines are produced after cryoablation, and these can also influence an immune response. Again, both immunosuppressive and immunostimulatory cytokines may be released depending on the tumour tissue, age and freeze rate [19]. For cryoablation of liver tumours, when more 
than $20 \%$ of the liver volume is ablated, a systemic inflammatory response can occur due to a release of cytokines interleukine-6 (IL-6), IL-10 and tumour necrosis factor alpha (TNFa), which can have marked systemic effects [7, 20-22]. Therefore, cryoablation is not the preferred treatment since heatbased ablations are better established in this setting [23]. Yet, two clinical studies reported favourable outcomes on overall survival when cryoablation was combined with immunotherapy of allogenic natural killer (NK) cell infusion and dendritic cell cytokine-induced killer (DC-CIK) cells [24, 25]. Preclinical work from den Brok et al. confirms the effect of cryoablation on the immune system. This study reported that cryoablation creates an antigen depot resulting in maturation of DCs. The maturation of DCs led to a tumour-specific immune response protecting half of the mice against a new injection of similar tumour cells.

When cryoablation was combined with an immune checkpoint inhibitor, anticytotoxic T lymphocyte-associated protein 4 (CTLA-4) antibody, this anti-tumour effect was further enhanced with up to $80 \%$ of the mice becoming tumour free [26]. Clinical work by Takaki et al. evaluated peripheral blood after heathand cold-based ablation modalities with pre-treatment (baseline) in different tumours showing no change in T cell subtypes (regulatory T cell (Tregs), T1 helper or Th2 helper cells) in all modalities, an elevation of cytotoxic T cells after heat-based ablative treatment was noted, and this was not identified after cryoablation [27]. In a group of hepatitis B-positive hepatocellular carcinoma patients, the presence of elevated programmed cell death protein 1 (PD-1) on T cells and programmed cell death ligand 1 (PD-L1) expression on tumour cells had a poor overall survival post cryoablation [28]. Theoretically, when combining cryoablation with a PD-1 inhibitor, such as nivolumab or pembrolizumab, the cryoablation induced adaptive immune resistance with upregulation of PD-L1 on tumour cells could be overcome, resulting in an effective anti-tumour $T$ cell response. This potential synergy between cryoablation and anti-PD-1 may result in a more effective disease control; see Fig. 3 [29]. To enhance the immunogenicity effect of the cryoablation, different immunotherapies can be given as shown in Table 1. Most immunotherapy enhances the innate immunity, namely natural killer (NK) cell therapy, dendritic cells (DCs) and CpG oligonucleotide ( $\mathrm{CpG}$ ODN). When cryoablation presents the contents of the tumour cells, the innate immune system can assimilate these contents and present it to T cells; an immune response specific to the tumour cells could be obtained. Table 2 is an overview exhibiting the most studied factors after cryoablation in the reviewed papers. 
Table 1. Summary of the major therapies with their mode of action used in combination with cryoablation in the reviewed papers. All therapies stimulate the immune system in a way and in combination with cryoablation an enhancement of this effect is hypothesized

\begin{tabular}{|c|c|c|}
\hline Therapy & Mode of action & $\begin{array}{l}\text { Number of } \\
\text { articles }\end{array}$ \\
\hline $\begin{array}{l}\text { CpG oligonucleotide (CpG } \\
\text { ODN) }\end{array}$ & $\begin{array}{l}\text { Is recognized by dendritic cells } \\
\text { (DCs) and B cells. Activates T cells, } \\
\text { natural killer (NK) cells, monocytes, } \\
\text { neutrophils and plasma cell } \\
\text { differentiation }\end{array}$ & 8 \\
\hline $\begin{array}{l}\text { Anti-cytotoxic T-lymphocyte- } \\
\text { associated protein } 4 \text { (anti } \\
\text { CTLA-4) }\end{array}$ & $\begin{array}{l}\text { Blocks the inhibitory receptor } \\
(C T L A-4) \text { on the } T \text { cell and therefore } \\
\text { activates the } T \text { cell for a specific } \\
\text { immune response }\end{array}$ & 6 \\
\hline Immature dendritic cells (DCs) & $\begin{array}{l}\text { Phagocytosis of pathogens; antigen- } \\
\text { presentation to other immune cells } \\
\text { (among others T cells) }\end{array}$ & 4 \\
\hline Natural Killer (NK) cell therapy & $\begin{array}{l}\text { Infusion with autologous NK cells to } \\
\text { directly kill tumour cells }\end{array}$ & 4 \\
\hline $\begin{array}{l}\text { Dendritic cell- cytokine } \\
\text { induced killer (DC-CIK) }\end{array}$ & $\begin{array}{l}\text { May act like T cells or NK cells } \\
\text { but is unrestricted to major } \\
\text { histocompatibility complex (MHC) }\end{array}$ & 3 \\
\hline $\begin{array}{l}\text { Granulocyte-macrophage } \\
\text { colony-stimulating factor (GM- } \\
\text { CSF) }\end{array}$ & $\begin{array}{l}\text { A protein that functions as a cytokine } \\
\text { and stimulates stem cells and can } \\
\text { induce an immune cascade }\end{array}$ & 3 \\
\hline $\begin{array}{l}\text { Anti-programmed death-ligand } \\
1 \text { (PD-L1) }\end{array}$ & $\begin{array}{l}\text { Blocks the receptor Programmed } \\
\text { death }-1 \text { on the tumour cell. This } \\
\text { results in activation of the } T \text { cell to } \\
\text { induce a specific immune response }\end{array}$ & 1 \\
\hline
\end{tabular}


Table 2. Overview of the most studied factors of cryoablation and the immune system in the reviewed papers

\begin{tabular}{|c|c|c|}
\hline Mice & & Total 28 articles \\
\hline Survival & $\uparrow$ & $17 / 17$ \\
\hline Rechallenge of primary tumour & $\uparrow$ & $12 / 12$ \\
\hline Reduction in distant metastasis & $\uparrow$ & $10 / 10$ \\
\hline Cytokine release & $\uparrow$ & $16 / 17$ \\
\hline IFN-y release & $\uparrow$ & $16 / 17$ \\
\hline TNF- $\alpha$ release & $\uparrow$ & $4 / 5$ \\
\hline $\mathrm{IL}-4$ & $\uparrow$ & $1 / 7$ \\
\hline IL-10 & $\uparrow$ & $1 / 4$ \\
\hline Th1/Th2 cytokine ratio & $\uparrow$ & $10 / 0$ \\
\hline CD4+ infiltration & $\uparrow$ & $12 / 16$ \\
\hline CD8+ infiltration & $\uparrow$ & $14 / 19$ \\
\hline Treg & $\downarrow$ & $5 / 6$ \\
\hline NK cells & $\uparrow$ & $3 / 4$ \\
\hline Human & & Total 17 articles \\
\hline Survival & $\uparrow$ & $8 / 8$ \\
\hline Quality of Life & $\uparrow$ & $4 / 4$ \\
\hline Cytokine release & $\uparrow$ & $6 / 7$ \\
\hline IF-y release & $\uparrow$ & $6 / 7$ \\
\hline TNF- $\beta$ release & $\uparrow$ & $3 / 4$ \\
\hline IL-10 & $\downarrow$ & $3 / 5$ \\
\hline $\mathrm{IL}-4$ & $\downarrow$ & $3 / 4$ \\
\hline $\mathrm{IL}-2$ & $\uparrow$ & $3 / 5$ \\
\hline Th1/Th2 cytokine ratio & $\uparrow$ & $5 / 0$ \\
\hline CD4+ infiltration & $\uparrow$ & $5 / 8$ \\
\hline CD8+ infiltration & $\uparrow$ & $5 / 8$ \\
\hline Treg & $\downarrow$ & $2 / 2$ \\
\hline NK cells & $\uparrow$ & $4 / 4$ \\
\hline
\end{tabular}




\section{Breast Cancer}

Cryoablation was approved for the treatment of fibroadenomas for over a decade [30]. In 2016, the American College of Surgeons Oncology Group (ACOSOG) alliance considered cryoablation as an effective treatment for unifocal ductal cancer, with a success rate of complete tumour ablation of $92 \%$ after correction for multifocal disease [31]. Also, for the treatment of stage IV breast cancer, cryoablation is a safe and effective procedure to control the disease and debulks the tumour in the breast [32].

Although antibodies are part of the treatment for human epidermal growth factor receptor 2 (HER2)-positive breast cancers, no active forms of immunotherapy such as immune checkpoint inhibitors are currently approved for breast cancer. Recently, the interim analysis of the Impassion 130 study with the combination of nab-paclitaxel plus atezolizumab revealed an impressive 10 months of improvement in overall survival compared with chemotherapy alone in PD-L1positive triple negative metastatic breast cancers [33]. Other immune checkpoint blocking antibodies, such anti-CTLA-4 antibody, are also under investigation [34].

One of the first reports confirming the immunogenicity of cryoablation in breast cancer was in a mammary mouse model. After cryoablation or surgery, mice were re-challenged with tumour cells and only $16 \%$ of the cryoablated exhibited tumour development compared to $86 \%$ of the surgically treated mice [35]. In a metastatic breast cancer mouse model, cryoablated mice treated with a high freeze rate $(100 \%$ cryoablation cycle) showed an improvement in overall survival with significant reduction in the number of pulmonary metastasis compared to treatment with a low freeze rate $(10 \%$ cryoablation cycle) or those treated with surgery [19]. When cryoablation was combined with injection of CpG ODN (a single-strand DNA molecule that acts as a toll-like receptor (TLR) agonist to stimulate and mature DCs) in mice, less tumour recurrence and secondary tumour growth were seen after the re-challenge compared to the mice that received cryoablation alone or surgery [36]. No significant difference was reported between $\mathrm{CpG}$ ODN alone or in combination with cryoablation groups, leaving the added role of cryoablation to $\mathrm{CpG}$ ODN injection undetermined regarding cytokine release and potential immune activation [36].

Other studies have investigated the combination of cryoablation with an immune checkpoint inhibitor (ipilimumab) 7 days before mastectomy in a group of patients with early-stage breast cancer. The pilot study, including 19 patients, showed that this approach was a safe option without delaying the mastectomy [37]. A post hoc analysis was performed to assess the possibility of $T$ cell 
receptor sequencing as a biomarker for $\mathrm{T}$ cell response to cryoablation, where no specific T cell response was observed [38]. Additionally, a phase II trial is ongoing where cryoablation in combined with ipilimumab and nivolumab before breast surgery in triple negative breast cancer patients after taxane-based neoadjuvant chemotherapy [39].

In another study, recurrent HER2-positive breast cancer patients were treated with the combination of cryoablation, trastuzumab and natural killer (NK) cell therapy (intravenous infusion of allogenic NK cells). These patients displayed a significantly prolonged progression-free survival (PFS), significantly larger numbers of $T$ cells and Th1 cytokines together with a significantly reduction in the number of circulation tumour cells in the peripheral blood compared to patients only treated with cryoablation alone or cryoablation and NK cell therapy. To note, PFS was not reached in the triple combination group, and the significantly prolonged PFS could be due to trastuzumab [40].

Niu et al. evaluated the use of cryoablation in combination with immunotherapy of DC-CIK cells in metastatic breast cancer patients versus chemotherapy or cryoablation alone. The group of patients that received multiple cryoablations (several sites) in combination with immunotherapy displayed a significantly longer median overall survival compared to the other groups [41].

Together, cryoablation before mastectomy is feasible and its combination with immunotherapy, consisting of NK cell therapy, DC-CIK or anti-CTLA-4 antibody, is safe and effective in different stages in breast cancer. These results encourage further investigation into the combination of cryoablation and immunotherapy for breast cancer patients. Two trials are currently open which combine cryoablation with immune checkpoint inhibitors (Table 3) [42, 43].

\section{Renal cell carcinoma}

In RCC, cryoablation is most frequently used to treat stage I cancer (ideally smaller than $4 \mathrm{~cm}$ taken as the largest diameter) in patients not eligible for surgical resection $[44,45]$. With optimal patient selection, results similar to partial nephrectomy can be achieved [46]. Immunotherapy for RCC has been used for quite some time, and nivolumab, a PD-1 inhibitor, is already approved for the treatment of RCC $[47,48]$.

Two animal studies showed the favourable effect of cryoablation in the microenvironment of RCC and in the kidney. The first study used two mice models, one with and one without injected RCC to observe an inflammatory 
immune response after cryoablation in the tumour or healthy kidney tissue. An infiltration of neutrophils, macrophages and CD4+ and CD8+ T cells was reported after cryoablation whereby no difference was observed after cryoablation of normal kidney tissue or tumour tissue [49]. Another study compared cryoablation with surgery and showed decreased tumour growth after the re-challenge of the tumour cells with significantly more T cells in the peripheral blood after cryoablation [50].

Kato et al. showed that in half of the patients with $\mathrm{T} 1 \mathrm{RCC}$, a significant increase in T cell receptor (TCR) B CD3 clonotypes of T-cells in post ablation tissue and blood was seen with a low diversity (TCR clones were not evenly distributed anymore) [51]. In another clinical study, two sessions of cryoablation of the pulmonary metastases, each combined with two intratumoural injections of granulocyte-macrophage colony-stimulating factor (GM-CSF), resulted in higher levels of NK cells, Th1 cytokines and T and B cells in the peripheral blood compared to baseline [52]. 


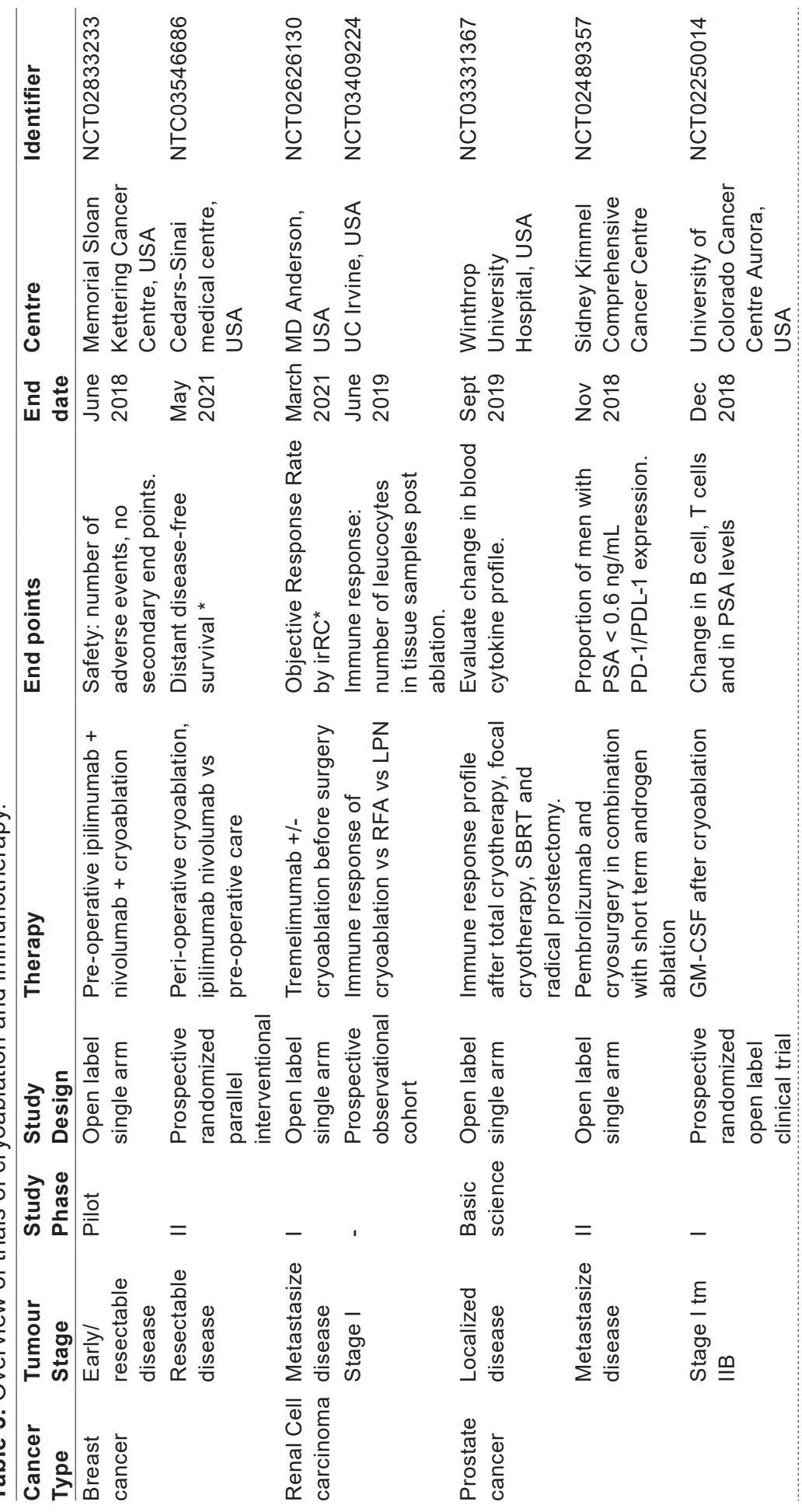




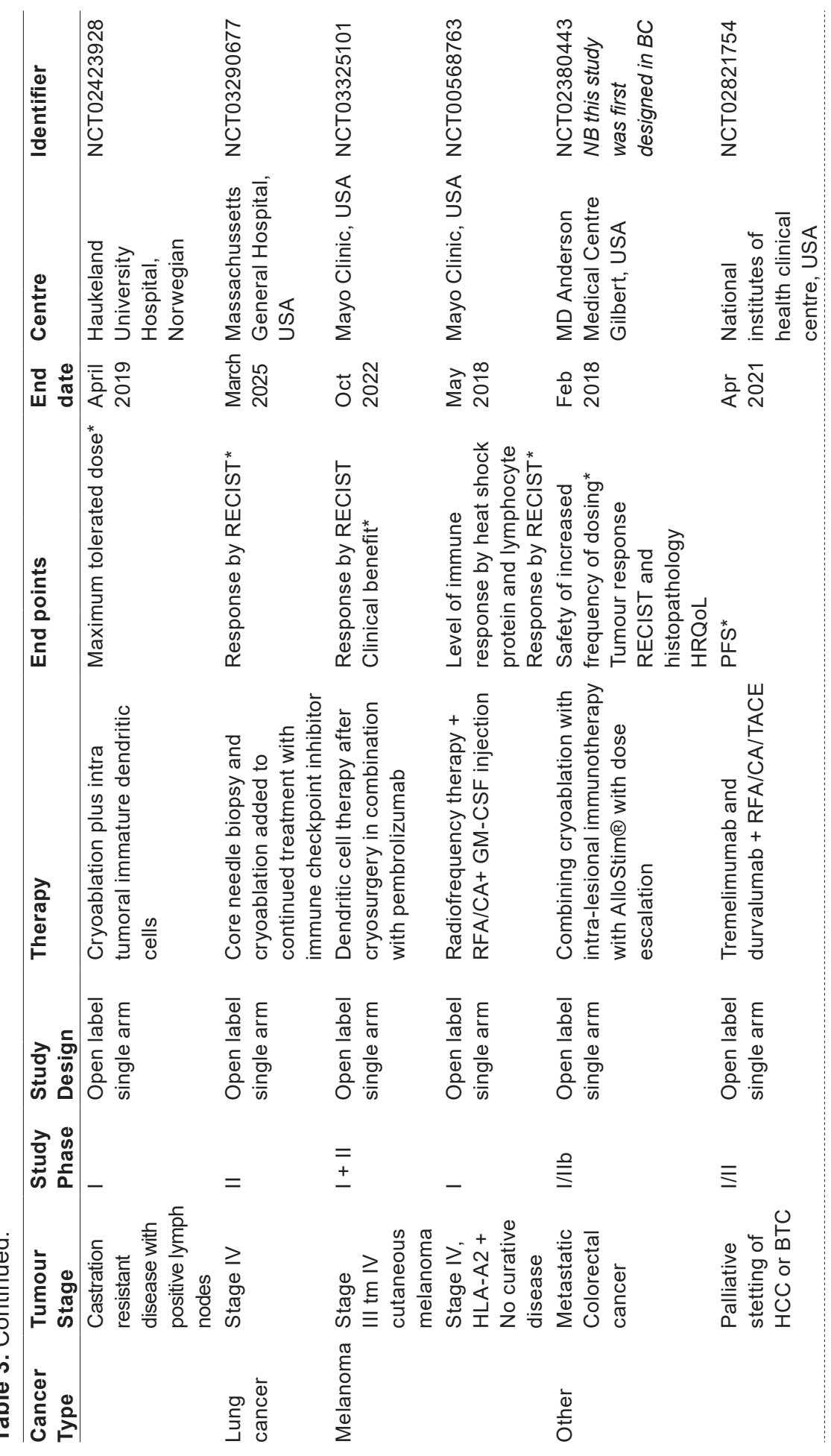




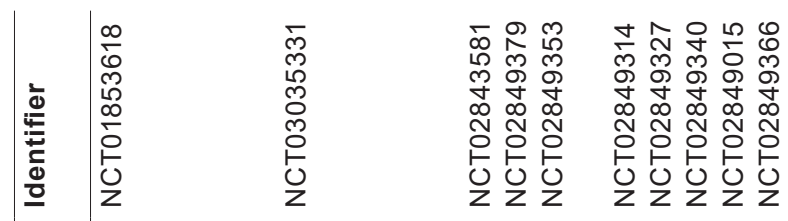

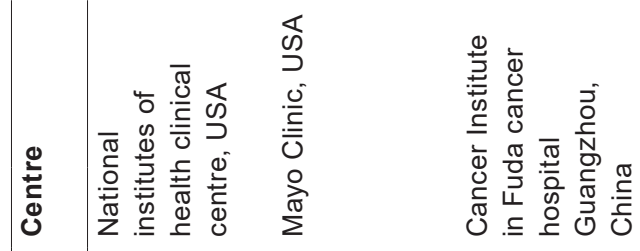

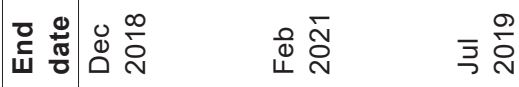

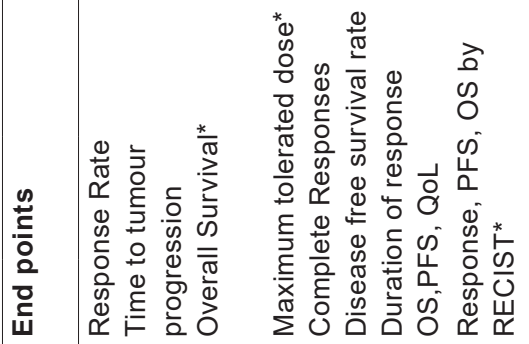

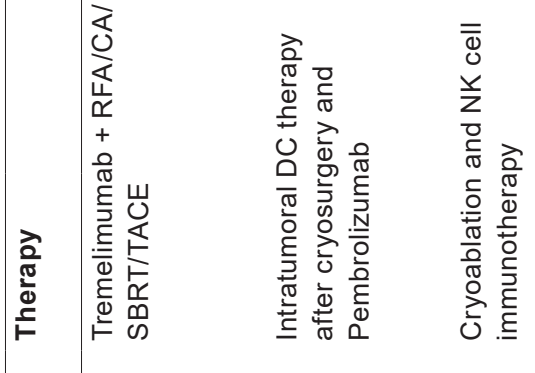

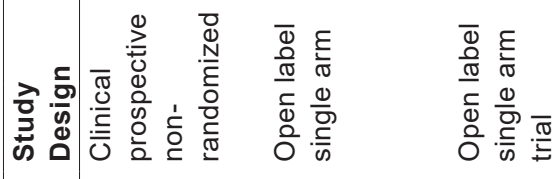

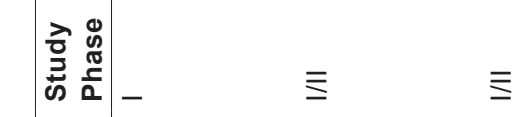

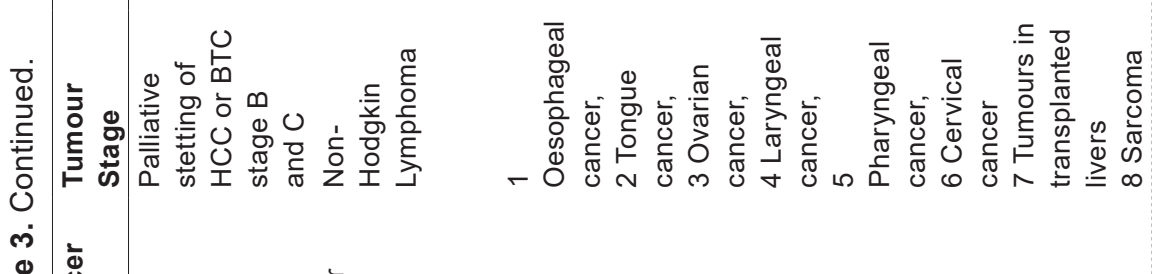

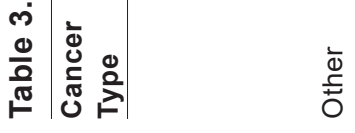




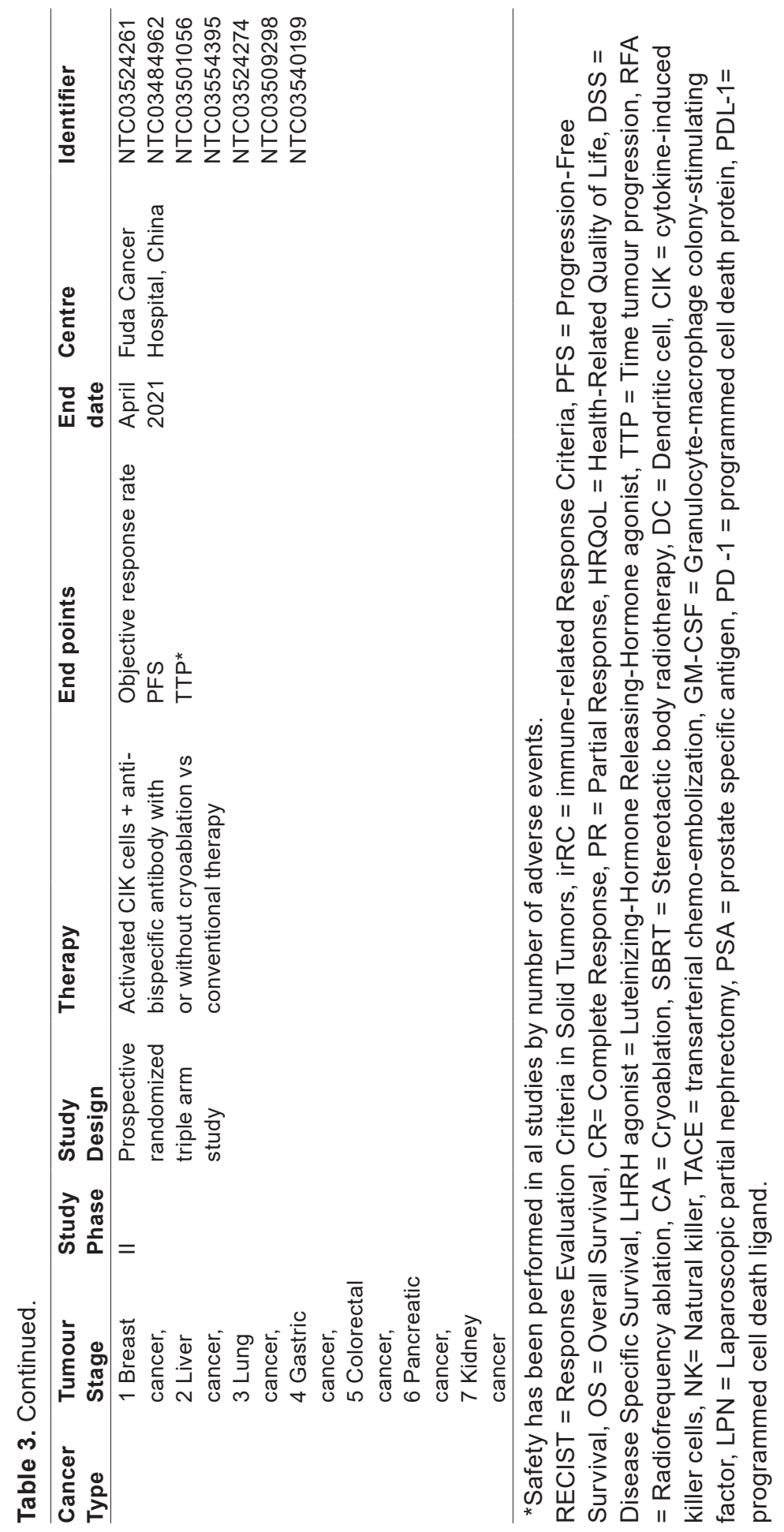


Lin et al. showed similar effects of allogeneic NK cell immunotherapy combined with cryoablation in 60 advanced RCC patients, and this treatment combination resulted in more tumour responses and decrease in Hounsfield units count than cryoablation on its own [53].

To summarise, cryoablation of RCC elicits an immune response and can be safely combined with GM-CSF and NK cell therapy. Currently, one trial is ongoing investigating the synergy of cryoablation with anti-PD-1 therapy (tremelimumab), and another trial investigates the effect of ablation of the immune system $[54,55]$.

\section{Prostate cancer}

Cryoablation is currently being used to treat stage I prostate cancer. Cryoablation could also be considered as salvage treatment for local recurrence after radiation therapy. Future perspectives in prostate cancer shift towards a more targeted therapy where cryoablation may have an important role in prostate cancer [56].

Presently in prostate cancer, the only approved immunotherapy is sipuleucel-T (Provenge), a DC-based immunotherapy that sensitises dendritic cells with prostate antigens and is used as a therapeutic vaccine [57]. Other immunotherapies evaluated have failed to show improvement in overall survival [58-60]. Current developments are focusing on immunotherapy for the subgroup with defects in DNA-repair mechanisms, which include microsatellite instability and breast cancer gene mutations.

Waitz et al. reported a regression in secondary tumour growth with infiltration of CD4+ and CD8+ T cells and lower counts of Tregs in mice treated by cryoablation and anti-CTLA-4 antibodies [29]. Another study reported that the combination of cryoablation with anti-CTLA-4 antibodies reduced distant metastasis in mice together with a reduction in the number of Tregs; these were lowest on day 14 but returned to normal levels at day 21 [61].

Recently, combination therapy of androgen deprivation plus anti-PD-1, antiCLTA-4 or placebo with or without cryoablation demonstrated a delay in distant tumour growth and decreased mortality in mice in the trimodal therapy groups [62]. Pre cryoablation tissue in high-risk localised prostate cancer patients showed elevated numbers of Tregs compared to healthy volunteers. Numbers of Tregs decreased significantly after cryoablation in the prostate patients, and, conversely, 7 of 12 patients had an increase of suppressive function of Tregs 
measured by immunosuppressive assay of CD4+CD25+CD127- which was linked to the probability of recurrence of the cancer in 2 patients [63].

Another clinical study reported significantly higher cytokines (TNF $\alpha$ and IFN-y) levels, increased T cell response to autologous tumour tissue (IFN-y ELISPOT assay) after 4 weeks and higher cytotoxic activity of T cells after 4 and 8 weeks (measured by luciferase assay) after cryoablation in 20 high-risk prostate patients [64]. In patients with metastatic hormone refractory prostate cancer, a combination of cryoablation and GM-CSF showed a $70 \%$ decrease of PSA levels and a median time to progression of 18 months. No correlation was seen between the increase tumour-specific $T$ cell responses in the peripheral blood and the increased cytolytic activity (measured by luciferase assay) after 4 and 8 weeks [65].

The addition of cryoablation to androgen deprivation therapy (ADT) in 30 prostate cancer patients with bone metastases significantly improved progression-free, cancer-specific and overall survival compared to 30 prostate patients only treated with ADT [66].

No clinical trials have been performed so far to evaluate a combination of antiCTLA-4 antibodies with cryoablation therapy in humans. Only immunotherapy with GM-CSF has been investigated. Currently, a phase II trial of the combination of pembrolizumab and cryosurgery in stage IV prostate patients is ongoing. In addition, other trials are ongoing searching for the relation between cryoablation and the effect on the immune system [67-70].

\section{Lung cancer}

Percutaneous local ablative therapies are considered viable options for the treatment of stage IA non-small-cell lung carcinoma (NSCLC). Recurrent lesions after radiation therapy or surgery and metastatic lesions can be treated by means of ablation as well [71, 72]. Cryoablation of lung lesions is associated with lower pain levels and fewer complications in tumours located close to the chest wall and mediastinum or central lesions close to the hilum; however, no clinical randomized studies have been executed comparing the different percutaneous ablative therapies [73, 74].

NSCLC is a heterogeneous group of cancers which is known for high numbers of tumour-specific mutations that are linked with response to immunotherapy [75]. In recent years, several immunotherapies have been approved for the 
treatment of lung cancer, namely PD-1 checkpoint inhibitors nivolumab and pembrolizumab and the anti-CTLA-4 inhibitor ipilimumab.

Preclinical work in a mouse model revealed that intratumoural injection of DCs with cryoablation elicits a Th1 response with higher levels of IFN-y and effector memory CD8+ $T$ cells observed from spleen cells resulting in protection against secondary tumours and prolonged survival [76]. In another study, the addition of CpG ODN to the cryoablation plus DCs resulted in a significant reduction of new tumour growth, fewer metastasis development and a prolonged survival compared to all the therapies alone. A decrease in Tregs and increase in cytotoxic $T$ cells were observed and linked to the better response in the combination group [77]. In another study, the same treatment combination showed a higher elevation of CD4+ and CD8+ T cells and IL-12, IFN-y and TNFa together with a delay in tumour growth and improved survival in mice treated with the combination therapy [78]. Takahashi et al. reported the greatest immune response (higher numbers of specific $T$ cells and higher levels of stimulating cytokines) and the slowest tumour growth after two cycles of cryoablation compared to one or three cycles of cryoablation [79].

Clinical work combining cryoablation and allogenic intravenous NK cells showed an improvement in the quality of life and tumour response rates compared to cryoablation alone. Additional phase II/III trials must be conducted to reveal the potential benefits in larger patient groups before combination treatment is considered an alternative [80]. Another strategy, consisting of a combination of cryoablation with gefitinib, an inhibitor of epidermal growth factor receptor's (EGFR) tyrosine kinase domain, showed significant improvement of overall response with a higher 1-year survival rate in patients treated with gefitinib and cryoablation compared to gefitinib alone [81]. Lastly, 166 metastatic NSCLC patients received either cryoablation alone, cryoablation followed by immunotherapy (DC-CIK) or chemotherapy or all three therapies. The survival of patients treated with cryoablation combined with chemo or immunotherapy was longer than treatment consisting of chemo or immunotherapy alone (18 and 17 months vs 8.5 and 12 months). The overall survival in patients that received the triple combination therapy (cryoablation, immunotherapy and chemotherapy) was significantly longer (27 months) compared to other groups [82].

These studies show positive results for the combination of cryoablation and stimulants to the immune system, NK cell therapy or DC-CIK, with 
improvement in survival. Clinical results are expected from a phase II study where cryoablation is combined with an immune checkpoint inhibitor [83, 84].

\section{Melanoma}

Cryoablation is used for the treatment of benign superficial lesions, such as actinic keratosis, but it is not indicated as a treatment for primary melanoma. Only in unresectable lesions with high metastatic load, cryoablation may diminish tumour load by ablation of the primary site $[85,86]$. The treatment of melanoma metastasis can be performed with cryoablation to slow down the rate of tumour spread $[87,88]$.

In metastatic mouse models, combinations with different immunostimulants (including TLR 9 and CPG) have shown an enhanced effect of cryoablation for suppression of new tumour growth [26, 89-91]. A pilot study observed the induction of endogenous heat-shock protein after administration of GM-CSF and radiofrequency ablation or cryoablation in metastatic melanoma patients, with a small number of subjects demonstrating the combination therapy as a feasible and safe therapeutic option [92].

The combination of cryoablation and immunotherapy may be beneficial in the metastatic stetting to overcome the limitations of the immunotherapy. Currently, two trials are open combining immunotherapy and cryoablation (Table 3).

\section{CONCLUSION}

Cryoablation has proven to be successful for local control in various cancer types. Mostly, it is indicated for tumours at an early stage or those not eligible for surgery. The synergies of local ablative techniques together with systemic treatments are currently one of the most exciting developments of interventional oncology. Particularly, given that cryoablation provides a pool of antigens visible for the immune system to induce an immune-specific activation directed against the tumour cells.

In this review, a total of 41 out of 45 publications show favourable effects for cryoablation when combined with other therapies, potentially enhancing the anti-cancer immune response. This emphasises the potential advantage of this ablation technique as an adjunct with immunotherapy. RCC and NSCLC are the neoplasms where cryoablation and its synergy with immunotherapy are predominantly studied. Both, immunostimulants for the innate and adaptive immune system demonstrate feasibility and effectiveness. For the translation 
of the results seen in animals and small groups of patients, larger prospective trials need to be designed to first study safety and efficacy before moving into randomized controlled settings.

In the next 5 years, several pilot, phase I and early II clinical trials currently in place will demonstrate whether or not the combination of cryoablation and the immune system will have a true beneficial effect. This benefit can come from two different approaches that is first the contribution of cryoablation to immunological systemic effect of immunotherapy. Second, the impact of immunotherapy to overcome the limitations of cryoablation related to the upregulation of PD-L1. The features of imaging and molecular biomarkers, such as PD-L1 and others will help to optimise the combination strategies.

Furthermore, the strategy of combining cryoablation with new therapeutic options (specifically DC vaccine, CAR T cells, oncolytic viruses and adoptive $T$ cell transfer) will provide a broader scale of immune-boosting therapies that will hopefully translate into the clinics and may thereby provide even better outcomes when combined with cryoablation. 


\section{References}

1. Cazzato RL, Garnon J, Ramamurthy N, Koch G, Tsoumakidou G, Caudrelier J et al. Percutaneous image guided cryoablation: current applications and results in the oncologic field. Med Oncol. 2016;33(12):140.

2. Baust JG, Gage AA. Progress toward optimization of cryosurgery. Technol Cancer Res Treat. 2004;3(2):95-101

3. Mues AC, Landman J. Results of kidney tumor cryoablation: renal function preservation and oncologic efficacy. World J Urol. 2010;28(5):565-570.

4. Chehab M, Friedlander JA, Handel J, Vartanian S, Krishnan A, Wong CY et al. Percutaneous cryoablation vs partial nephrectomy: cost comparison of T1a tumors. J Endourol. 2016; 30(2):170-176.

5. van Amerongen MJ, Jenniskens SFM, van den Boezem PB, Fütterer JJ, de Wilt JHW. Radiofrequency ablation compared to surgical resection for curative treatment of patients with colorectal liver metastases - a metaanalysis. HPB (Oxford). 2017;19(9):749-756.

6. Rivero JR, De La Cerda J 3rd, Wang H, Liss MA, Farrell AM, Rodriguez R et al. Partial nephrectomy versus thermal ablation for clinical stage T1 renal masses: systematic review and meta-analysis of more than 3,900 patients. J Vasc Interv Radiol. 2018;29(1):18-29.

7. Jansen MC, van Hillegersberg R, Schoots IG, Levi M, Beek JF, Crezee H et al. Cryoablation induces greater inflammatory and coagulative responses than radiofrequency ablation or laser induced thermotherapy in a rat liver model. Surgery. 2010;147(5):686-695.

8. Chu KF, Dupuy DE. Thermal ablation of tumours: biological mechanisms and advances in therapy. Nat Rev Can 14. 2014; (3):199-208.

9. Cooper AJ, Fraser JD, Maclver. A Host responses to cryoablation of normal kidney and liver tissue. Br J Exp Pathol. 1978; 59(1):97-104.

10. Shulman S, Brandt EJ, Yantorno C. Studies in cryo-immunology. II Tissue and species specificity of the autoantibody response and comparison with iso-immunization. Immunology 1968; 14(2):149-158.

11. Ablin RJ. Cryoimmunotherapy. Br Med J. 1972;3:476.

12. Mole $\mathrm{RH}$. Whole body irradiation; radiobiology or medicine? $\mathrm{Br} \mathrm{J}$ Radiol. 1953;26(305):234-241.

13. Soule E, Bandyk M, Matteo J. Percutaneous ablative cryoimmunotherapy for micrometastaic abscopal effect: No complications. Cryobiology. 2018;82:22-26.

14. Matzinger P. Tolerance, danger, and the extended family. Annu Rev Immunol. 1994;12:991-1045.

15. Skoberne M, Beignon AS, Bhardwaj N. Danger signals: a time and space continuum. Trends Mol Med. 2004;10(6):251-257.

16. Sabel MS. Cryo-immunology: a review of the literature and proposed mechanisms for stimulatory versus suppressive immune responses. Cryobiology. 2009;58(1):1-11.

17. Chan JK, Roth J, Oppenheim JJ, Tracey KJ, Vogl T, Feldmann M et al. Alarmins: awaiting a clinical response. J Clin Invest 2012;122(8):2711-2719

18. Basu S, Binder RJ, Suto R, Anderson KM, Srivastava PK. Necrotic but not apoptotic cell death releases heat shock proteins, which deliver a partial maturation signal to dendritic cells and activate the NF-kappa B pathway. Int Immunol. 2000;12(11):1539-1546.

19. Sabel MS, Su G, Griffith KA, Chang AE. Rate of freeze alters the immunologic response after cryoablation of breast cancer. Ann Surg Oncol. 2010;17(4):1187-1193. 
20. Ahmad F, Gravante G, Bhardwaj N, Strickland A, Basit A, West K et al. Changes in interleukin-1 $\beta$ and 6 after hepatic microwave tissue ablation compared with radiofrequency, cryotherapy and surgical resections. Am J Surg 2010;200(4):500-506.

21. Sadikot RT, James Wudel L, Jansen DE, Debelak JP, Yull FE, Christman JW et al. Hepatic cryoablationinduced multisystem injury: bioluminescent detection of NF-KB activation in a transgenic mouse model. J Gastrointest Surg. 2002; 6(2):264-270.

22. Seifert JK, France MP, Zhao J, Bolton EJ, Finlay I, Junginger T et al. Large volume hepatic freezing: association with significant release of the cytokines interleukin- 6 and tumor necrosis factor a in a rat model. World J Surg. 2002;26(11):1333-1341.

23. Vroomen LGPH, Petre EN, Cornelis FH, Solomon SB, Srimathveeravalli G. Irreversible electroporation and thermal ablation of tumors in the liver, lung, kidney and bone: what are the differences? Diagn Interv Imaging. 2017;98(9):609-617.

24. Niu LZ, Li JL, Zeng JY, Feng M, Liao MT, Yao F et al. Combination treatment with comprehensive cryoablation and immunotherapy in metastatic hepatocellular cancer. World J Gastroenterol. 2013;19(22):3473-3480.

25. Lin M, Liang S, Wang X, Lian Y, Zhang M, Chen J et al. Cryoablation combined with allogenic natural killer cell immunotherapy improves the curative effect in patients with advanced hepatocellular cancer. Oncotarget. 2017;8(47):81967-81977.

26. den Brok MH, Sutmuller RP, Nierkens S, Bennink EJ, Frielink C, Toonen LW et al. Efficient loading of dendritic cells following cryo and radiofrequency ablation in combination with immune modulation induces anti-tumour immunity. $\mathrm{Br} \mathrm{J}$ Cancer. 2006;95(7):896-905.

27. Takaki H, Imai N, Thomas CT, Yamakado K, Yarmohammadi H, Ziv E et al. Changes in peripheral blood T-cell balance after percutaneous tumor ablation. Minim Invasive Ther Allied Technol. 2017;26(6):331-337.

28. Zeng Z, Shi F, Zhou L Zhang MN, Chen Y, Chang XY et al. Upregulation of circulating PD-L1/PD-1 is associated with poor post-cryoablation prognosis in patients with HBVrelated hepatocellular carcinoma. PLoS One. 2011;6(9):e23621.

29. Waitz R, Solomon SB, Petre EN, Trumble AE, Fasso M, Norton L et al. Potent induction of tumor immunity by combining tumor cryoablation with anti-CTLA-4 therapy. Cancer Res. 2012; 72(2):430-439

30. Bea VJ, Black D, Hunt K. Percutaneous ablation in the treatment of breast cancer. In: Howard-McNatt M (eds) Changing Paradigms in the Management of Breast Cancer. Springer 2018, Cham, pp 71-84

31. Simmons RM, Ballman KV, Cox C, Carp N, Sabol J, Hwang RF et al. A phase II trial exploring the success of cryoablation therapy in the treatment of invasive breast carcinoma:results from ACOSOG (Alliance) Z1072. Ann Surg Oncol. 2016;23(8):2438-2445

32. Pusceddu C, Melis L, Ballicu N, Meloni P, Sanna V, Porcu A et al. Cryoablation of primary breast cancer in patients with metastatic disease: considerations arising from a single-centre data analysis. Biomed Res Int. 2017;2017:3839012.

33. Miles D, Andre F, Gligorov J, Verma S, Xu B, Cameron et al. IMpassion131: phase III study comparing $1 \mathrm{~L}$ atezolizumab with paclitaxel vs placebo with paclitaxel in treatmentnaive patients with inoperable locally advanced or metastatic triple negative breast cancer (mTNBC). Ann Oncol. 2017;28(Suppl 5):105

34. Nakasone ES, Hurvitz SA, McCann KE. Harnessing the immune system in the battle against breast cancer. Drugs Context. 2018;12(7):212520.

35. Sabel MS, Nehs MA, Su G, Lowler KP, Ferrara JL, Chang AE. Immunologic response to cryoablation of breast cancer. Breast Cancer Res Treat. 2005;90(1):97-104 
36. Veenstra JJ, Gibson HM, Littrup PJ, Reyes JD, Cher ML, Takashima A et al. Cryotherapy with concurrent $\mathrm{CpG}$ oligonucleotide treatment controls local tumor recurrence and modulates HER2/neu immunity. Cancer Res. 2014;74(19):5409-5420

37. McArthur HL, Diab A, Page DB, Yuan J, Solomon SB, Sacchini V et al. A pilot study of preoperative single dose ipilimumab and/or cryoablation in women with early-stage breast cancer with comprehensive immune profiling. Clin Cancer Res. 2016;22(23):5729-5737

38. Page DB, Yuan J, Redmond D, Wen YH, Durack JC, Emerson R et al. Deep sequencing of T-cell receptor DNA as a biomarker of clonally expanded TILs in breast cancer after immunotherapy. Cancer Immunol Res. 2016;4(10):835-844

39. US National Library of Medicine. NCT03546686. In: ClinicalTrials.gov. https:// clinicaltrials.gov/ct2/show/NCT03546686. Accessed 27 July 2018

40. Liang S, Niu L, Xu K, Wang X, Lian $Y$ et al. Tumor cryoablation in combination with natural killer cells therapy and herceptin in patients with HER2-overexpressing recurrent breast cancer. Mol Immunol. 2017;92:45-53

41. Niu L, Mu F, Zhang C, Li Y, Liu W, Jiang F et al. Cryotherapy protocols for metastatic breast cancer after failure of radical surgery. Cryobiology. 2013;67(1):17-22

42. U.S. National Library of Medicine US National Library of Medicine. NCT02833233. In: ClinicalTrials.gov. https://clinicaltrials.gov/ct2/show/NCT02833233?term=cryoablation \&cond=breast+cancer\&rank=3. Accessed 16 June 2018

43. Increased Frequency of AlloStim(TM) Dosing in Combination With Cryoablation in Metastatic Breast Cancer Patients - Full Text View - ClinicalTrials.gov. https://clinicaltrials. gov/ct2/show/NCT02018419? term=cryoablation\&cond=breast+cancer\&rank $=6$. Accessed 16 Mar 2018.

44. Uhlig A, Hahn O, Strauss A, Lotz J, Trojan L et al. Treatment for Localised T1a clear cell renal cell carcinoma: survival benefit for cryosurgery and thermal ablation compared to deferred therapy. Cardiovasc Intervent Radiol. 2018;41(2):277-283.

45. Breen DJ, King AJ, Patel N, Lockyer R, Hayes M. Image-guided cryoablation for sporadic renal cell carcinoma: three- and 5-year outcomes in 220 patients with biopsyproven renal cell carcinoma. Radiology. 2018;289(2):554-561.

46. Xing M, Kokabi N, Zhang D, Ludwig JM, Kim HS. Comparative effectiveness of thermal ablation, surgical resection, and active surveillance for T1a renal cell carcinoma: a surveillance, epidemiology, and end results (SEER)-Medicare-linked population study. Radiology. 2018;288(1):81-90.

47. Choueiri TK, Hessel C, Halabi S, Sanford B, Michaelson MD, Hahn O et al. Cabozantinib versus sunitinib as initial therapy for metastatic renal cell carcinoma of intermediate or poor risk (Alliance A031203 CABOSUN randomised trial): progression-free survival by independent review and overall survival update. Eur J Cancer. 2018;94:115-125.

48. Ross K, Jones RJ. Immune checkpoint inhibitors in renal cell carcinoma. Clin Sci (Lond). 2017; 131(21):2627-2642.

49. Matin SF, Sharma P, Gill IS, Tannenbaum C, Hobart MG, Novick AC et al. Immunological response to renal cryoablation in an in vivo orthotopic renal cell carcinoma murine model. J Urol. 2010;183(1):333-338.

50. Kim HK, Pyun JH, Cho S, Kang SG, Lee JG, Kim JJ et al. Tumor-specific immunity induced by cryoablation in a murine renal cell carcinoma model. Korean J Urol. 2014 Dec; 55(12):834-840.

51. Kato $T$, Iwasaki $T$, Uemura $M$, Nagahara A, Higashihara $H$, Osuga $K$ et al. Characterization of the cryoablation-induced immune response in kidney cancer patients. Oncoimmunology. 2017;6(7):e1326441. 
52. Thakur A, Littrup P, Paul EN, Adam B, Heilbrun LK, Lum LG. Induction of specific cellular and humoral responses against renal cell carcinoma after combination therapy with cryoablation and granulocyte-macrophage colony stimulating factor: a pilot study. J Immunother. 2011;34(5):457-467.

53. Lin M, Xu K, Liang S, Wang X, Liang Y, Zhang M et al. Prospective study of percutaneous cryoablation combined with allogenic NK cell immunotherapy for advanced renal cell cancer. Immunol Lett. 2017;184:98-104.

54. Pilot Study of Presurgical Tremelimumab With or Without Cryoablation in Patients With Metastatic Renal Cell Carcinoma (RCC) - Full Text View - ClinicalTrials.gov. https:/l clinicaltrials.gov/ct2/show/NCT02626130. Accessed 19 Mar 2018.

55. US National Library of Medicine. NCT02843607. In: ClinicalTrials.gov. https:// clinicaltrials.gov/ct2/show/NCT02843607. Accessed 27 July 2018.

56. Tay KJ, Tsivian M, Polascik TJ (2017) Prostate cryotherapy. In: Hughes S (eds) Management Management of prostate cancer. Springer, Cham, pp 273-285

57. Schepisi G, Farolfi A, Conteduca V, Martignano F, De Lisi D, Ravaglia G et al. Immunotherapy for prostate cancer: where we are headed. Int J Mol. 2017;18(12):2627.

58. Beer TM, Kwon ED, Drake CG, Fizazi K, Logothetis C, Gravis G, et al. Randomized, double-blind, phase III trial of Ipilimumab versus placebo in asymptomatic or minimally symptomatic patients with metastatic chemotherapy-naive castrationresistant prostate cancer. J Clin Oncol. 2017;35(1):40-47.

59. Hansen AR, Massard C, Ott PA, Haas NB, Lopez JS, Ejadi S et al. Pembrolizumab for advanced prostate adenocarcinoma: findings of the KEYNOTE-028 study. Ann Oncol. 2018;29(8):1807-1813.

60. Kwon ED, Drake CG, Scher HI, Fizazi K, Bossi A, van den Eertwegh AJ et al. Ipilimumab versus placebo after radiotherapy in patients with metastatic castration-resistant prostate cancer that had progressed after docetaxel chemotherapy (CA184-043): a multicentre, randomised, double-blind, phase 3 trial. Lancet Oncol. 2014;15(7):700-712.

61. Li F, Guo Z, Yu H, Zhang X, Si T, Liu C et al. Anti-tumor immunological response induced by cryoablation and anti-CTLA-4 antibody in an in vivo RM-1 cell prostate cancer murine model. Neoplasma 2014;61(6):659-671.

62. Benzon B, Glavaris SA, Simons BW, Hughes RM, Ghabilli K, Mullane P et al. Combining immune checkpoint blockade and cryoablation in an immunocompetent hormone sensitive murine model of prostate cancer. Prostate Cancer Prostatic Dis. 2018;21(1):126-136.

63. Si TG, Wang JP, Guo Z. Analysis of circulating regulatory T cells (CD4+CD25+CD127-) after cryosurgery in prostate cancer. Asian J Androl. 2013;15(4):461-465.

64. Si T, Guo Z, Hao X. Immunologic response to primary cryoablation of high-risk prostate cancer. Cryobiology. 2008;57(1):66-71.

65. Si T, Guo Z, Hao X. Combined cryoablation and GM-CSF treatment for metastatic hormone refractory prostate cancer. J Immunother. 2009;32(1):86-91.

66. Si T, Guo Z, Yang X, Zhang W, Xing W. The oncologic results of cryoablation in prostate cancer patients with bone metastases. Int J Hyperthermia. 2018 Nov;34(7):1044-148.

67. US National Library of Medicine. NCT03331367. In: clinicaltrials.gov. https://clinicaltrials. gov/ct2/show/NCT03331367?cond=NCT03331367\&rank=1. Accessed 19 Mar 2018

68. US National Library of Medicine. NCT02489357. In: Clinicaltrials.gov. https:// clinicaltrials.gov/ct2/show/NCT02489357?cond=NCT02489357\&rank=1. Accessed 19 Mar 2018

69. US National Library of Medicine. NCT02250014. In: clinicaltrials.gov. https://clinicaltrials. gov/ct2/show/NCT02250014?cond=NCT02250014\&rank=1. Accessed 19 Mar 2018 
70. US National Library of Medicine. NCT02423928. In: Clinicaltrials.gov. https:// clinicaltrials.gov/ct2/show/NCT02423928?cond=NCT02423928\&rank=1. Accessed 19 Mar 2018

71. de Baere T, Tselikas L, Woodrum D, Abtrin F, Littrup P, Deschamps F, Suh R et al. Evaluating cryoablation of metastatic lung tumors in patients--safety and efficacy: the ECLIPSE trial-interim analysis at 1 year. J Thorac Oncol. 2015;10(10):1468-1474.

72. Moore $\mathrm{W}$, Talati $\mathrm{R}$, Bhattacharji $\mathrm{P}$, Bilfinger $\mathrm{T}$. Five-year survival after cryoablation of stage I non-small cell lung cancer in medically inoperable patients. J Vasc Interv Radiol. 2015;26(3):312-319.

73. Lee KS, Erinjeri JP. Decision making in interventional oncology: ablative options in the lung. Semin Intervent Radiol. 2017;34(2):176-181.

74. Mouli SK, Kurilova I, Sofocleous CT, Lewandowski RJ. The role of percutaneous image-guided thermal ablation for the treatment of pulmonary malignancies. AJR Am J Roentgenol. 2017;209(4):740-751.

75. Lyu GY, Yeh YH, Yeh YC, Wang YC. Mutation load estimation model as a predictor of the response to cancer immunotherapy. NPJ Genom Med. 2018;30;3:12.

76. Machlenkin A, Goldberger O, Tirosh B, Paz A, Volovitz I, Bar-Haim E et al. Combined dendritic cell cryotherapy of tumor induces systemic antimetastatic immunity. Clin Cancer Res. 2005;11(13):4955-4961

77. Alteber Z, Azulay M, Cafri G, Vadai E, Tzehoval E, Eisenbach L. Cryoimmunotherapy with local coadministration of ex vivo generated dendritic cells and CpG-ODN immune adjuvant, elicits a specific antitumor immunity. Cancer Immunol Immunother. 2014;63(4):369-380.

78. Zhang M, Yin T, Lu Y, Feng H. The application of cytidyl guanosyl oligodeoxynucleotide can affect the antitumor immune response induced by a combined protocol of cryoablation and dendritic cells in Lewis lung cancer model. Med Sci Monit. 2016; 22:1309-1317.

79. Takahashi Y, Izumi Y, Matsutani N, Dejima H, Nakayama T, Okamura R et al. Optimised magnitude of cryosurgery facilitating anti-tumor immunoreaction in a mouse model of Lewis lung cancer. Cancer Immunol Immunother. 2016;65(8):973-982.

80. Lin M, Liang SZ, Wang XH, Liang YQ, Zang MJ, Niu LZ et al. Clinical efficacy of percutaneous cryoablation combined with allogenic NK cell immunotherapy for advanced non-small cell lung cancer. Immunol Res. 2017;65(4):880-887.

81. Gu XY, Jiang Z, Fang W. Cryoablation combined with molecular target therapy improves the curative effect in patients with advanced nonsmall cell lung cancer. J Int Med Res. 2011;39(5):1736-1743.

82. Yuanying Y, Lizhi N, Feng M, Xiaohua W, Jianying Z, Fei $Y$ et al. Therapeutic outcomes of combining cryotherapy, chemotherapy and DC-CIK immunotherapy in the treatment of metastatic non-small cell lung cancer. Cryobiology. 2013;67(2):235-240.

83. BrUOG 317:Nivolumab and Ablation For Patients With Advanced Non-Small Cell Lung Cancer Progressing After at Least One Prior Therapy For Metastatic Disease - Full Text View - ClinicalTrials.gov. https://clinicaltrials.gov/ct2/show/NCT02469701. Accessed 5 Nov 2018.

84. US National Library of Medicine. NCT03290677. In:clinicaltrials.gov.https:// clinicaltrials.gov/ct2/show/NCT03290677?term=cryoablation+and+immune\&cond =Lung+Cancer\&rank=1. Accessed 5 Nov 2018.

85. Abramovits W, Graham G, Har-Shai Y, Strumia R (2016) Dermatological Cryosurgery and Cryotherapy. 1st ed. 2016 Springer. 
86. Tanaka S (2001) Cryosurgery for malignant melanoma. In: Korpan NN (eds) Basics of cryosurgery. Springer, Vienna, pp 289-293

87. Joosten JJ, Muijen GN, Wobbes T, Ruers TJ. In vivo destruction of tumor tissue by cryoablation can induce inhibition of secondary tumor growth: an experimental study. Cryobiology. 2001;42:49-58.

88. Rivoire M, De Cian F, Meeus P, Gignoux B, Fréring B, Kaemmerlen Pl. Cryosurgery as a means to improve surgical treatment of patients with multiple unresectable liver metastases. Anticancer Res. 2000;20(5C):3785-3790.

89. Kudo-Saito C, Fuwa T, Kawakami Y. Targeting ALCAM in the cryotreated tumour microenvironment successfully induces systemic antitumour immunity. Eur J Cancer. 2016;62:54-61.

90. den Brok MH, Sutmuller RP, Nierkens S, Bennink EJ, Toonen LWJ, Figdor CG et al. Synergy between in situ cryoablation and TLR9 stimulation results in a highly effective in vivo dendritic cell vaccine. Cancer Res. 2006;66(14):7285-7292.

91. Nierkens S, den Brok MH, Sutmuller RP, Grauer OM, Bennink E, Morgan ME et al. In vivo colocalization of antigen and CpG [corrected] within dendritic cells is associated with the efficacy of cancer immunotherapy. Cancer Res. 2008;68(13):5390-5396.

92. Domingo-Musibay E, Heun JM, Nevala WK, Callstrom M, Atwell T, Galanis E et al. Endogenous heatshock protein induction with or without radiofrequency ablation or cryoablation in patients with stage IV melanoma. Oncologist. 2017;22(9):1026-1e93. 



\section{CHAPTER}

General discussion 
In this thesis, we investigated different interventional oncology (IO) procedures in patients with liver metastatic breast cancer (LMBC) and with renal cell carcinoma (RCC). We aimed to identify factors associated with safety, efficacy and overall survival (OS) to improve treatment stratification in daily clinical practice and to develop further studies.

\section{Part I: Intra-arterial therapies for liver metastatic breast cancer}

Patients with LMBC undergo systemic treatment; chemo- and/or hormonal therapy in receptor-positive patients. The aim is to prolong while maintaining a good quality of life. The expected efficacy of the systemic drugs decreases with subsequent lines of chemotherapy to only $24 \%$ after $3^{\text {rd }}$ line chemotherapy in hormone-positive breast cancer patients [1]. In addition, liver metastases can cause hepatic dysfunction which may affect the efficacy and safety of the systemic chemotherapy [2]. Intra-arterial liver-directed therapies may provide a chemo holiday in patients with progressive disease during several chemotherapeutic lines or can be effective for chemo refractory patients [3].

To date, the role of intra-arterial therapy in LMBC is not clear and is therefore not included in the European Society for Medical Oncology guidelines [4]. This is mainly due to the heterogeneous data in literature as shown in our systemic review in Chapter 2. The included studies showed that the intra-arterial IO therapies were performed at different time points of the disease, with diverse (extra) hepatic tumour burden after various lines of chemotherapy. In literature these factors have all shown to impact OS [5, 6], and therefore comparison between the therapies for LMBC cannot be performed. Given the fact that most patients were chemo refractory after several chemotherapy lines, we can at least deduce that the efficacy rate of intra-arterial therapies in this group is not nihil starting from $8 \%$ up to $100 \%$. However, since there is no randomized controlled data about the efficacy of intra-arterial therapy in LMBC patients, no strong conclusions could be drawn.

In our retrospective evaluation of 176 patients, we showed that intra-arterial therapy by MMC infusion is a safe and effective treatment option in an advanced LMBC group refractory to systemic chemotherapy (Chapter 3). We obtained a local disease control in $58 \%$ of the patients at low toxicities. Two patients showed renal toxicities, however, no hemolytic uremic syndrome occurred among the total of 599 intra-arterial administered MMC infusions. Therefore, we concluded that intra-arterial infusion of MMC is safe. After intra-arterial MMC treatment, $50 \%$ of the treated patients were able to continue their systemic 
treatment, hence, MMC infusion provided a chemo holiday during which the patients could recover from adverse effects of their systemic treatment.

Besides MMC, other intra-arterial chemotherapeutic agents are available. Vogl et al. combined MMC with Gemcitabine and achieved a higher response rate with low-grade adverse events and a longer OS [7]. To note, only $8.3 \%$ of the patients had extra-hepatic disease compared to $73 \%$ in our study in Chapter 3 . Two other studies that combined several chemotherapeutic agents also achieved higher response rates and longer OS compared to our cohort [8, 9], although true comparison is difficult because of the heterogeneity of the data.

We found that patients treated with multiple chemotherapy lines, extended liver disease consisting of a tumour burden $(>50 \%)$ or deteriorated liver function had a worse OS (Chapter 3 ). These results might help to improve patient selection in daily practice to select patients that benefit most from intra-arterial therapy. It should be objectified if patients quality of life (QoL) is indeed better with intraarterial therapy compared to systemic therapy.

Breast cancer is a highly heterogenetic disease with many subtypes and different prognosis, each treated differently. Our work could not identify a type of breast cancer (e.g. hormone positive patients) that would benefit most from intra-arterial therapy. Only in an univariate analysis, triple negative receptor status was significantly associated with a worse OS. Two studies found an association for positive estrogen (ER) receptor status and a lower death risk [10,11]. This is in line with a large study of survival analysis of de novo metastatic breast cancer in which ER and PR positive breast cancer patients had a lower death risk in an adjusted model in over a 10000 patients [12]. Treatment stratification for subgroups of LMBC patients should therefore be a subject of further prospective studies.

We showed that the addition of MMC infusion therapy immediately after trans arterial radioembolization (TARE) was safe without additional adverse events (Chapter 4). However, 30\% of the patients developed extra-hepatic disease progression after this combination treatment. It is therefore debatable whether the sequential intra-arterial therapies of TARE and MMC, would be a valuable treatment combination for LMBC. A more interesting question would be if the combination of intra-arterial and systemic treatment would be more beneficial in terms of local and systemic control compared to solely systemic treatment. 
Martin et al. showed a surprisingly prolonged (47 months) OS in LMBC patients treated with the combined TACE of doxorubicin loaded beads and systemic chemotherapy. This could be the result of lead-bias in which the follow-up of the patients simply started earlier on resulting in a longer OS [13]. Currently, the combination of TARE and systemic chemotherapy is under investigation in a large multicenter randomized controlled trial for patients with CRLM [14]. The results of this trial may be important for further prospective studies to prove whether the combination of intra-arterial and systemic therapy would be beneficial in terms of PFS and OS in LMBC patients.

The main goal for systemic treatment in LMBC patients is to increase survival at tolerable doses and toxicities. With the latter challenges of systemic treatment, the addition of intra-arterial therapy can potentially provide a break in chemotherapy to recover from severe adverse events. Intra-arterial treatment after failure of systemic treatment may provide patients a better local control with better quality of life.

\section{Part II: Percutaneous ablation in renal cell cancer}

The European Association of Urology (EAU) guidelines for RCC recommends partial nephrectomy (PN) as first-line treatment for stage T1 disease. Candidates less optimal for surgery could be considered for minimal invasive IO therapies such as percutaneous ablation [15]. Available literature comparing percutaneous ablation with PN contain a high selection bias, in which the elderly are selected for ablation, which potentially skews towards a lower survival [16]. Several RCT's are running comparing ablation with PN [46].

In contrast to surgery for renal masses, after percutaneous ablation no specimen is available after the procedure to confirm malignancy and to prove complete eradication of the tumour with free margins. Therefore a renal mass biopsy (RMB) before or during the ablation procedure is needed. In Chapter 5 , we showed that RMB performed during a separate session from the ablation session reduces overtreatment in patients with a renal mass. Others evaluated the performance of an RMB either before or during the ablation, but included patients who all underwent ablations and no changes in clinical management could be reported $[17,18]$. In our cohort we included all patients planned for ablation, treated or non-treated. We found that up to $80 \%$ of the patients with a biopsy proven benign renal mass chose not to proceed to the ablative therapy. Hence, performing an RMB in a separate session before the ablation provides an opportunity for the physician to inform the patient on the benefits and risks and facilitates a shared decision making. In addition, such a regimen resulted 
in unnecessary treatment in $32.5 \%$ of the patients. Potential overtreatment of benign renal masses is of great concern in comorbid patients with higher mortality risk due to causes other than their benign renal mass.

Compared to radiofrequency ablation (RFA), microwave ablation (MWA) achieves higher energies from a single probe and is therefore less influenced by the heat sink effect [19]. The heat sink effect is the influence of nearby blood vessels that lower the temperature within the ablation zone and decrease the efficacy [20]. In chapter 6 , we concluded that MWA is a safe and effective ablation technique for CT1 RCC with a significantly lower efficacy and safety for cT1b tumours compared to cT1a tumours. We showed that the tumour size and location in proximity to the collecting system, indicated as the modified R.E.N.A.L. nephrometry score, influenced oncological outcome after MWA.

Smaller exophytic lesions showed excellent efficacy and safety rates after MWA, which is in line with the available evidence [21]. Recurrence after ablation can occur late (Chapter 6), therefore extensive follow-up is required by consecutive imaging using contrast enhanced computed tomography (CT), which is less ideal in younger patients. Younger patients should therefore best be treated with surgery.

Lower efficacy rates of percutaneous ablation are described for tumours over $4 \mathrm{~cm}$ which is in line with our findings [22]. Our cohort contained large lesions at challenging locations, e.g. nearby the collecting system, which were treated with MWA as last treatment option. We experienced that MWA for large lesions was feasible, but since $50 \%$ had residual disease a second ablative treatment following MWA should be considered beforehand.

Shapiro et al. compared MWA with partial or radical nephrectomy in T1b tumours and MWA was 95\% effective and recurred in 5\% [23]. An important difference is that the new MW system was used in Shapiro's study, the NeuWave system, in which multiple probes can be placed at once leading to a synergistically improved development of the ablation zone compared to placement of each probe on its own. Future studies have to prove whether the NeuWave is indeed superior to the standard MW system taken the tumour size, location and physician experience into account.

During cryoablation (CA), multiple probes can be used to develop a large ablation zone resulting in tumour control in lesions up to $7 \mathrm{~cm}$ [24]. Several reports also suggest that $\mathrm{CA}$ protects the renal collecting system in a greater 
extent than RFA and MWA, whereby ablation of endophytic lesions is possible without major adverse events [25, 26]. Since April 2018 we have a CA system available in our hospital, which gave us the opportunity to re-ablate patient using a different ablation technique if MWA fails. In Chapter 7 we showed that $\mathrm{CA}$ is feasible after failure of MWA in endophytic lesions with complete ablation achieved in eight out of nine patients with only two minor adverse events in this complex tumours. During a follow-up of at least one year, $66 \%$ of our patients remained disease free. Therefore CA offered a nephron sparing minimal invasive treatment in this group of patients for whom radical nephrectomy can be avoided.

From an extensive literature review of CA and immunotherapy in Chapter 8 , we found that most preclinical reports suggest that $C A$ induced a systemic immune effect and enhance immunotherapies, also called the abscopal effect. However, limited data was available in humans and more studies are necessary to prove this benefit. If proven promising, an abscopal effect of CA when combined with immunotherapy, could be a way to overcome immune suppression and to increase efficacy of immunotherapy in advanced disease, potentially increasing OS. With the increasing evidence of effective immunotherapy both in adjuvant and neoadjuvant setting it will be interesting to see whether or not CA will have a role in immunotherapy and future studies are needed.

\section{Conclusions:}

This thesis shows the safety and efficacy for interventional oncology procedures in LMBC patients and patients with RCC.

We showed that intra-arterial therapy by MMC infusion is safe and effective in an advanced LMBC group refractory to systemic chemotherapy. With the challenges of systemic chemotherapy regarding toxicity and efficacy, the addition of intra-arterial therapy may be a promising step to provide a break during the systemic treatment (chemo-holiday) or serve as treatment option in chemo refractory LMBC. Patients treated after several lines of chemotherapy, with extended liver disease, a tumour burden of over $50 \%$ or deteriorated liver function, had a poor OS. A sequential treatment of TARE and intra-arterial MMC infusion is feasible in LMBC patients, but we believe that this is not the best treatment regimen due to observed progression of extra-hepatic disease in $30 \%$. A combination of intra-arterial therapy with systemic therapy could perhaps be more beneficial and should be a subject of future studies in LMBC. 
Percutaneous ablation is an effective alternative treatment to partial nephrectomy (PN) in T1a RCC with minimal adverse events. Several RCT's are running to prospectively compare ablation with $\mathrm{PN}$. We showed that performance of a renal mass biopsy (RMB) during a separate session before the ablation procedure can reduce overtreatment of patients with benign masses. MWA is a safe and effective ablation technique for CT1a RCC, however, a significantly lower efficacy and safety was found for cT1b. Additionally, we showed that the tumour size and location (proximity to the renal collecting system) of the tumour indicated as the mRENAL nephrometry score, influenced oncological outcome after MWA. CA was feasible after failure of MWA in endophytic lesions and resulted in complete ablation in $66 \%$ of the patients with these challenging tumours.

This thesis also stresses the need for high-level evidence for Interventional Oncology procedures to understand its position within the spectrum of local therapies such as surgery and external beam irradiation. Collaboration with other disciplines is essential in a multidisciplinary approach to select the best treatment. Ideally, RCT's comparing the different treatment modalities are necessary to provide high evidence data regarding efficacy and survival of the treatments, although remain a challenge because of the relatively small sample sizes, heterogeneity in patients and in treatments. Prospective registries and cohort studies have in the mean-time to function as the best ways to learn from these therapies.

\section{Recommendations:}

Based on our work and in the context of available evidence, we have the following recommendations for clinical practice:

In advanced LMBC patients, progressive after multiple lines of systemic chemotherapy, MMC infusion could be considered as a local treatment to provide a chemo holiday.

Intra-arterial therapy can be considered as treatment option in chemo-refractory LMBC patients.

Patients with a renal mass planned for percutaneous ablation should undergo biopsy in a separate session prior to the ablation to confirm malignancy. 
Partial Nephrectomy (PN) remains the standard treatment for T1 RCC. However patients less eligible for PN could be referred for percutaneous ablation.

For patients with a peripheral T1a RCC, MWA should be considered as upfront treatment. Because of the increased risk of incomplete ablation with MWA, especially in large and central tumours, sub sequent completion therapy such as cryoablation or surgery should be taken into consideration. 


\section{References}

1. Park IH, Lee KS, Ro J. Effects of second and subsequent lines of chemotherapy for metastatic breast cancer. Clin Breast Cancer. 2015;15(1):e55-62.

2. Agarwal K, Jones DE, Burt AD, Hudson M, James OF. Metastatic breast carcinoma presenting as acute liver failure and portal hypertension. Am J Gastroenterol. 2002;97(3):750-1.

3. Gordon AC, Uddin OM, Riaz A, Salem R, Lewandowski RJ. Making the case: intraarterial therapy for less common metastases. Semin Intervent Radiol. 2017;34(2):132-9.

4. Cardoso F, Senkus E, Costa A, Papadopoulos E, Aapro M, Andre F, et al. 4th ESOESMO International Consensus Guidelines for Advanced Breast Cancer (ABC 4) dagger. Ann Oncol. 2018;29(8):1634-57.

5. Liu L, Chen F, Zhao J, Yu H. Correlation between overall survival and other endpoints in metastatic breast cancer with second- or third-line chemotherapy: Literature-based analysis of 24 randomized trials. Bull Cancer. 2016;103(4):336-44.

6. Bonotto M, Gerratana L, lacono D, Minisini AM, Rihawi K, Fasola G, et al. Treatment of metastatic breast cancer in a real-world scenario: is progression-free survival with first line predictive of benefit from second and later lines? Oncologist. 2015;20(7):719-24.

7. Vogl TJ, Zangos S, Eichler K, Selby JB, Bauer RW. Palliative hepatic intraarterial chemotherapy (HIC) using a novel combination of gemcitabine and mitomycin C: results in hepatic metastases. Eur Radiol. 2008;18(3):468-76.

8. Hsiao JH, Chang HT, Tseng YD, Chiang CL, Chen IS, Chen YC, et al. Hepatic arterial infusion chemotherapy is a feasible treatment option for breast cancer with liverpredominant metastatic disease. In Vivo. 2018;32(6):1635-41.

9. Tsimberidou AM, Vaklavas C, Fu S, Wen S, Lim JA, Hong D, et al. Hepatic arterial infusion therapy in advanced cancer and liver-predominant disease: the MD Anderson Experience. Hepato-Gasteroenterol. 2013;60(127):1611-23.

10. Chang J, Charalel R, Noda C, Ramaswamy R, Kim SK, Darcy M, et al. Liver-dominant breast cancer metastasis: a comparative outcomes study of chemoembolization versus radioembolization. Anticancer Res. 2018;38(5):3063-8.

11. Duan XF, Dong NN, Zhang T, Li Q. The prognostic analysis of clinical breast cancer subtypes among patients with liver metastases from breast cancer. Int $\mathrm{J}$ Clin Oncol. 2013;18(1):26-32.

12. Eng LG, Dawood S, Sopik V, Haaland B, Tan PS, Bhoo-Pathy N, et al. Ten-year survival in women with primary stage IV breast cancer. Breast Cancer Res Treat. 2016;160(1):145-52.

13. Martin RC, Robbins K, Fages JF, Romero FD, Rustein L, Tomalty D, et al. Optimal outcomes for liver-dominant metastatic breast cancer with transarterial chemoembolization with drug-eluting beads loaded with doxorubicin. Breast Cancer Res Treat. 2012;132(2):753-63.

14. Chauhan N, Mulcahy MF, Salem R, Benson lii AB, Boucher E, Bukovcan J, et al. TheraSphere Yttrium-90 Glass microspheres combined with chemotherapy versus chemotherapy alone in second-line treatment of patients with metastatic colorectal carcinoma of the liver: protocol for the epoch phase 3 randomized clinical trial. JMIR Research Protocols. 2019;8(1):e11545.

15. Ljungberg B, Albiges L, Abu-Ghanem Y, Bensalah K, Dabestani S, Fernandez-Pello $\mathrm{S}$, et al. European Association of Urology Guidelines on Renal Cell Carcinoma: The 2019 Update. Eur Urol. 2019;75(5):799-810. 
16. Abu-Ghanem Y, Fernandez-Pello S, Bex A, Ljungberg B, Albiges L, Dabestani S, et al. Limitations of available studies prevent reliable comparison between tumour ablation and partial nephrectomy for patients with localised renal masses: a systematic review from the european association of urology renal cell cancer guideline panel. Eur Urol Oncol. 2020.

17. Wells SA, Wong VK, Wittmann TA, Lubner MG, Best SL, Ziemlewicz TJ, et al. Renal mass biopsy and thermal ablation: should biopsy be performed before or during the ablation procedure? Abdom Radiol (NY). 2017;42(6):1773-80.

18. Tsang Mui Chung MS, Maxwell AW, Wang LJ, Mayo-Smith WW, Dupuy DE. Should renal mass biopsy be performed prior to or concomitantly with thermal ablation? J Vasc Interv Radiol. 2018;29(9):1240-4.

19. Cornelis FH, Marcelin C, Bernhard JC. Microwave ablation of renal tumors: A narrative review of technical considerations and clinical results. Diagn Interv Imaging. 2017;98(4):287-97.

20. Kim C. Understanding the nuances of microwave ablation for more accurate posttreatment assessment. Future oncology (London, England). 2018;14(17):1755-64.

21. Choi SH, Kim JW, Kim JH, Kim KW. Efficacy and safety of microwave ablation for malignant renal tumors: an updated systematic review and meta-analysis of the literature since 2012. Korean J Radiol. 2018;19(5):938-49.

22. Shakeri S, Afshari Mirak S, Mohammadian Bajgiran A, Pantuck A, Sisk A, Ahuja P, et al. The effect of tumor size and location on efficacy and safety of US- and CTguided percutaneous microwave ablation in renal cell carcinomas. Abdom Radiol (NY). 2019;44(6):2308-15.

23. Shapiro DD, Wells SA, Best SL, Hedican SP, Ziemlewicz TJ, Lubner MG, et al. Comparing outcomes for patients with clinical t1 b renal cell carcinoma treated with either percutaneous microwave ablation or surgery. Urology. 2020;135:88-94.

24. Gunn AJ, Joe WB, Salei A, El Khudari H, Mahmoud KH, Bready E, et al. Percutaneous cryoablation of stage $\mathrm{t} 1 \mathrm{~b}$ renal cell carcinoma: safety, technical results, and clinical outcomes. Cardiovasc Intervent Radiol. 2019;42(7):970-8.

25. Murray CA, Welch BT, Schmit GD, Schmitz JJ, Weisbrod AJ, Callstrom MR, et al. Safety and efficacy of percutaneous image-guided cryoablation of completely endophytic renal masses. Urology. 2019;133:151-6.

26. Makki A, Aastrup MB, Vinter H, Ginnerup B, Graumann O, Borre M, et al. Renal cryoablation - does deep endophytic ablation affect the renal collecting system? Scand J Urol. 2020;54(1):33-9. 
General discussion 

Summary 
The aim of this thesis was to investigate different interventional oncology procedures for the management of local control in liver metastatic breast cancer (LMBC) patients (Part I) and patients with renal cell carcinoma (RCC) (Part II).

\section{Part I: Intra-arterial therapies for liver metastatic breast cancer}

In chapter 2, we performed a systematic review to assess the evidence of intra-arterial therapies in LMBC patients on response rate, adverse events (AEs) and overall survival (OS). We described that the 29 included studies show promising results although high level evidence is lacking. The outcomes differed widely between all studies, due to a pronounced heterogeneity of the patient populations, treatment protocols and response evaluation which impaired direct comparison between the therapies. The combination of an intraarterial therapy and systemic treatment yielded the longest OS, probably due to lead-bias, but suggest the opportunity for the combination of intra-arterial therapy and systemic chemotherapy.

In Chapter 3 we analyzed the safety, efficacy and factors influencing outcome of Mitomycin C (MMC) infusion in 176 heavily pre-treated LMBC patients of the University Hospitals (UZ) Leuven between 2000 and 2017. We showed that hepatic disease control was obtained in $58 \%$ with only $17.5 \%$ AEs grade $\geq 3$ and a median OS of 7.8 months. An increased number of prior therapies, a higher liver tumour burden and elevated levels of bilirubin and ALT were associated with a worse OS. These findings may help to improve patient selection in future studies. Fifty percent of the patients was eligible for systemic therapy after the MMC infusions. We therefore concluded that MMC infusion is a safe and effective treatment option in advanced LMBC patients.

Chapter 4 shows the results of a feasibility study performed in UZ Leuven of the sequential treatment of intra-arterial MMC infusion in four escalating cohorts after selective internal radiation therapy (SIRT) using Yttrium-90 $\left({ }^{90} \mathrm{Y}\right)$ resin microspheres in $\angle M B C$ patients. The sequential treatment was possible in 12 out of the 16 patients with no additional AEs after the escalating MMC infusions. One grade $3 \mathrm{AE}$ occurred after ${ }^{90} \mathrm{Y}$ SIRT and consisted of a gastrointestinal ulcer with consequently exclusion of further MMC infusions. We concluded that sequential treatment of intra-arterial infusion of MMC after ${ }^{90} \mathrm{Y}$ SIRT is feasible when MMC is administrated in different escalating dose cohorts. However, caution is needed to prevent reflux after ${ }^{90} \mathrm{Y}$ SIRT in LMBC patients. 


\section{Part II: Percutaneous ablation in renal cell cancer}

In Chapter 5 the difference between renal mass biopsy (RMB) performed either before or during the ablation procedure was assessed in a multi-center retrospective analysis of 714 patients. Patients that underwent an RMB before the planned ablation with a benign pathology result decided to not undergo the ablation in $80 \%$. Performance of an RMB during the ablation procedure led to potentially unnecessary ablation of renal masses in $32.5 \%$. Performing an RMB before the planned ablation therefore reduces overtreatment and allows patients and physicians to adjust clinical management according to the histological RMB results.

In chapter 6, we evaluated the efficacy and safety of microwave ablation (MWA) in 100 patients with stage $\mathrm{CT} 1$ renal cell carcinoma (RCC). MWA was a safe and effective treatment in cT1a tumours and a significantly lower primary efficacy and safety was found in $\mathrm{cT} 1 \mathrm{~b}$ lesions whereby $48 \%$ of the $\mathrm{T} 1 \mathrm{~b}$ lesions received another treatment for local control. The m.R.E.N.A.L nephrometry score showed a significant independent association with an incomplete ablation. Five patients developed an urinary tract stenosis in central lesions whereby close monitoring of the urinary tract is recommended in ablation of tumours adjacent to the urinary tract.

In Chapter 7, we show the results of nine patients with a renal mass treated by cryoablation (CA) for their residual or recurrent disease after prior MWA. CA showed a complete ablation in 8 patients with only two minor AEs in a cohort of challenging lesions. During a follow-up of at least one year, $66 \%$ of the patients remained disease free and therefore CA offered a minimally invasive nephron sparing treatment option in most patients with the attempt to avoid radical nephrectomy and preservation of kidney function.

In Chapter 8, we reviewed the current evidence of the combination of CA with immunomodulatory drugs (immunotherapy). A total of 41 out of 45 publications show favorable effects for $\mathrm{CA}$ when combined with other therapies, potentially enhancing the anti-cancer immune response. RCC and NSCLC were the neoplasms where CA and its synergy with immunotherapy are predominantly studied. Both, immunostimulants for the innate and adaptive immune system demonstrate feasibility and effectiveness. For the translation of the results seen in animals and small groups of patients, larger prospective trials need to be designed to first study safety and efficacy before moving into randomized controlled settings. 
Het doel van deze thesis was om verschillende oncologische interventie procedures te evalueren op effectiviteit en veiligheid in borstkanker patienten met levermetastasen en niercelcarcinoom. Deel I evalueert verschillende intra-arteriële therapieën voor de behandeling van borstkanker patienten met levermetastasen. In deel II onderzochten wij de rol percutane ablatie in de behandeling van niercelcarcinoom.

\section{Deel I: Intra-arteriële therapieën voor borstkanker patienten met lever- metastasen}

Hoofdstuk 2 geeft een systematisch overzicht weer van de beschikbare literatuur van intra-arteriële therapieën in borstkanker patienten met levermetastasen op de uitkomsten effectiviteit, veiligheid en algemene overleving. Wij concluderen dat de 29 geïncludeerde studies veelbelovende resultaten bevatten, hoewel gerandomiseerd bewijs momenteel ontbreekt. De uitkomsten van de studies waren uiteenlopend met onder andere, heterogene patiënten populaties, behandelprotocollen en respons beoordelingen, waardoor vergelijking niet mogelijk was. De combinatie van een intra-arteriële therapie en systemische behandeling resulteerde in de langste algemene overleving, waarschijnlijk door lead-time bias, echter suggereert dit een potentiële kans voor een succesvolle combinatie therapie.

In hoofdstuk 3 hebben wij de effectiviteit en veiligheid van Mitomycine C (MMC)infusies geanalyseerd in 176 hevig voorbehandelde borstkanker patienten met levermetastasen patiënten in het universiteit ziekenhuis (UZ) Leuven van 2000 2017. De MMC-infusies resulteerden in een lokale ziekte controle van $58 \%$ met slechts graad 3 complicaties of hoger bij $17.5 \%$ en een mediane algemene overleving van 7.8 maanden. Een verhoogd aantal eerdere systemische therapieën, een hogere levertumorbelasting en verhoogd niveau van bilirubine en ALAT waren geassocieerd met een slechtere mediane overleving. Deze bevindingen kunnen bijdragen aan een verbetering in de patiëntenselectie van toekomstige studies. Vijftig procent van de patiënten kwam in aanmerking voor systemische chemotherapie na de MMC-infusies. We concludeerden daarom dat MMC-infusies een veilige en effectieve behandelingsoptie is bij gevorderde lever gemetastaseerd borst kanker patiënten.

Hoofdstuk 4 toont de resultaten van een haalbaarheidsstudie naar de sequentiële behandeling van intra-arteriële MMC-infusies in 4 escalerende cohorten na selectieve interne radiatie therapie (SIRT) met behulp van Yttrium-90 $\left({ }^{90} \mathrm{Y}\right)$ harsmicrosferen in borstkanker patienten met levermetastasen patiënten uitgevoerd in UZ Leuven. De sequentiële behandeling was mogelijk 
in 12 van de 16 patiënten zonder additionele complicaties na escalatie van de MMC infusies. Slechts één graad 3 complicatie trad op na ${ }^{90} Y$ SIRT bestaande uit een maagulcus met als gevolg uitsluiting van verdere MMC-infusies. We concludeerden dat sequentiële behandeling van intra-arteriële infusie van MMC na ${ }^{90} Y$ SIRT haalbaar is wanneer MMC wordt toegediend in verschillende escalerende dosiscohorten. Voorzichtigheid is echter geboden om reflux na ${ }^{90} Y$ SIRT bij borstkanker patienten met levermetastasen te voorkomen.

\section{Deel II: Percutane ablatie voor de behandeling van renaal cel carcinoom} Hoofdstuk 5 analyseert het verschil tussen het uitvoeren van een biopsie vóór of tijdens de ablatieprocedure op overbehandeling en follow-up, in een multicenter retrospectieve analyse van 714 patiënten met een niermassa. Patiënten die vóór de geplande ablatie een biopsie ondergingen met een goedaardig histologisch resultaat, besloten in $80 \%$ de ablatie niet te ondergaan. Biopten tijdens de ablatieprocedure leidden tot een potentieel onnodige ablatie van niermassa's in $32,5 \%$. Het uitvoeren van een biopt vóór de geplande ablatie vermindert daarom overbehandeling en stelt patiënten en artsen in staat de klinische behandeling aan te passen aan de histologische biopsie resultaten.

In hoofdstuk 6 evalueerden we de werkzaamheid en veiligheid van microgolfablatie (MWA) in 100 patiënten met stadium T1 renaal cel carcinoom. MWA was een veilige en effectieve behandeling voor T1a tumoren. Een significant lagere primaire effectiviteit werd gezien in T1b tumoren, waarbij $48 \%$ van de $\mathrm{T} 1 \mathrm{~b}$ tumoren $(>4 \mathrm{~cm})$ nog een additionele behandeling moest ondergaan voor lokale controle. De m.R.E.N.A.L-nefrometrie score toonde een significante onafhankelijke associatie met een onvolledige ablatie. Vijf patiënten met een centrale laesie ontwikkelden een urinewegstenose, met nierfunctie verlies in twee patiënten. Voorzorg is daarom geadviseerd in centrale laesies met een nauwe relatie tot het pyelocalicieel systeem.

Hoofdstuk 7 toont de resultaten van negen patiënten behandeld met cryoablatie (CA) vanwege hun residuele of terugkerende renaal cel carcinoom na het eerder falen van MWA. CA liet een complete ablatie zien in 8 van de 9 patiënten met slechts laaggradige complicaties in een serie met gecompliceerde laesies. Tijdens een follow-up van ten minste één jaar bleef $66 \%$ van de patiënten lokaal ziektevrij. CA bood een minimaal invasieve nefronsparende behandelingsoptie voor de meeste patiënten met als doel een radicale nefrectomie te voorkomen en de nierfunctie te behouden. 
In hoofdstuk 8 hebben we de beschikbare literatuur uiteen gezet over de combinatie van CA met immunomodulerende geneesmiddelen (waaronder immunotherapie). In totaal toonden 41 van de 45 publicaties gunstige effecten voor CA in combinatie met immunomodulerende geneesmiddelen en een versterkend immuunrespons werd gesuggereerd bij de combinatie van CA met immunotherapie. Niercelcarcinoom en niet-kleincellig longcarcinoom waren de kankersoorten waarin CA en de synergie met immunotherapie voornamelijk werd bestudeerd. Immunomodulerende geneesmiddelen voor zowel het aangeboren als adaptieve immuunsysteem toonden haalbaarheid en effectiviteit aan in combinatie met CA. De geïncludeerde studies bestonden vooral uit preklinische studies of zeer kleine klinische studies, waarbij grotere prospectieve onderzoeken nodig zijn om de veiligheid en werkzaamheid aan te tonen voordat deze combinatie in een gerandomiseerde setting kan worden bestudeerd. 



\section{Valorisation}


Since cancer is the second leading cause of death worldwide, research towards improvement of diagnosis and treatment stratification is needed. During the recent years, the treatment of cancer has improved the survival rates of cancer patients tremendously. However, it has been stated that cured cancer patients have a poorer quality of life as a consequence of the late effects of the treatments. Subsequently, minimally invasive treatments with lower morbidity rates have been increasingly adopted as treatment option for cancer care.

Interventional oncology (IO) uses image-guided procedures with the aim to prolong survival and maintain quality of life. During the last decade, IO procedures have frequently been used in clinical practice and are adapted in several international guidelines. 10 procedures are able to provide the diagnosis of cancer by performing biopsies, treat patients in a curative or palliative setting and provide symptom control. Almost every cancer patient undergoes one sort of IO procedure and improvement of these procedures are therefore essential for cancer patients.

To provide minimal invasive 10 treatment, data is necessary to select the best patient population to achieve the highest efficacy rates. In this thesis, we investigated the efficacy and safety of intra-arterial liver directed therapies in liver metastatic breast cancer (LMBC) patients and percutaneous ablation in patients with renal cell carcinoma (RCC). We analyzed relatively large cohorts, enabling us to determine factors influencing the outcome of the interventional oncology procedures.

\section{Part I: Intra-arterial therapies for liver metastatic breast cancer}

Breast cancer is the second most diagnosed cancer type and the fourth cause of death in the Netherlands. When breast cancer is diagnosed at an early stage of the disease, curation is often possible. Contrary, LMBC has a poor prognosis with survival rates up to 3 years. Standard treatment for LMBC is systemic treatment by means of chemotherapy or (hormone) targeted treatment. Many patients develop toxicities from the chemotherapy which impairs quality of life or become chemo refractory to the systemic treatment. Intra-arterial therapies are liver directed $\mathrm{IO}$ procedures performed under image guidance to provide local control in the liver at minimal side effects that can be administrated in chemo refractory LMBC patients or function as chemo holiday in LMBC patients.

In the Netherlands, intra-arterial therapies are registered for patients with primary liver tumours, colorectal liver metastases or neuroendocrine neoplasma. To date, intra-arterial therapies are not regularly performed as 
treatment in the Netherlands in LMBC patients, mainly because LMBC patients often have extra-hepatic disease and will consequently only receive chemo or targeted therapy. However, liver metastases may cause impairment of liver function and therefore especially endangers the patient's life. Intra-arterial therapy can than function as a minimal invasive technique to control the liver metastases and improve quality of life. With the results of this thesis, the awareness of this treatment option for LMBC patients has increased in Europe and the Netherlands.

Mitomycin $\mathrm{C}(\mathrm{MMC})$ infusion is an intra-arterial therapy whereby a chemotherapeutical (MMC) is administrated via intra-arterial access in the hepatic arteries every four weeks. It is a relatively easy and inexpensive procedure for interventional radiologists that can be performed in many centers in the Netherlands. Only a one-day hospital observation is required for this procedure and most patients experience these treatments as innocent with resume of daily life within a few days. Intra-arterial therapy by MMC infusion is not a new innovative procedure, but expands the toolbox of treatment options for LMBC patients with a minimal invasive treatment option.

This thesis added to the knowledge of MMC infusions by reporting on one of largest cohort of LMBC patients treated with MMC. We determined which patients benefit the most from the intra-arterial therapy and observed a worse overall survival in patients with an increased number of prior therapies, upfront deteriorate liver function and excessive tumor burden. Our data has been presented at (inter) national congresses to achieve recognition for this therapy. With these results, we can further implement MMC infusion in the Netherlands and determine in advance which patients may benefit the most from the treatment. Furthermore, interventional radiologists can council patients in advance of the MMC infusion with expectations based on a large cohort.

This thesis also includes an innovative treatment combination of two intraarterial therapies which was not reported before in LMBC patients. We showed that sequential therapy by MMC and Yttrium-90 is feasible and safe. Patients with liver dominant disease can be treated for a longer period by intra-arterial therapy to control the liver disease. However, $30 \%$ of the patients could not receive the combination treatment due to extra-hepatic disease progression. This raises the question if the sequential treatment of two intra-arterial therapies is the best treatment option. Maybe a combination with systemic treatment would be more beneficial for LMBC patients. With these reports important factors have been determined to develop future studies for LMBC 
patients and hopefully inspires more clinicians to use intra-arterial therapies in LMBC patients.

\section{Part II: Percutaneous ablation in renal cell cancer}

Patients with stage I RCC have excellent outcomes with 10-year survival rates between 95 and $100 \%$ after elimination of the tumour. In the past decade a more minimal invasive nephron sparing treatment approach has therefore been accepted as a treatment option. Patients that were previously treated with removal of the entire kidney (radical nephrectomy), can now undergo a partial nephrectomy (PN). Compared to PN, percutaneous ablation is associated with a lower comorbidity and mortality with excellent preservation of the kidney function.

During percutaneous ablation extreme high or low temperatures are conducted via needles for tumour destruction. Over the last years, percutaneous ablation has increasingly been used for treatment of small renal masses. Patients treated by percutaneous ablation have a reduced number of hospital day admissions and lower complications rates compared to PN. In this thesis, we defined some of the factors that may add to the knowledge of percutaneous ablation and provide the least invasive treatment for RCC patients.

We showed that by performing the biopsy before the planned ablation procedure, patients have the opportunity to deliberate on the treatment with the physician, thereby reducing overtreatment and providing essential information for treatment stratification. The outcome of this study affected the management of RCC patients in clinical practice of the renal cancer network Amsterdam. Patients with a T1a RCC whom are planned for ablation now first undergo a biopsy, as opposed to previous management in which patients received a biopsy during the ablative treatment. In the future also other centers in the Netherlands will adopt this management, which will reduce unnecessary treatments of patients with a renal mass in the Netherlands.

Microwave ablation (MWA) is a relatively newer ablation technique with less reports available. In chapter 6 we showed that MWA is a safe and effective treatment for T1 RCC and is most effective and safe in smaller peripheral tumours. We determined that size and location are key to obtain a complete treatment in MWA. Hence, our results will help to select the right patient for the best oncological outcome in T1 RCC and hopefully motivate physicians to use the MW system for renal ablations in this patient population. 
Percutaneous ablation is not generally accepted and widely used as treatment in T1b tumours with limited reports available. This thesis describes two ablation techniques for large tumours, namely; MWA and cryoablation. We showed that MWA for T1b lesions was feasible, only $50 \%$ of the patients needed a subsequent treatment following MWA which should be considered beforehand. In addition, we reported the outcome of patients whom were treated with cryoablation after failure of MWA with a $100 \%$ success rate in four patients with a T1b tumours. Our results are promising for cryoablation in T1b tumours, yet larger reports are needed. This thesis therefore functions as inspiration for future research for minimal invasive treatment option in RCC patients.

Last, another innovative treatment modality has been described in this thesis, namely the combination of cryoablation and immunotherapy. Immunotherapy has showed a remarkable survival gain for several cancer types. Unfortunately, not all patients respond to the immunotherapy, due to, among others, escapement of cancer cells to the immune system. Percutaneous ablation may prime the immune system by providing a pool of cancer specific antigens that can initiate a specific immune response against the cancer cells. This thesis investigated the evidence of cryoablation and immunotherapy in different cancer types. Most included studies in the critical review described a positive effect of the combination therapy regarding survival and implies that future research in this field might be of great benefit. 
Widdershoven $\mathrm{CV}^{*}$, Aarts $\mathrm{BM}^{*}$, Zondervan PJ, Henderickx MEL, Klompenhouwer EG, van Delden O, Prevoo W, Montauban van Swijndregt $A D$, van Moorselaar RJA, Bex $A^{*}$, Lagerveld $B W^{*}$. Renal biopsies performed before versus during ablation of T1 renal tumors: implications for prevention of overtreatment and follow-up. Abdominal Radiology 2020; Online publication.

Aarts BM, Prevoo W, Meier MAJ, Bex A, Beets-Tan RGH, Klompenhouwer EG, Gómez FM. Percutaneous microwave ablation of histologically proven T1 renal cell carcinoma. Cardiovascular Interventional Radiology 2020; Jul;43(7):10251033.

Aarts $\mathrm{BM}^{*}$, Klompenhouwer EG *, Dresen RC, Deroose CM, Beets-Tan RGH, Punie K, Neven P, Wildiers H, Maleux G. Sequential intra-arterial infusion of ${ }^{90} \mathrm{Y}$-labeled microspheres and Mitomycin $\mathrm{C}$ in chemo refractory liver metastatic breast cancer patients: a single centre pilot study. Radiology and Oncology 2020; Jan 21;54(1):33-39.

Aarts $\mathrm{BM}^{*}$, Klompenhouwer EG *, Dresen RC, Laenen A, Beets-Tan RGH, Punie K, Neven P, Wildiers H, Maleux G. Intra-arterial Mitomycin C infusion in a large cohort of advanced liver metastatic breast cancer patients: safety, efficacy and factors influencing survival. Breast Cancer Research and Treatment 2019; Aug;176(3):597-605.

Aarts BM, Klompenhouwer EG, Rice SL, Imani F, Baetens T, Bex A, Horenblas S, Kok M, Haanen JBAG, Beets-Tan RGH, Gómez FM. Cryoablation and immunotherapy: an overview of evidence on its synergy. Insights into Imaging 2019; May 20;10(1):53.

van Londen M, Aarts BM, Hillebrands JL, Bakker SJL, Navis G, and de Borst $\mathrm{MH}$. Tubular maximum phosphate reabsorption capacity in living kidney donors is independently associated with one year recipient GFR. American Journal of Physiology - Renal Physiology 2018; Feb 1;314(2):F196-F202.

van Londen $\mathrm{M}^{*}$, Aarts $\mathrm{BM}^{*}$, Deetman PE, van der Weijden J, Eisenga MF, Navis G, Bakker SJL and de Borst MH. Post-Transplant Hypophosphatemia and the Risk of Death-Censored Graft Failure and Mortality after Kidney Transplantation. Clinical Journal of the American Society of Nephrology 2017; Aug 7;12(8):1301-1310. 
Met veel plezier heb ik de afgelopen 2,5 jaar gewerkt in het Antoni van Leeuwenhoek ziekenhuis en het Universitair Ziekenhuis Leuven waarbij ik met veel inspirerende mensen heb mogen samenwerken. Onderzoek doe je niet alleen, maar in team verband, waaruit ik ontzettend veel energie en plezier heb gehaald. Daarmee wil ik in het bijzonder de volgende mensen bedanken:

Prof. dr. R.G.H. Beets-Tan, beste Regina, jouw energie, ambities en wetenschappelijke inzichten maken jou de beste promotor die ik mij kon wensen. Ik heb genoten van onze meetings en jouw inspirerende verhalen. Bedankt voor alle mogelijkheden die jij mij geeft en de begeleiding waarvoor ik altijd bij jou terecht kan!

Mijn co-promotoren: dr. F.M. Gómez Muñoz en dr. E.G. Klompenhouwer, zonder jullie inzet, steun en vriendschap was mijn thesis en PhD tijd nooit hetzelfde geweest.

Dear Fernando, it was a great pleasure to work with you and work on your fantastic ideas. Although you have two jobs in two different countries, you always manage to answer my questions and emails directly. Whenever I desired extra work you directly came up with a new idea for a paper or presentation; you fed this research junkie well! You put an enormous amount of trust in me, thank you for everything my friend!

Beste Lisa, vanaf dag één werd jij mijn voorbeeld, als jonge vrouwelijke interventieradioloog met een groot wetenschappelijk brein. Jij bent een fantastisch betrokken begeleider, ook persoonlijk, die altijd tijd voor mij maakt naast de drukke kliniek. Jouw snelle klinische en gestructureerde wetenschappelijke inzichten hebben mij geholpen om deze thesis af te ronden in een korte tijd. Na onze meetings kon ik altijd weer met bakken energie verder, bedankt voor alle mooie momenten!

Prof. dr. G. Maleux, beste professor Maleux, bedankt voor de begeleiding tijdens mijn tijd in Leuven. Het was een unieke en leerzame ervaring om in Leuven onderzoek te mogen doen, jullie werk te mogen analyseren en jullie praktijk te mogen bekijken.

Prof. dr. R.C. Dresen, beste Elleke, bedankt voor alle hulp bij het RECIST scoren en het meedenken over de studies.

Prof. dr. H. Wildiers, beste professor Wildiers, hartelijk dank voor de samenwerking en het delen van uw ervaringen met borstkanker patienten met levermetastasen. 
De interventieradiologen en laboranten uit het AvL en UZL, in het bijzonder: drs. W. Prevoo, beste Warner, bedankt voor alle hulp en spontane bezoekjes. Drs. F. Imani, beste Farshad, bedankt voor het bijwonen van alle, altijd gezellige, procedures. Drs. T.R. Baetens, beste Tarik, jouw klinische en gedetailleerde inzicht hielpen mij altijd weer een stap verder. Bedankt voor alle input!

Drs. C.V. Widdershoven, beste Christiaan, je bent begonnen als student aan het biopten artikel waar ik jou eerst mocht begeleiden en welke wij daarna samen hebben kunnen afronden en publiceren voor onze beide proefschriften. Het was een mooie leerzame samenwerking; bedankt en succes met de rest van je $\mathrm{PhD!}$

Leden van de beoordelingscommissie: prof. dr. V.C.G. Tjan-Heijnen, prof. dr. M.W. de Haan, prof. dr. G.A. van Koeveringe, prof. dr. M. van Goethem en prof. dr. M.G.E.H. Lam, ik wil jullie hartelijk bedanken voor jullie tijd voor het beoordelen van mijn proefschrift.

Leden OOA commissie: prof. dr. M.P.M. Stokkel, dr. A. Bex en dr. M. Kok. Dank voor jullie betrokkenheid bij mijn promotie traject. Beste Axel, bedankt voor de samenwerking binnen de nierkanker. Ik heb veel mogen leren van jouw deskundigheid en niet te vergeten het bezoek in Royal Hospital in Londen. Beste Marleen, jij was een betrokken OOA lid en een voorbeeld om mee te werken, bedankt!

Mijn paranimfen: drs. S.E. Vollenbrock en mr. Q.A.M. Broekema. Met jullie aan mijn zijde weet ik zeker dat het goed gaat komen op deze dag!

Lieve Soof, wat was het een feest met jou als collega! Niet vaak maak je mee dat je zo snel met iemand op één lijn zit. Veel meer hoef ik hier niet over uit te weiden, ik heb genoten van alle tijd samen en daar komen ongetwijfeld nog heel veel mooie herinneringen bij!

Lieve $\mathbf{Q}$, ik mag van geluk spreken met zo'n lieve betrouwbare vriendin aan mijn zijde. Altijd lachen samen, maar ook als het even tegen zit ben jij er voor mij. Weinig advocaten die zo veel van alle PhD struggles af weten!

Dr. J.S.A. Belderbos, lieve José, via jou maakte ik al vroeg in mijn studie kennis met het AvL en het artsenvak. Je gaf mij inspiratie hoe je het vak kan invullen als arts en onderzoeker om kankerpatiënten verder te helpen. Tijdens mijn PhD gaf jij mij elke keer het zetje om een stapje verder te zetten, bedankt voor alles! 
Alle collega's, de PhD studenten en radiologen van het tuinhuis, bedankt voor de top tijd waarbij ik altijd bij jullie terecht kon voor een vraag, menig small talk of goede discussie!

Jorrita, zonder jouw ondersteuning en aanwezigheid is het tuinhuis gewoon niet hetzelfde! Zuhir, thank you for all your help, always open for questions despite your own busy schedule. Prof. dr. Nguyen-Kim, it was very special to have you as a colleague; a true inspiration! leva, your knowledge about IR helped me considerably.

Ezgi, babe, je was een top hulp voor mijn sollicitatie en een super fijne collega om mee samen te werken, daarnaast ben je altijd in voor een gezellige borrel of hapje eten!

Lieve Marit, al ging jij snel weg uit het tuinhuis en nam ik jouw plekje over, wij zagen elkaar alleen maar meer! Gewaagd aan elkaar op de tennisbaan en dansvloer, ik ben blij dat ik er een altijd eerlijke en gezellige vriendin bij heb!

En dan natuurlijk mijn lieve kamergenoten aka de relativeerberen: Sophie, Maurits, Lisa, Femke, Charlotte, jullie waren fantastische collega's! Samen in ons hok maakten we de ups en downs van elkaar mee en kon ik altijd terecht bij jullie; bedankt!

Al mijn lieve vrienden en vriendinnen, bedankt voor alle welkome afleiding.

Mijn (schoon)familie: Bas en Lilian, Sebas en Juul, Lavinia en Steven, bedankt voor jullie interesse en medeleven!

Lieve sissies, de afgelopen jaren hebben wij een bijzondere band opgebouwd waar ik onwijs veel waarde aan hecht. Marijke; ondanks jouw drukke baan en sociale leven maak je altijd ook tijd voor mij. Jouw andere kijk op zaken helpt mij altijd! Annemiek; ook al ben jij mijn kleine zusje, je voelt als een gelijke vriendin. Wij kunnen altijd bij elkaar terecht, vooral nu wij zo dicht bij elkaar wonen!

Lieve pap en mam, jullie onvoorwaardelijke liefde en steun hebben mij de mogelijkheid gegeven om dit alles te bereiken. Ik hoop dat ik nog lang van jullie mag genieten, op nog vele mooie en bijzondere momenten samen!

En dan als laatste en voor mij het meest speciaal en belangrijk; lieve Derk, jij staat echt altijd klaar voor mij! Al heb jij niet aan de inhoud mee geholpen, zeker wel aan alle bijkomende zaken. Ik ben super trots wat wij beide hebben bereikt de afgelopen 10 jaar, het allerbelangrijkste; een geweldig leven samen! 
Brigitte Maximiliana Aarts, calling name Brigit, was born in Rotterdam on 11-11-1990. She followed pre-university education (VWO) at the Comenius College in Hilversum with a major in science and health and a minor in economics. In 2009, she took a gap year in Santa Barbara, California, following an undergraduate program of Liberal Arts at Santa Barbara City College. After returning to the Netherlands, she studied Life Science and Technology at the Rijksuniversiteit Groningen from 2010-2011 before she started her medical degree in 2011. Brigit obtained her medical degree at the University of Groningen in 2017. During her medical study she was involved in several social committees and joined the research team for living kidney donors at the Nephrology department, supervised by prof. dr. G.J. Navis and prof. dr. M.H. de Borst. After her medical degree she moved to Amsterdam and started as $\mathrm{PhD}$ candidate at the Radiology department at the Netherlands Cancer Institute under supervision of Prof. dr. R.G.H. Beets-Tan, dr. E.G. Klompenhouwer and dr. F.M. Gómez Muñoz. Part of her PhD was performed in the UZ Leuven in collaboration with prof. dr. G. Maleux and prof. dr. H. Wildiers. In 2020 she started her residency program Radiology and Nuclear Medicine at the Amsterdam University Medical Centre, location VU. 
